\author{
Universidade de São Paulo \\ Instituto de Física
}

\title{
Equações de Onda Generalizadas e Quantização Funtorial para Teorias de Campo Escalar Livre.
}

\author{
João Braga de Góes e Vasconcellos
}

Orientador: Prof. Dr. João Carlos Alves Barata

Dissertação de mestrado apresentada ao Instituto de Física para a obtenção do título de Mestre em Ciências

\section{Banca Examinadora:}

Prof. Dr. João Carlos Alves Barata (Instituto de Física - Universidade de São Paulo)

Prof. Dr. Paulo Afonso Faria da Veiga (Instituto de Ciências Matemáticas e de Computação - Universidade de São Paulo)

Prof. Dr. André Gustavo Scagliusi Landulfo (Centro de Ciências Naturais e Humanas Universidade Federal do ABC) 


\section{FICHA CATALOGRÁFICA \\ Preparada pelo Serviço de Biblioteca e Informação do Instituto de Física da Universidade de São Paulo}

Vasconcellos, João Braga de Góes e

Equações de Onda Generalizadas e Quantização Funtorial para Teorias de Campo Escalar Livre. São Paulo, 2016.

Dissertação (Mestrado) - Universidade de São Paulo.

Instituto de Física. Depto. de Física Matemática.

Orientador: Prof. Dr. João Carlos Alves Barata

Área de Concentração: Física Matemática - Teoria Quântica de Campos Algébrica.

Unitermos: 1. Física; 2. Física Matemática; 3. Teoria de Campos e Ondas; 4. Teoria Quântica de Campos.

USP/IF/SBI-020/2016 


\author{
University of Sao Paulo \\ Physics Institute
}

\title{
Generalized Wave Equations and Functorial Quantization for Free Scalar Field Theories.
}

\author{
João Braga de Góes e Vasconcellos
}

Supervisor: Prof. Dr. João Carlos Alves Barata

Thesis presented to the Physics Institute of the University of Sao Paulo in partial fulfillment of the requirements for the degree of Master in Science.

Examining Commission:

Prof. Dr. João Carlos Alves Barata (Physics Institute - University of Sao Paulo)

Prof. Dr. Paulo Afonso Faria da Veiga (Institute of Mathematics and Computer Sciences University of Sao Paulo)

Prof. Dr. André Gustavo Scagliusi Landulfo (Centro de Ciências Naturais e Humanas Federal University of ABC) 




\title{
Agradecimentos (Acknowledgement)
}

In respect to the people whom I thank here, this section is presented in Portuguese.

\begin{abstract}
$* * *$
Esta é a última seção que escrevo para minha dissertação: as correções indicadas pela banca já foram feitas, os esclarecimentos necessários estão, no momento em que escrevo este texto, quase prontos. Contudo, sob outro olhar posso dizer que essa foi a primeira seção que comecei a escrever, ainda quando saí da sala do meu orientador após nossa primeira reunião oficial de orientação. Naquele momento, ele me entregou o livro que seria a principal referência para meu mestrado, e eu, tão contente quanto ingênuo, fui para minha sala fazer a coisa mais natural para mim àquela altura: ler o livro.

Me lembro de duas coisas daquele dia: minha alegria quase infantil, digna de criança pequena voltando às aulas, e de pensar o seguinte: "vou lendo o livro; as coisas que não entender direito eu vou grifando e depois vejo o que são". No primeiro parágrafo, ainda com os riscos a lápis, praticamente não há substantivo que não esteja sublinhado, e no meu segundo dia de mestrado, lá estava eu estudando Teoria de Conjuntos. Mas quanto à alegria que eu sentia andando pelo corredor do Departamento de Física Matemática carregando aquele bloco de papéis, ela era acompanhada de uma profunda gratidão por um número não tão pequeno de pessoas que me ajudaram de diversas maneiras a estar ali, e um dos grandes méritos desses dois anos de pós-graduação sem dúvida foi o substancial acréscimo de elementos a esse conjunto. A todas essas pessoas, gostaria de tentar aqui expressar o quanto sou grato.
\end{abstract}

No dicionário Aurélio, encontra-se, como uma das possíveis definições para o verbo orientar, "guiar, dirigir, nortear". É uma definição que me faz pouco sentido no contexto de uma pós-graduação, pela experiência que tive até agora. Eu vim parar na Física Matemática um tanto perdido: durante parte da minha graduação, e, sobretudo, nas iniciações científicas que fiz, muito do que via me parecia apresentado de maneira estranha, como se para houvesse algo mais que não estava sendo dito. É claro que isso não acontecia em todos os cursos nem em todos os livros, e tampouco quero dar a impressão mentirosa de ter sido um aluno brilhante capaz de ver a todo instante além do que me era apresentado. Em todo caso, mais do que apontar questões específicas e pontos que 
não compreendia, havia um certo desconforto meu com partes do curso, principalmente quando cursei as disciplinas de Mecânica Quântica da graduação e quando fiz uma iniciação científica em fundamentos da Teoria Quântica de Campos. Se meus professores e orientadores fossem ruins, ainda poderia culpá-los, mas esse estava longe de ser o caso. Em meio a tudo isso, nutria certa simpatia pelo meu professor de Grupos e Tensores, incrivelmente formal e rigoroso no tratamento dos conceitos apresentados. Por minha convivência com ele, e também com o Professor Domingos Marchetti, com quem cursei as disciplinas de Física Matemática II e III, passei a formar a opinião de que a base conceitual que eu procurava, principalmente na mecânica quântica, estava intima e fundamentalmente relacionada a uma análise profunda da matemática empregada na teoria. Esses dois anos de mestrado só serviram para reforçar essa opinião: aos poucos, graças ao meu orientador, fui abandonando a visão de que a matemática serve para a física como uma mera ferramenta.

Assim, se eu escolhi a área de Teoria Quântica de Campos em Espaços Curvos por ser uma combinação do que mais me despertava curiosidade, a Mecânica Quântica e a Relatividade Geral, a escolha de meu orientador, antigo professor de Grupos e Tensores, foi baseada na intuição de que da nossa relação eu poderia começar a construir uma profunda compreensão da Mecânica Quântica, da Relatividade, da Teoria Quântica de Campos e da Física em geral. Pelo que falei do meu primeiro dia de mestrado, é desnecessário dizer que não tinha tanta noção do que meu orientador quis dizer quando me disse que proporia um projeto "um tanto exigente do ponto de vista matemático", e por isso é que digo que cheguei aqui um pouco perdido.

Contudo, ainda que tenha subestimado a tarefa de desenvolver uma "profunda compreensão da TQC", minha escolha de mestrado não poderia ter sido mais acertada ainda que o processo não tenha se assemelhado tanto ao que diz meu Aurélio. Sem dúvida, essa orientação me rendeu uma relação completamente nova e muito mais interessante com a Física e a Matemática. Ao ler as palavras "guiar, dirigir, nortear", tenho a impressão de que o papel de um orientador se baseia em apontar as direções para o aluno, e, por mais que em diversos momentos de ansiedade eu tenha desejado intensamente que meu orientador me dissesse exatamente o que, como e para quando fazer, da nossa relação orientador-aluno, na qual eu sempre tive bastante liberdade, ele fez surgir algo muito mais rico, uma relação pessoal minha com meu trabalho. Orientar um mestrado não deve ser tarefa simples. Porém, o que o Prof. João Barata fez foi algo muito além de uma realização institucional e burocrática: foi me acompanhar e, através da liberdade que me deu e da sua confiança, permitir que eu começasse a desenvolver uma relação pessoal com a Física, a Matemática, a Ciência e, a partir disso tudo e de maneira não restrita, com o mundo. Sempre tive dúvidas de o que teria levado ele a aceitar me orientar, dado meu estado de ignorância no início do mestrado, mas em todo caso as reuniões, as conversas, as mesmas dúvidas respondidas diversas vezes (sempre com muita paciência), as broncas contidas mas muito claras durante as apresentações de seminários, a confiança que pude depositar nele e, principalmente, a confiança que o Prof. João Barata depositou em mim, quase sempre maior do que a que eu tinha em mim mesmo, moldaram uma relação que, a meu ver, está longe de caber em "guiar, dirigir, nortear". Não tenho dúvida alguma de que minha relação com o conhecimento e com a vida carregará sempre os incríveis frutos da orientação que tive a honra de receber 
ao longo desse mestrado, com o Prof. João Barata.

É lógico que essa pós-graduação e essa orientação não teria sido possíveis se não fosse pela paciência e pela atenção de meus colegas de grupo. Sou profundamente grato tanto pelas várias vezes que me tiraram dúvidas, me indicaram referências e me mostraram meus erros, quanto pelos momentos de descontração que tivemos, fundamentais para o equilíbrio no meu ambiente de trabalho. Assim, quero aqui agradecer aos colegas Cedrick Mello, Guilherme Germano, Lissa Campos, Marcela Gontijo, Marcos Brum, Ricardo da Silva, Thiago Raszeja e Lucas Müssnich. Agradeço especialmente ao Cedrick e ao Marcos, que me dedicaram especial atenção ao longo de meu mestrado.

Quero também agradecer à banca examinadora que avaliou meu trabalho, formada pelos professores Paulo da Veiga e André Landulfo, que fizeram observações importantes para a conclusão deste mestrado.

Ademais, não posso deixar de mencionar alguns professores que foram de grande importância para mim. A professora Frederique Grassi, com que tive a oportunidade de dar monitoria nos cursos de Mecânica Quântica I e II, me permitiu revisitar parte do que motivou meu mestrado e me iniciar numa atividade didática. O respeito e a atenção que ela me dedicou enquanto trabalhamos juntos eu não poderia esperar, e essas duas monitorias seguem para mim como referência de uma boa relação profissional. Além do mais, participar de um curso de graduação com outro papel foi bastante importante para meu aproveitamento da pós-graduação.

A meus orientadores de iniciação científica, professora Renata Funchal e professores Gustavo Burdman e Adilson da Silva, que me apresentaram a teoria quântica de campos e boa parte da Física, também sou muito grato. Em particular, o professor Gustavo Burdman dedicou considerável atenção à formação de seus orientandos. A professora Renata Funchal, por sua vez, teve contribuição fundamental no que hoje entendo pela Academia, pela carreira acadêmica e pela atividade de pesquisa; ela é, sem dúvida, uma das pessoas que mais respeito e admiro intelectualmente, como pesquisadora e como professora. Seus cursos foram dos melhores que assisti na graduação e no mestrado.

O professor Walter Pedra, que ministrou a disciplina "Álgebra $C^{*}$ e Fundamentos Matemáticos da Mecânica Quântica e Mecânica estatística", e o professor Christian Jaekel, com quem cursei "Álgebras de Operadores e Teoria Quântica Local Relativística" também tiveram importante contribuição nesse trabalho e no meu curso de mestrado.

Meus colegas de pós-graduação, não apenas meus colegas de grupo de pesquisa, merecem também muito desses agradecimentos. Meus companheiros de sala, Fábio Chibana de Castro e Fabrízio Bernardi, especialmente merecem não apenas meu obrigado, mas meus parabéns pela paciência comigo e minhas desculpas - pela bagunça, por não parar de falar, por esquecer o café na cafeteira logo antes do feriado. O esforço e a disciplina tranquila do Chibana foram e ainda são um grande exemplo para mim, e a organização de sua mesa, sempre impecável ao final de cada dia de trabalho, me fez criar vergonha na cara e me dedicar um pouco mais ao cuidado com meu ambiente de trabalho, embora eu ainda esteja muito aquém desse meu caro colega. Se isso já não bastasse, o Chibana veio para essa sala trazendo consigo uma cafeteira, e frequentemente chego para trabalhar pela manhã e já encontro café quente, ou depois do almoço sou contemplado com a frase "eu fiz café". É emocionante. O Fabrízio, por sua vez, em vários momentos foi quem mais me ajudou a suportar o mestrado, o departamento, uma prova, uma disciplina, o 
que quer que fosse - não apenas um colega, o Fabrízio sempre foi uma grande companhia para tudo, com uma disposição que eu sinto não conseguir retribuir a altura.

Dentre os frutos do meu mestrado, posso destacar também a amizade que hoje levo com meus colegas Rodrigo Voivodic e Ricardo Costa de Almeida - esse que se orgulha de ser meu único colega explicitamente sitado em minha dissertação. Rodrigo e Ricardo tiveram enorme paciência comigo, me tirando dúvidas a fio, e às vezes se indignaram com minhas perguntas apenas o bastante para eu ver o quão ridículo era eu ter que perguntar aquilo. Em particular, o Rodrigo principalmente contribuiu para eu melhorar a forma como me apresento, um eufemismo para dizer que ele me ajudou a ter mais confiança no que faço e falo. Por sua vez, o Ricardo é um companheiro de estudo e trabalho inestimável, além de um incrível amigo, dono de uma inteligência rara e fascinante, e poder ter sua companhia tem me ensinado muito sobre tantas coisas, de Física e Matemática a assuntos diversos. A convivência com os dois tem sido uma grande motivação para estudar e crescer intelectualmente, e nutro enorme admiração por eles.

Quero também agradecer a minha amiga Jéssica Santiago, cujo processo de escolha de tema de mestrado e orientador, assim como cujo desenvolvimento do mestrado e início de doutorado tanto me motivaram e inspiraram. Ademais, ter tido Henrique Zanolli como colega de pós-graduação foi de grande ajuda: uma companhia verdadeiramente agradável e uma das melhores pessoas que conheço para se discutir Física. Minha relação com a matemática, por sua vez (e que ainda engatinha, por sinal), não seria a mesma sem a frutífera convivência, desde um curso de verão, com Bruno Hideki, Bruno Jacóia, Diego Barboza, Eric Ossami e Ulisses Lakatos.

Além disso, pessoas de outros ambientes também produziram significativa influência na minha formação e, particularmente, na minha relação com meu trabalho. Dentre elas, gostaria inicialmente de agradecer aos meus pais. Agradecer à minha mãe não é fácil: é difícil apontar precisamente pelo que sou grato, já que foram tantas coisas até hoje, afinal, que acho que o mais honesto é dizer: obrigado por tudo. A dedicação que minha mãe empregou na formação de seus filhos, eu mesmo não sei se seria capaz de reproduzir. Sou imensamente grato a todo o apoio que recebi dela, em especial durante a realização da minha pós-graduação, e por toda a fé e o amor que sempre teve por mim. Caracterizar a contribuição de meu pai para minha formação também é difícil: ele é, sem dúvida, das pessoas de raciocínio mais rápido que conheço, e é impossível negar que a forma como ele pensa me influenciou, embora eu não tenha herdado sua rapidez, característica desse lado da família. Não apenas a forma como trata os problemas, como também seus interesses, muito se notam em mim. Ainda hoje, o esforço que meus pais empregam ao trabalho é de fazer inveja a muitos jovens de vinte e tantos anos - eu inclusive. Não posso deixar de agradecer a meu caro padrasto, Henrique, que sempre me dedicou grande ajuda e interesse, incrivelmente paciente e com quem desenvolvi uma parceria inestimável; o interesse dele pelo meu mestrado sempre me surpreendeu. À minha madrasta, Celina, agradeço pelo interesse em mim e por ter sido sempre uma companhia de conversa tão agradável. Conversar, debater e explicar, principalmente quando se interessa por uma área técnica e abstrata, são exercícios fundamentais, e a Celina foi uma das pessoas que me proporcionou dos melhores ambientes para tal. Nessa linha de pessoas com quem pude aprender através de importantes trocas de idéias, gostaria de destacar meu amigo Betto, que costumava transformar o jantar na minha casa em conversas sempre 
interessantes. Meu caro amigo Maurício Gertsenchtein, provavelmente das melhores pessoas que já encontrei por aí, foi também um grande orientador em diversos aspéctos; muito provavelmente seguir em frente com minha graduação não teria sido possível sem sua ajuda.

Por sua vez, meu avô Mario não imagina o quanto o tempo que passei ao seu lado, vendo-o trabalhar e conversando com ele (não existe no mundo quem seja capaz de desenvolver as mesmas conversas que ele) contribuíram na minha formação, assim como o valor que minha avó, Laura, sempre deu à matemática me serviu de grande incentivo ao longo da vida. É um conforto imenso encontrar em alguém da família o amor por algo em comum, principalmente quando existe em nossa sociedade uma cultura de desprezo por esse algo, como vemos ocorrer com a Física e a Matemática. Além disso, em verdade digo que minha formação e educação não teriam sido possíveis sem a ajuda de minha avó, meu tio Luiz e meu irmão André. Meu avô Cyro, por sua vez, sempre foi figura presente e exemplo para mim, enquanto à minha avó Sylvia eu agradeço por todo o carinho que dedica aos netos, e por ter várias vezes me acomodado, em sua casa, em sua mesa, em seu colo e em seus abraços. Com essas duas, se casa e comida de avó fossem mérito acadêmico, eu era candidato a Prêmio Nobel.

Quero também agradecer ao meu tio Drauzio, cuja disciplina e dedicação ao trabalho me serviram de exemplo, e que, juntamente com minha tia Regina, contribuiu significativamente à minha formação como cientista. Sou particularmente grato por terem me acomodado durante o tempo que fiquei estudando no Rio de Janeiro.

Ao meu amigo Paulo Secches dedico um agradecimento especial: não apenas mostrou grande interesse por mim, como também só pude estudar o que hoje estudo e produzir o que até hoje produzi graças a sua ajuda.

Agradeço também a todos aqueles que permitiram que eu assistisse ao Congresso Internacional de Física Matemática em 2015.

Aos meus tios Christina e Luiz, agradeço a presença e o entusiasmo (inclusive) na minha defesa. Sem me alongar mais, quero dizer que sou grato a toda a família, tios e primos que não mencionei explicitamente, aos meus caros amigos, e aos meus irmãos, cunhadas, sobrinhas e sobrinhos - a curiosidade dos pequenos me é muito cara, e a companhia e parceria de meus irmãos são inestimáveis.

Agradeço à Universidade de São Paulo, ao Instituto de Física, ao Departamento de Física Matemática e às funcionárias Cecília Blanco, Simone Shinomiya, (Maria) Amelia Genova e João Borges, por toda a ajuda e paciência, e a Dona Elenice e Dona Loudes pelo carinho com os alunos do departamento. Também agradeço à Comissão de PósGraduação desse instituto e a seus funcionários, por todo o apoio.

Agradeço ao $\mathrm{CNPq}$ pelo apoio financeiro concedido para a realização deste trabalho, e pela reserva técnica disponibilizada.

Por fim, quero agradecer à Amanda, por toda a parceria, companhia, paciência, interesse e cuidado. Tudo isso - o mestrado, a Física, a Matemática, as álgebras de observáveis, os campos e tudo o mais, não seria tão interessante sem sua companhia. Devo destacar a paciência e o cuidado que sempre me dedicou. Embora seja difícil para mim admitir, agradeço pelos momentos que me convenceu a deixar o trabalho de lado, mas principalmente por tornar o trabalho, além de tantas outras coisas, muito mais interessante. 
A todos, meu muito obrigado. 


\section{Resumo}

Nesta dissertação apresentamos um método de quantização matemática e conceitualmente rigoroso para o campo escalar livre de interações. Trazemos de início alguns aspéctos importantes da Teoria de Distribuições e colocamos alguns pontos de geometria Lorentziana. O restante do trabalho é dividido em duas partes: na primeira, estudamos equações de onda em variedades Lorentzianas globalmente hiperbólicas e apresentamos o conceito de soluções fundamentais no contexto de equações locais. Em seguida, progressivamente construímos soluções fundamentais para o operador de onda a partir da distribuição de Riesz. Uma vez estabelecida uma solução para a equação de onda em uma vizinhança de um ponto da variedade, tratamos de construir uma solução global a partir da extensão do problema de Cauchy a toda a variedade, donde as soluções fundamentais dão lugar aos operadores de Green a partir da introdução de uma condição de contorno. Na última parte do trabalho, apresentamos um mínimo da Teoria de Categorias e Funtores para utilizar esse formalismo na contrução de um funtor de segunda quantização entre a categoria de variedades Lorentzianas globalmente hiperbólicas e a categoria de redes de álgebras $C^{*}$ satisfazendo os axiomas de Haag-Kastler. Ao fim, retomamos o caso particular do campo escalar quântico livre.

Palavras-chave: Equações de Onda em Variedades Lorentzianas, Campo Escalar Livre, Equação de Klein-Gordon, Segunda Quantização, Funtor de Quantização, Axiomas de Haag-Kastler. 



\section{Abstract}

In this thesis we present a both mathematical and conceptually rigorous quantization method for the neutral scalar field free of interactions. Initially, we introduce some aspects of the Theory of Distributions and we establish some points of Lorentzian geometry. The rest of the work is divided in two parts: in the first one, we study wave equations on globally hyperbolic Lorentzian manifolds, hence presenting the concept of fundamental solutions within the context of locally defined wave equations. Next, we progressively construct fundamental solutions for the wave operator from the Riesz distribution. Once established a solution to the wave equation in a neighbourhood of a point of the manifold, we move forward to produce a global solution from the extension of the Cauchy problem to the whole manifold. At this stage, fundamental solutions are replaced by Green's operators by the imposition of appropriate boundary conditions. In the last part, we present a minimum on the Theory of Categories and Functors. This is followed by the use of this formalism in the development of a second-quantization functor between the category of Lorentzian globally hyperbolic manifolds and the category of nets of $C^{*}$-algebras obeying Haag-Kastler axioms. Finally, we turn our attention to the particular case of the quantum free scalar field.

Key-words: Wave equations on Lorentzian Manifolds, Free Scalar Fields, Klein-Gordon Equation, Second Quantization, Quantization Functor, Haag-Kastler Axioms. 



\section{Contents}

1 Preliminaries $\quad 21$

1.1 Introduction and Notation . . . . . . . . . . . . . . . . . . . 21

1.2 Tensors . . . . . . . . . . . . . . . . . . . . 22

1.3 Manifolds . . . . . . . . . . . . . . . . . . . . . . 23

1.4 Vector Bundles . . . . . . . . . . . . . . . . . . . . . . . . 24

1.5 Connections on Vector Bundles . . . . . . . . . . . . . . . 26

1.6 Spacetimes . . . . . . . . . . . . . . . . . 27

1.7 Differential Operators . . . . . . . . . . . . . . . . . . 30

2 Topics on the Theory of Distributions 33

2.1 Introduction . . . . . . . . . . . . . . . . 33

2.2 Distributions . . . . . . . . . . . . . . . . . . . . . 34

2.3 Fourier Transform of Distributions . . . . . . . . . . . . . . . . . 39

2.4 Further Operations with Distributions . . . . . . . . . . . . . . 40

2.5 Distributions on Manifolds . . . . . . . . . . . . . . . 51

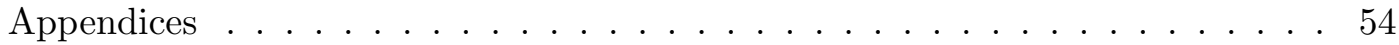

A Appendix: Topics on Fourier Transform . . . . . . . . . . . 54

3 The classical theory of wave equations on manifolds $\quad 61$

3.1 Introduction . . . . . . . . . . . . . . . . 61

3.2 The Wave Equations and Fundamental Solutions . . . . . . . . . . . . . 62

3.3 Riesz Distribution . . . . . . . . . . . . . . . . . . . . 63

3.4 The Formal Solution . . . . . . . . . . . . . . . . . 70

3.5 The Existence of "True" Fundamental Solutions . . . . . . . . . . . . . . 75

3.6 Non-homogeneous wave equations . . . . . . . . . . . . . . . . . 84

3.7 Globalization . . . . . . . . . . . . . . . . . . 85

3.8 Green's operator . . . . . . . . . . . . . . . . . . . . . . . . 91

4 Functorial Quantization $\quad 93$

4.1 Introduction . . . . . . . . . . . . . . . . . . . . . 93

4.2 Categories . . . . . . . . . . . . . . . . . . . . . . 94

$4.3 C^{*}$-Algebras . . . . . . . . . . . . . . . . . . . . 96

4.4 Weyl Systems . . . . . . . . . . . . . . . . . . . . . 98

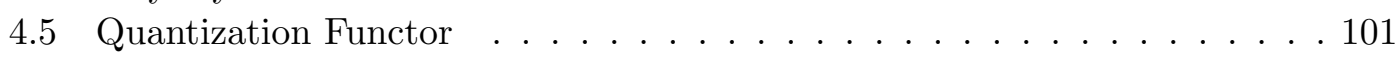


Index

116

Bibliography

121 


\section{Introduction}

Quantum Field Theory (QFT) dates back from the decade of 1920, when Paul A. M. Dirac published his paper "The Quantum theory of the emission and absorption of radiation", [1]. Since then, a lot has changed in a framework that attempts to unify Quantum Mechanics and Relativity, in the sense of containing, coherently, the fundamental principles of the two theories. Not only complete new understandings arose throughout the almost 90 years of QFT, but many achievements and developments in Physics were possible due to QFT. As examples, we may cite the construction and current success of the Large Hadron Collider, the confirmations of the Standard Model of Particle Physics, the development of theories with spontaneously broken symmetry, and the union of electromagnetic and weak interactions. In general, we may say that QFT has provided us with new ways to unleash the intimal nature of this Universe, both through experiments and theories investigating its Nature.

The cornerstone of Quantum Physics is the canonical commutation relation

$$
[P, Q]=-i .
$$

Within the context of Quantum Mechanics, with its finitely-many degrees of freedom, Stone-von Neumann theorem affirms the existence of a unique representation of this commutation relation into the operator algebra - up to an unitary equivalence. However, when we move to Quantum Field Theory, this theorem no longer applies, and we are left with different representations of the canonical commutation relation. An axiomatic approach to QFT consists then on choosing a specific representation, and setting its properties as axioms. For instance, in Minkowski space, we usually deal with vacuum representation, i.e., the one which posses a cyclic vector state describing the vacuum. Through the description of Weyl representations, which makes explicit use of the symmetry group of Minkowski space, the Poincaré group, we are then able to define particles. This is just an example of what is lost when we move to general spaces.

The necessity of considering what are the fundamental aspects to be imposed to a quantum field theory on curved spacetimes culminates in the Haag-Kastler axioms, to be presented in the last chapter: an axiomatic structure for local quantum theories concerning the observation process on which an experiment consists. The categorical language, used in the mentioned "functorial quantization", was firmly established in this context after the work of Brunetti, Fredenhagen and Verch, [2], as a "natural language" to describe transformations, particularly covariance condition. 
Exemplifying this abstract and general formalism, we present, by the end of this work, an analysis of free neutral bosonic fields, the simplest non-trivial example known. It is based on the Klein-Gordon equation

$$
\left(\square+m^{2}\right) \phi=0,
$$

first formulated by Erwin Schrödinger, and later by Oskar Klein, Walter Gordon and Vladimir Fock. The propagation of relativistic free bosonic particles, such as the pion, is modelled by the Klein-Gordon equation, as well as the components of any other bosonic field, as it is the case of the electromagnetic field.

Historically, the attempt to a relativistic eigenvalue equation for quantum states, a Lorentz invariant equation equivalent to Schrödinger equation of Quantum Mechanics such as (2), resulted in several problems. In particular, as discussed in [3], this interpretation of (2) would result in negative energy eigenvalues, and even more, these with negative probability.

The alternative interpretation following Dirac's mentioned article was a solution in terms of operators of creation and annihilation, equivalent to the ladder operators for the quantum harmonic oscillator, giving a substantial new meaning for (2). This necessity of field viewpoint, reinforced by the incongruence in Quantum Mechanics between time and position, while both are so intimately related in Relativity - see [4], resulted in a solution

$$
\phi(\mathbf{x})=\frac{1}{(2 \pi)^{3}} \int \frac{d^{3} p}{\sqrt{2 \omega_{p}}}\left(a e^{i \mathbf{p} \cdot \mathbf{x}}+a^{\dagger} e^{-i \mathbf{p} \cdot \mathbf{x}}\right)
$$

where

$$
\omega=\sqrt{p^{2}+m^{2}} .
$$

In this work, we shall develop a formal way to obtain an equivalent result within the context of curved spacetimes, after a precise description of a local quantum theory in this background. It should be noticed that our focus will remain on observables, and, thus, no discussion about states will be presented. 


\section{Chapter 1}

\section{Preliminaries}

\subsection{Introduction and Notation}

We here intend to present some basic material invoked throughout chapters 3 and 4 . In considering what was discussed in the foreword of this work, we have not the intention of providing a deep exposition of these topics, nor of making this chapter a report of every basic study the author had to undergo during his master's course. Therefore, we wish here to establish the notation to be used from now on, and to present the crucial basic ideas involved in this work. We should emphasize that some concepts shall be presented without the proper rigorous care, and maybe important parts in between shall be held implicit, while some points may be treated probably with unnecessary rigour and attention. The main references to this part are [5] for tensors, although for a more detailed and vaster presentation of this topic we should refer to [6] and [7], and [8] for smooth manifolds. The basics on Differential Geometry and Lorentzian manifolds were extracted from [5], [9] and [10], the last one the main reference for differential operators.

First of all, we should clarify part of the notation we shall use. As usual, we shall denote by $\mathbb{K}$ the field under consideration whenever there is no reason or no interest in specifying whether we are working with $\mathbb{R}$ or $\mathbb{C}$. We also may deal with the subsets $\mathbb{R}_{+}:=(0,+\infty)$ and $\mathbb{R}_{+}^{0}:=[0,+\infty)$; as for the natural numbers, $\mathbb{N}$ will be used to denote the non-negative integers, $\mathbb{N} \equiv\{0,1,2, \ldots\}$, and we shall use the Bourbaki notation $\mathbb{N}^{*}:=\mathbb{N} \backslash\{0\}$. If $z \in \mathbb{C}$, its conjugate will be represented by $\bar{z}$. The dot notation "." for product is absolutely not precise in this work and may be used for some different things: the product by an scalar in a vector space, an algebra product or the natural pairing between sections of a bundle $\mathrm{E}$ and its dual $\mathrm{E}^{*}$ - the definition of those objects is presented further in this chapter; we believe the context will make clear the meaning of such a notation. Almost every vector space presented is regarded as finite dimensional and, particularly, we shall only deal with finite dimensional manifolds. The metric of the $(1+n)$-dimensional Minkowski space $\mathcal{M}^{n}$ is here considered with signature $(-1,1, \cdots, 1)$. For inner and pseudo-inner products, we use the notation $\langle\cdot, \cdot\rangle$ or also the dot ".", the latter mostly for the product in $\mathbb{K}^{n} ;(\cdot, \cdot)$ will be used for ordered pairs and sometimes, when explicitly indicated, for the natural pairing, meaning then the same of "." in this context. Definitions will be indicated by the symbol ":=", while the 
symbol "三" is reserved to indicated strictly coincidence - i.e., equality in every point, or an alternative notation for some already defined object.

At the end of this work, there is an index with symbols, which we hope may help solving any doubt about definitions. Further clarifications about notation may be presented throughout the text, if needed.

\subsection{Tensors}

Let $V$ be a vector space over $\mathbb{K}$. A $\mathbf{k}, \mathbf{l}$-tensor on $V$ is a $\mathrm{k}+\mathrm{l}$ linear map

$$
T: \underbrace{V^{*} \times \cdots \times V^{*}}_{k} \times \underbrace{V \times \cdots \times V}_{l} \longrightarrow \mathbb{K}
$$

where $V^{*}$ denotes the dual space of $V$. Suppose $V$ has dimension n, and let $T, S$ be k,land i,j-tensors on $V$, respectively. We define the tensor product between them as the map

$$
\begin{gathered}
T \otimes S: \underbrace{V^{*} \times \cdots \times V^{*}}_{k+i} \times \underbrace{V \times \cdots \times V}_{l+j} \longrightarrow \mathbb{K} \\
T \otimes S\left(v_{1}^{*}, \ldots, v_{k+i}^{*}, v_{1}, \ldots, v_{l+j}\right):= \\
T\left(v_{1}^{*}, \ldots, v_{k}^{*}, v_{1}, \ldots, v_{l}\right) S\left(v_{k+1}^{*}, \ldots, v_{k+i}^{*}, v_{l+1}, \ldots, v_{l+j}\right)
\end{gathered}
$$

Considering now a basis $\left\{e_{1}, \ldots, e_{n}\right\}$ for $V$ and the dual basis $\left\{b_{1}, \ldots, b_{n}\right\}$ in $V^{*}$, we have for a general tensor $T$

$$
\begin{aligned}
T\left(v_{1}^{*}, \ldots, v_{k}^{*}, v_{1}, \ldots, v_{l}\right)= \\
=T\left(\sum_{j} v_{1 j}^{*} b_{j}, \ldots, \sum_{j} v_{k j}^{*} b_{j}, \sum_{j} v_{1 j} e_{j}, \ldots, \sum_{j} v_{l j} e_{j}\right) \\
=\sum_{j_{1}, \ldots, j_{k+l}=1}^{n} v_{1 j_{1}}^{*} \ldots v_{k j_{k}}^{*} v_{1 j_{k+1}} \ldots v_{l j_{k+l}} \underbrace{T\left(b_{j_{1}}, \ldots, b_{j_{k}}, e_{j_{k+1}}, \ldots, e_{j_{k+l}}\right.}_{:=T_{j_{1} \cdots j_{k+l}} \in \mathbb{K}}) \\
=\sum_{j_{1}, \ldots, j_{k+l}=1}^{n} v_{1 j_{1}}^{*} \ldots v_{k j_{k}}^{*} v_{1 j_{k+1}} \ldots v_{l j_{k+l}} T_{j_{1} \ldots j_{k+l}},
\end{aligned}
$$

and for fixed basis, the association $T \longmapsto T_{j_{1} \cdots j_{k+l}}$ is an isomorphism. Now, we know that for each $v_{i j}$ in the summation above we have $v_{i j}=b_{j}\left(v_{i}\right)$ and the analogous relation for the dual vectors, so we may state 


$$
\begin{gathered}
T\left(v_{1}^{*}, \ldots, v_{k}^{*}, v_{1}, \ldots, v_{l}\right)= \\
\underbrace{\sum T_{j_{1} \cdots j_{k+l}} e_{j_{1}} \otimes \cdots \otimes e_{j_{k}} \otimes b_{j_{k+1}} \otimes \cdots \otimes b_{j_{k+l}}}_{\equiv T}\left(v_{1}^{*}, \ldots, v_{k}^{*}, v_{1}, \ldots, v_{l}\right) .
\end{gathered}
$$

Hence, we conclude the existence of an isomorphism between the set of k,l-tensors and the space of $(k+l-1)$ multilinear maps into $V$,

$$
\underbrace{V^{*} \times \cdots \times V^{*}}_{k} \times \underbrace{V \times \cdots \times V}_{l-1} \longrightarrow V .
$$

We regard a k-tensor as a 0,k-tensor.

\subsection{Manifolds}

Intuitively, a manifold is a space which locally looks like $\mathbb{R}^{n}$ or $\mathbb{C}^{n}$. Precisely, we define a topological manifold as a Hausdorff second-countable topological space M, together with a collection $\left\{(\phi, U)_{i}\right\}_{i}$ such that each $U_{i} \subset \mathrm{M}$ is an open subset of $\mathrm{M}, \bigcup_{i} U_{i}=\mathrm{M}$ and $\phi_{i}: U_{i} \longrightarrow \phi_{i}\left(U_{i}\right) \subset \mathbb{K}^{n}$ is an homeomorphism into its image. The number $n$ in $\mathbb{K}^{n}$ is called the dimension of the topological manifold, and it can be proved to be unique - see, for example, [8]: if the functions $\phi \circ \psi^{-1}$ and its inverse are both well defined (i. e., if their domains are non-empty), they form a bijection between vector spaces, which then should have the same dimension.

The conditions of a topological space being Hausdorff and second-countable are not indispensable; however, by imposing those hypothesis we exclude from the definition cases in which we shall not be interested throughout this work.

Let $\mathrm{M}$ be a topological manifold, and let $(\phi, U) \equiv \phi$ be the intrinsic pair formed by an open subset $U \subset M$ and a map $\phi: U \longrightarrow \phi(U) \subset \mathbb{K}^{n}$ homeomorphic to its image; we shall call such a pair a chart on M, and throughout this work we shall suppose $n<\infty$. Consider the set $\{(\phi, U),(\psi, V)\}$ of two charts in M such that both $U \cap V \neq \emptyset$ and the function

$$
\left.\psi \circ \phi^{-1}\right|_{\phi(U \cap V)}: \phi(U \cap V) \subset \mathbb{K}^{n} \longrightarrow \psi(U \cap V) \subset \mathbb{K}^{n}
$$

is differentiable, i. e., $C^{\infty}$; every $C^{\infty}$-homeomorphism whose inverse is also $C^{\infty}$ is called a diffeomorphism. In those circumstances, the charts are said to overlap smoothly. Whenever necessary, we may refer to a chart as a function $\phi$, considering its domain sub-understood.

Let now $\mathscr{A}$ be a set of smooth overlapping charts on M covering the space - i.e., $\mathscr{A}=\left\{\left(\phi_{i}, U_{i}\right)\right\}_{i}$ with $\bigcup_{i} U_{i}=M$. We call such a set an atlas on $\mathrm{M}$, and denote $\overline{\mathscr{A}}$ the set of all charts in M overlapping smoothly with elements of $\mathscr{A}$. Whe call $\overline{\mathscr{A}}$ a differential structure on $\mathrm{M}$. The pair $(\mathrm{M}, \mathscr{A}) \equiv M$ is called a smooth manifold; since we shall work only with smooth manifolds, we shall often call them simply manifolds. It should 
be noted that, in the above construction, all the relations are defined to hold in the trivial case when the domains of the charts are disjoint.

The continuity of a function $f: M_{1} \longrightarrow M_{2}$ between two manifolds is established considering the topology of each manifold. Such a function is said to be differentiable at a point $p \in \mathrm{M}_{1}$ if there are charts $(\phi, U)$ in $\mathrm{M}_{1}$ and $(\psi, V)$ in $\mathrm{M}_{2}$ such that $p \in U$ and the function $\left.\psi \circ f \circ \phi^{-1}\right|_{\phi(U \cap V)}: \phi(U \cap V) \subset \mathbb{R}^{n} \longrightarrow \psi(f(U \cap V)) \subset \mathbb{R}^{m}$ is differentiable at $\phi(p) ; f$ is then called differentiable or smooth if it is differentiable at every point of its domain. Once again we emphasize that by differentiable we mean $C^{\infty}$.

A map $v_{p}: \mathscr{F}(\mathrm{M}) \longrightarrow \mathbb{K}$, where $\mathscr{F}(\mathrm{M})$ denotes the set of $\mathbb{K}$-valued differentiable functions in $\mathrm{M}$ is called a derivation at a point $p \in \mathrm{M}$ if it satisfies

$$
v_{p}(f g)=f(p) v_{p}(g)+g(p) v_{p}(f) .
$$

For a given open $U \subset M$ with $p \in U$, we define $\mathscr{F}_{p}(U)$ as the the quotient $\mathscr{F}(U) / \sim$ where we identify functions which agree on a smaller neighborhood of $p$; this should be regarded as a technical detail and one may think of $\mathscr{F}_{p}(M)$ as the set of functions defined in an arbitrarily small neighbourhood of $p$. Equation (1.1) defines a property we shall name Leibniz rule after it resemblance with the Leibniz rule of Calculus. For each $p \in M$, we denote $\mathrm{T}_{p} \mathrm{M}$, the tangent space at $\mathbf{p}$, the set of all tangent vectors at $\mathrm{M}$, i.e., the set of all linear maps $\mathscr{F}_{p}(\mathrm{M}) \longrightarrow \mathbb{K}$ obeying (1.1). For each $p \in \mathrm{M}, \mathrm{T}_{p} \mathrm{M}$ is a vector space over $\mathbb{K}$ with the usual addition and scalar multiplication of functions. It is not hard to show that if $(\phi, U)$ is a chart in $p \in \mathrm{M}$ and if $x^{i}:=u^{i} \circ \phi$ where $u^{i}$ are the canonical $\mathbb{K}^{n} \longrightarrow \mathbb{K}$ projections, then $\left\{\left.\frac{\partial}{\partial x^{i}}\right|_{p}\right\}_{i}$ form a basis for $\mathrm{T}_{p} \mathrm{M}$

Let $f: M \longrightarrow N$ be given. The differential of $f$ at $p$ is the function

$$
\begin{aligned}
d f_{p} \equiv f_{* p}: T_{p} M & \longrightarrow T_{f(p)} N \\
v & \longmapsto f_{* p} \in \mathscr{F}^{*}(N) \\
f_{* p}(v)(g) & =v_{p}(g \circ f) \quad \forall g \in \mathscr{F}(N) .
\end{aligned}
$$

As shown for example in [9], the hypothesis considered ensure the topological manifold is paracompact and has a smooth partition of unity subordinate to any open covering of the manifold.

\subsection{Vector Bundles}

Let $\mathrm{E}$ and $\mathrm{M}$ be two smooth manifolds, and let $\pi: E \longrightarrow M$ be a surjective given map. The triplet $(\mathrm{E}, \mathrm{M}, \pi)$ is called a $\mathbb{K}$-vector bundle if, for all $p \in \mathrm{M}$,

- the set $\pi^{-1}(p) \equiv \mathrm{E}_{p} \in \mathrm{E}$, which we call a fiber at $p$, has the structure of a vector space over the field $\mathbb{K}$;

- there exists an open neighbourhood $U \subset \mathrm{M}$ of $p$ and a diffeomorphism

$$
\phi: \pi^{-1}(U) \longrightarrow U \times \mathbb{R}^{k}
$$


such that its restriction to a fiber, $\mathrm{E}_{q} \longrightarrow\{q\} \times \mathbb{R}^{k}$, is a vector space isomorphism. Such open set $U$ is named trivializing open set, the collection $\{(U, \phi)\}$ is called a local trivialization and $k \in \mathbb{N}^{*}$ is called the rank of the vector bundle.

If $(\mathrm{E}, \mathrm{M}, \pi)$ is a vector bundle, we call $\mathrm{E}$ the total space and $\mathrm{M}$ the base space, since $\pi$ projects $\mathrm{E}$ onto $\mathrm{M}^{1}$. We shall often denote the bundle by $\mathrm{E} \longrightarrow \mathrm{M}$ whenever the map is implicit, or simply by E, whenever both the map and the base space are implicit. Since we shall work only with vector bundles, the word "bundle" shall denote vector bundle, although we should emphasize there are other kinds of bundles.

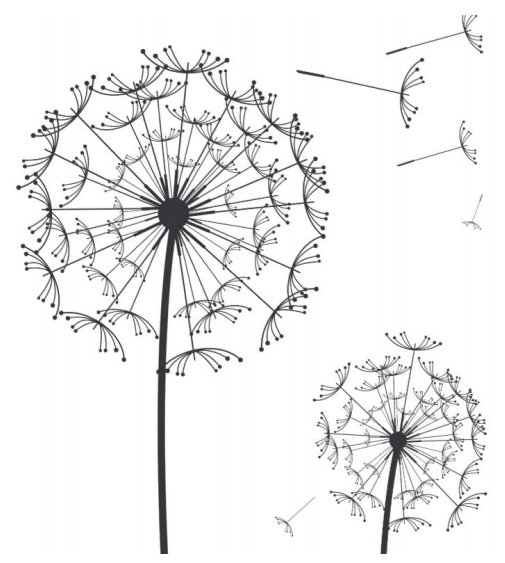

Figure 1.1: Dandelion. Image adapted from a poster by Micheline Kanzy, extracted from $h t t p:$ //www.zazzle.com.br/dente_de_leao_preto_poster - 228943950401736416

Examples: The tangent space of the manifold M, TM, constructed as the disjoint union $\bigsqcup_{p \in \mathrm{M}} \mathrm{T}_{p} \mathrm{M}$ is a vector bundle, whose fibres at each $p \in \mathrm{M}$ are the vector spaces $\mathrm{T}_{p} \mathrm{M}$. If $\mathrm{E} \longrightarrow \mathrm{M}$ and $\mathrm{F} \longrightarrow \mathrm{M}$ are two vector bundles over the same space $\mathrm{M}$, we may construct the product bundle by taking each fibre to be $\mathrm{E}_{p} \otimes \mathrm{F}_{p}$; similarly, we may consider the bundles $\mathrm{E} \longrightarrow \mathrm{M}$ and $\mathrm{F} \longrightarrow \mathrm{N}$ and construct the product bundle fibre by fibre as $\mathrm{E}_{p} \otimes \mathrm{F}_{q}, p \in \mathrm{M}$ and $q \in \mathrm{N}$. Given $\mathrm{E} \longrightarrow \mathrm{M}$, we may define the dual bundle by identifying $\left(\mathrm{E}_{p}\right)^{*}=: \mathrm{E}_{p}^{*}$ - in particular, the bundle $\mathrm{TM}^{*} \equiv \mathrm{T}^{*} \mathrm{M}$ is called cotangent bundle. For an intuitive idea of a vector bundle, consider the dandelion, a common name for some flowers of the gender Taraxacum (see fig. 1.1): we may conceive its base space $\mathrm{M}$ as the two-dimensional sphere $S^{2}$ to be the part of the plant the seeds are connected to, the total space as the three-dimensional Euclidean space $\mathbb{R}^{3}$ where the flower is, and the vector spaces as the one-dimensional spaces formed by the seeds. Of course, this is just to be seen as a intuitive representation of a vector bundle, which the dandelion is not since it has only a finite number of seeds, all of them with finite length joint together in a surface that is not perfectly circular, not to mention the fact the Universe is not a three-dimensional Euclidean space but locally; anyway, plants seem to be almost understanding the concept.

\footnotetext{
${ }^{1}$ Calling $\pi$ a projection is absolutelly not rigorous - or at least it does not necessarily agree with the common notion of a projection. Nevertheless, we shall call the intrinsic map in a vector bundle as a projection from $\mathrm{E} \longrightarrow \mathrm{M}$.
} 
Let $S: \mathrm{M} \longrightarrow$ E be locally an inverse of the projection $\pi$, i.e., such that at each fibre $\left.\pi \circ S\right|_{p}=\mathrm{id}_{\mathrm{M}}$. Such a map is called a section on the bundle. Since sections are defined at each fibre, the support of a section makes sense when considering the null vector of a certain fibre: $\operatorname{supp} S:=\overline{\left\{x \in \mathrm{M} \mid S(x) \neq 0 \in \mathrm{E}_{x}\right\}}$, with the closure being given in terms of the topology of $\mathrm{M}$. We shall denote the set of $C^{\infty}$-sections on a bundle by $C^{\infty}(\mathrm{M}, \mathrm{E})$, and the set of those which have compact support by $\mathscr{D}(\mathrm{M}, \mathrm{E})$.

\subsection{Connections on Vector Bundles}

The definition of connection on a vector bundle provides a way to differentiate a section. We shall define it as follows: a (affine) connection is a $\mathbb{K}$-bilinear map

$$
\begin{gathered}
\nabla: C^{\infty}(\mathrm{M}, \mathrm{TM}) \times C^{\infty}(\mathrm{M}, \mathrm{E}) \longrightarrow C^{\infty}(\mathrm{M}, \mathrm{E}) \\
(X, S) \longmapsto \nabla_{X} S
\end{gathered}
$$

obeying

(i) $\mathscr{F}(\mathrm{M})$-linearity w.r.t. $C^{\infty}(\mathrm{M}, \mathrm{TM})$ : for all $X \in C^{\infty}(\mathrm{M}, \mathrm{TM})$ and $S \in C^{\infty}(\mathrm{M}, \mathrm{E})$,

$$
\nabla_{f X} S=f \nabla_{X} S \quad \forall f \in \mathscr{F}(\mathrm{M})
$$

(ii) $\nabla$ is a derivation w.r.t. $C^{\infty}(\mathrm{M}, \mathrm{E})$ : for all $S \in C^{\infty}(\mathrm{M}, \mathrm{E})$ and for each fixed $X \in C^{\infty}(\mathrm{M}, \mathrm{TM})$

$$
\nabla_{X}(f S)=f \nabla_{X} S+X(f) S \quad \forall f \in \mathscr{F}(\mathrm{M}) .
$$

A connection $\nabla$ on a vector bundle $\mathrm{E}$ induces a map

$$
\begin{gathered}
\nabla^{\prime}: C^{\infty}(\mathrm{M}, \mathrm{E}) \longrightarrow C^{\infty}\left(\mathrm{M}, \mathrm{T}^{*} \mathrm{M} \otimes \mathrm{E}\right) \\
S \longmapsto \nabla^{\prime} S
\end{gathered}
$$

such that for each section $S \in C^{\infty}(\mathrm{M}, \mathrm{E})$ and for each $f \in \mathscr{F}(\mathrm{M})$,

$$
\nabla^{\prime}(f S)=d f \otimes S+f \nabla^{\prime} S .
$$

and therefore the product rules w.r.t. sections are equivalent for $\nabla$ and $\nabla^{\prime}$, in the sense that $\nabla \Leftrightarrow \nabla^{\prime}$. Given a map $\nabla^{\prime}$, which we shall also call a connection on the bundle E, for each vector field $X \in \mathrm{TM}$ we may write

$$
\nabla_{X} S \equiv\left(X, \nabla^{\prime} S\right):=\left(p r \otimes \operatorname{id}_{\mathrm{E}}\right)\left(\nabla^{\prime} S\right)
$$


where $p r: \mathrm{T}^{*} \mathrm{M} \times \mathrm{TM} \longrightarrow \mathbb{R}$ is the natural pairing $\operatorname{pr}\left(X^{*}, Y\right):=X^{*} \cdot Y \equiv\left(X^{*}, Y\right)$ and $X \longmapsto X^{*}$ is the natural pair from TM $\longrightarrow \mathrm{T}^{*} \mathrm{M}$. It is then possible to see that $\nabla^{\prime}$, regarded as a map from $C^{\infty}(\mathrm{M}, \mathrm{TM}) \times C^{\infty}(\mathrm{M}, \mathrm{E}) \longrightarrow C^{\infty}(\mathrm{M}, \mathrm{E})$ is a connection, and giving the same name for both $\nabla$ and $\nabla^{\prime}$ is no abuse. We call del the symbol $\nabla$ for any connection.

If $\mathrm{E}$ and $\mathrm{E}^{\prime}$ are two vector bundles over the same $\mathrm{M}$, connections $\nabla$ in $\mathrm{E}$ and $\nabla^{\prime}$ in $\mathrm{E}^{\prime}$ induce a connection $\mathrm{D}$ in $\mathrm{E} \otimes \mathrm{E}^{\prime}$ given by

$$
\begin{aligned}
\mathrm{D}: C^{\infty}\left(\mathrm{M}, \mathrm{E} \otimes \mathrm{E}^{\prime}\right) & \longrightarrow C^{\infty}\left(\mathrm{M}, \mathrm{T}^{*} \mathrm{M} \otimes \mathrm{E} \otimes \mathrm{E}^{\prime}\right) \\
\mathrm{D}\left(S \otimes S^{\prime}\right) & :=(\nabla S) \otimes S^{\prime}+S \otimes\left(\nabla^{\prime} S^{\prime}\right) .
\end{aligned}
$$

Consider $\mathrm{M}$ a smooth manifold with a given connection $\nabla$ on TM, and let $c: I \subset$ $\mathbb{R} \longrightarrow \mathrm{M}$ be a smooth curve. If $X \in C^{\infty}(\mathrm{M}, \mathrm{TM})$ is a vector field defined over $c(I)$, there is a (unique) correspondence $D / d t$ which associates another vector field $D X / d t$, and which satisfies:

(i) $\frac{D}{d t}$ is $\mathbb{K}$-linear map in $C^{\infty}(\mathrm{M}, \mathrm{TM})$;

(ii) it is a derivative w.r.t. smooth functions $I \longrightarrow \mathbb{R}: \frac{D}{d t} f X=\frac{\mathrm{d} f}{\mathrm{~d} t} X+f \frac{D}{d t} X$ for all $X$ and for all $f$ as presented;

(iii) if, on the other hand, $X$ is a field over a curve $c$, induced by a field $Y \in C^{\infty}(\mathrm{M}, \mathrm{TM})$ in such a way that $X(t)=Y(c(t))$, then $\frac{D}{d t}=\nabla_{\dot{c}} Y$.

The association $\frac{D}{d t}$ is called covariant derivative, and its existence and uniqueness as presented may be found proved in [11] and [7]. If for all $t \in I$ we have $\frac{D}{d t} X=0$, we say the field is parallel.

Lemma 1. Let $c: I \longrightarrow \mathrm{M}$. If $X_{0} \in T_{c\left(t_{0}\right)} \mathrm{M}$ for some $t_{0} \in I$, there is a unique parallel vector field $X$ such that $X\left(t_{0}\right)=X_{0}$; we call $X(t)$ the parallel transport of $X\left(t_{0}\right)$ throughout $c$.

\subsection{Spacetimes}

Let $V$ be a $n$-dimensional real vector space. If $B_{1}$ and $B_{2}$ are two basis for $V$, then the determinant $\operatorname{det} T\left(B_{1}, B_{2}\right)$ of the basis transformation matrix $T$ is either positive or negative, but not null. We define an equivalence relation on the collection $B$ of basis of $V$ by $B_{1} \sim B_{2} \Leftrightarrow \operatorname{det} T\left(B_{1}, B_{2}\right)>0$. The collection $B / \sim=: \mathcal{O}(V)$ will be called the set of orientations on $V$, for reasons that will be presented soon.

Let $\pi: \mathrm{E} \longrightarrow \mathrm{M}$ be a vector bundle; since for each $p \in \mathrm{M} \mathrm{E}_{p}$ defines a vector space, we may consider the collection $\mathcal{O}\left(\mathrm{E}_{p}\right)$ for each $p$. An orientation for $\mathrm{E}$ is then a function $p \in \mathrm{M} \longmapsto \mathcal{O}\left(\mathrm{E}_{p}\right)$ such that for all $p \in \mathrm{M}$ there are a $U \subset \mathrm{M}$ and a basis $\left\{\xi_{1}, \ldots, \xi_{n}\right\}$ for the section of $\pi^{-1}(U)$ (which means a basis $\left\{\xi_{1}(q), \ldots, \xi_{n}(q)\right\}$ for all $q \in U$ ) such that

$$
\mathcal{O}\left(\mathrm{E}_{q}\right)=\left[\left\{\xi_{1}(q), \ldots, \xi_{n}(q)\right\}\right] \quad \forall q \in U
$$


We say the bundle $\mathrm{E}$ is orientable if it possesses an orientation. The manifold $\mathrm{M}$ is sad to be orientable if TM is orientable.

Consider now a positive definite symmetric non-degenerated 2-tensor field $g$ defined on $\mathrm{M}$, which means that, at each point $x \in \mathrm{M}, g$ defines a inner-product in $\mathrm{T}_{p} \mathrm{M}$. The pair $(\mathrm{M}, g) \equiv \mathrm{M}$ is then called a Riemannian Manifold, in which case $g$ is called a Riemannian metric. We define the index of a symmetric bilinear form $\omega: V \times V \longrightarrow \mathbb{K}$ as the dimension of the largest subspace $W \subset V$ such that $\left.\omega\right|_{W \times W}$ is negative definite. Therefore, a symmetric non-degenerated 2-tensor field $g$ of index 1 defines, in an equivalent way, a Lorentzian metric, and thus we call the pair ( $\mathrm{M}, g) \equiv \mathrm{M}$ a Lorentzian manifold in this case.

Let $\mathcal{M}$ denote the $1+n$ dimensional Minkowski space, the vector space $\mathbb{R} \times \mathbb{R}^{n}$ with metric $\langle x, y\rangle:=-x_{0} y_{0}+\sum_{i=1}^{n} x_{i} y_{i}$. We characterize a vector $x$ in this space according to this metric as

spacelike, if $\langle x, x\rangle>0$;

timelike, if $\langle x, x\rangle<0$;

null, or lightlike if $\langle x, x\rangle=0$;

causal, if $\langle x, x\rangle \leq 0$.

Consider a $(1+\mathrm{n})$-dimensional vector space $V$ over $\mathbb{R}$ with a non-degenerate pseudoinner product $V \times V \longrightarrow \mathbb{R}$ of index one; for a pseudo-inner product we mean an inner-product, except for the condition of positive definiteness - i.e., an alternative name or euphemism for a symmetric non-degenerate 2-tensor field. It is straightforward that $V$ is then isometric to $\mathcal{M}^{n}$, and we shall use the notation $\langle\cdot, \cdot\rangle$ for the pseudo-inner product in whatever vector space we consider as long as no misunderstanding is possible. Define the function

$$
\begin{aligned}
& \gamma: V \longrightarrow \mathbb{R} \\
& \gamma(v):=-\langle v, v\rangle
\end{aligned}
$$

which enables us to extend the usual classes of vectors in Minkowski space to $V$, defining spacelike, timelike and light or nulllike vectors as in Minkowski case.

Let $\mathrm{M}$ be an oriented Lorentzian manifold. We say $\mathrm{M}$ is timeoriented if its orientation is given by a timelike vector field $\mathfrak{n}$ : if $\mathrm{M}$ in connected and if the bundle $\mathrm{E}$ is orientable, then it is possible to show that $\mathrm{E}$ has exactly two orientations; therefore, consider TM with a basis with $\mathfrak{n}$ within, or some equivalent basis, and we have a timeoriented Lorentzian manifold. We shall often refer to such manifolds as spacetimes. In addition, let $\alpha:[0,1] \longrightarrow \mathrm{M}$ have a continuous curve as image, and we may say the curve is spacelike, timelike, lightlike and/or causal according to the respective characterization of its tangent vector. Then, for each $x \in \mathrm{M}$, the set of points of $\mathrm{M}$ which may be connected to $x$ through a timelike curve, denoted by $I(x)$, has two connected components: the set $I_{+}(x)$ of points $y \in I(x)$ such that the timelike curve from $x$ to $y$ is future directed, called the chronological future of $x$, and the set $I_{-}(x)$ of points 
$y \in I(x)$ such that the timelike curve connecting $x$ to $y$ is past directed, the chronological past of $x$. In an equivalent way, if we replace the condition "timelike curve" by "causal curve", for each $x \in \mathrm{M}$ we have the set $J(x):=J_{+}(x) \cup J_{-}(x)$ formed by the causal future and by the causal past, which is the closure of $I(x)$ in Minkowski space. Whenever necessary, the manifold of which $J$ is a subset will be indicated: for example, we may write $J^{\mathrm{M}}(x)$ instead of just $J(x)$. If $O$ is a non-empty subset of M, we define its chronological future and past $I_{ \pm}(O)$ respectively as $I_{ \pm}(O):=\bigcup_{x \in O} I_{ \pm}(x)$, and similarly we define its causal future and causal past as $J_{ \pm}(O)$, respectively.

A given non-empty $O \subset \mathrm{M}$ is respectively called future or past compact in $\mathrm{M}$ if $J_{ \pm}(x) \cap O$ is compact for all $x \in \mathrm{M}$. We say $O$ is causally compatible if each causal curve in M connecting two points of $O$ lays within $O$, i. e., if $J_{ \pm}^{O}(x)=O \cap J_{ \pm}^{\mathrm{M}}(x)$ for all $x \in O$.

A given connection $\nabla$ on the bundle $\mathrm{TM} \longrightarrow \mathrm{M}$ is said to be compatible with the metric $g$ if for each smooth curve $c: I \longrightarrow \mathrm{M}$ and if for each pair of parallel vector fields $X, Y$ throughout $c, g(X, Y)=0$. On the other hand, the connection is called symmetric if for all vector fields $X, Y, \nabla_{X} Y-\nabla_{Y} X=[X, Y]$. In the present circumstances, it is possible to prove that in a given Riemannian manifold $M$, there is a unique connection $\nabla$ both symmetric and compatible with the metric; we call such connection the Riemannian connection. The proof of this statement, named LeviCivita theorem, may be found in [11].

Let $\nu: I \longrightarrow \mathrm{M}$ be a smooth curve in $\mathrm{M}$, a manifold with a given affine connection $\nabla$. Let $t \in I \longmapsto \dot{\nu}(t) \in \mathrm{T}_{\nu(t)} \mathrm{M}$ be the association of the tangent vector $X$ of $\nu$ at $t$. We call $\nu$ a geodesics if $\frac{D}{d t} \dot{\nu}(t)=0$ for all $t \in I$. If $v \in \mathrm{TM}$ is the parallel tangent vector of $\nu$, we may represent $\nu \equiv \nu_{X}$. The Riemannian exponential map at a certain $p \in \mathrm{M}$ is the map

$$
\exp _{p}: \mathrm{T}_{p} \mathrm{M} \longrightarrow \mathrm{M}
$$

such that $\exp _{p}(v)=\nu_{v}(1)$. The importance of this map is that it maps lines through the origin in $\mathrm{T}_{p} \mathrm{M}$ to geodesics through $p$ : for fixed $v \in \mathrm{T}_{p} \mathrm{M}$ and $t \in \mathbb{R}$, the geodesics $x \in I \longmapsto \nu_{v}(t x)$ has initial velocity $t v$ and hence $\exp _{p}(t v)=\nu_{t v}(1)=\nu_{v}(t)$. In a neighbourhood $U \subset \mathrm{M}$ of $p$ where the exponential is invertible, we may define the function

$$
\begin{gathered}
\Gamma_{x}: \mathrm{M} \longrightarrow \mathbb{R} \\
\Gamma_{x}(y):=-\left\langle\exp _{x}^{-1}(y), \exp _{x}^{-1}(y)\right\rangle=\gamma\left(\exp _{x}^{-1}(y)\right)
\end{gathered}
$$

We say the subset $O$ is causal if it is "causally closed", that is, if its closure $\bar{O}$ is in a certain geodesically convex ${ }^{2} O^{\prime}$ and if for each $x, y \in \bar{O}, J_{+}^{O^{\prime}}(x) \cap J_{-}^{O^{\prime}}(y)$ is in $\bar{O}$ and it is compact; $O$ is called achronal or acausal if it has no influence over itself, i.e., if each lightlike curve or causal curve, respectively, meets $O$ at most once. Let $I \subset \mathbb{R}$ be an

\footnotetext{
${ }^{2}$ Henceforth, we shall say just convex meaning geodesically convex, the property of a set to have any two of its points connected by a geodesics within the set.
} 
interval and let $\alpha: I \longrightarrow \mathrm{M}$ be a curve in $\mathrm{M}$; an extension to $\alpha$ is a curve $\beta: I^{\prime} \longrightarrow \mathrm{M}$ such that $\alpha(I) \subset \beta\left(I^{\prime}\right)$. The curve $\alpha$ is called inextensible if for all extension $\beta$, $\beta\left(I^{\prime}\right)=\alpha(I)$. A subset $S \subset \mathrm{M}$ is called a Cauchy surface if each inextensible timelike curve in M meets $S$ exactly once.

The Cauchy development of $O \in \mathrm{M}$ is the set $D(O)$ of points of $\mathrm{M}$ through which each inextensible causal curve in $\mathrm{M}$ meets $O$. The manifold $\mathrm{M}$ is sad to obey the causality condition if it contains no closed causal curve; as a counter-example, the torus endowed with the relative topology of $\mathbb{R}^{n}+1$ does not satisfy the causality condition (see [12]). On the other hand, the manifold is sad to obey the strong causality condition if, for each $x \in \mathrm{M}$, there is a neighbourhood $N$ such that each curve with initial and final points within an open $U \subset N, x \in U$, lays entirely in $N$, a condition that may be described by the requirement of non-existence of "almost closed" causal curves.

The manifold $\mathrm{M}$ is called globally hyperbolic if it obeys the strong causality condition and if for each pair of points $x, y \in \mathrm{M}, J_{+}(x) \cap J_{-}(y)$ is compact. The reason for the name "globally hyperbolic" comes from the equivalence between the three conditions

(i) M is globally hyperbolic;

(ii) there is a Cauchy surface $S \subset \mathrm{M}$;

(iii) $\mathrm{M}$ has a differentiable foliation by Cauchy surfaces; i.e., $\mathrm{M}$ is isometric to $\mathbb{R} \times S$ with metric $-\beta d t \otimes d t+g$, where $\beta$ is a smooth positive function and $g$ is a Riemannian metric on $S$ depending also smoothly on $t \in \mathbb{R}$, and each $S_{t} \equiv\{t\} \times S$ is then a smooth spacelike Cauchy surface of M.

One example is conveniently presented: let $S$ be a Riemannian manifold, and let $I \subset \mathbb{R}$ be an interval. Then, $\mathrm{M}:=I \times S$ is globally hyperbolic iff $S$ is complete, which, in particular, happens if it is compact.

\subsection{Differential Operators}

We re-stablish the notion of a d'Alembert operator in the following way. For a given pair of vector bundles $\mathrm{E}, \mathrm{F}$ defined over a common base space $\mathrm{M}$, a $\mathbb{K}$-linear operator $P: C^{\infty}(\mathrm{M}, \mathrm{E}) \longrightarrow C^{\infty}(\mathrm{M}, \mathrm{F}), \mathbb{K}=\mathbb{R}, \mathbb{C}$ depending whether the bundle is real or complex, acting on sections is called a differential operator if it may be expressed locally as

$$
P=\sum_{|\alpha| \leq k} A_{\alpha} \frac{\partial^{|\alpha|}}{\partial x^{\alpha}} .
$$

where $\alpha \in \mathbb{N}^{n}$ is a multi-index, $|\alpha|=\alpha_{j_{1}}+\cdots+\alpha_{j_{n}}$ and $A_{\alpha}$ is a homomorphism between the bundles $\mathrm{E}$ and $\mathrm{F}$ for each $\alpha$. I.e., if for every $p \in \mathrm{M}$ there is a trivialized open neighbourhood $U \subset \mathrm{M}$ of $p$ with respect to both $\mathrm{E}$ and $\mathrm{F}$, such that for every section $S \in C^{\infty}(\mathrm{M}, \mathrm{E})$, when restricted to $U$, the equality above is true. Consider then the differential operator $P$ described by (1.9) around some $p \in \mathrm{M}$ with trivializations in $\mathrm{E}$ 
and $\mathrm{F}$. Then, for each $v^{*} \in \mathrm{T}_{p} \mathrm{M}^{*}$ we may write $v^{*}=\sum v_{j}^{*} d x_{j}$, so that the principal symbol of a differential operator is the map given by

$$
\begin{array}{r}
\rho: \mathrm{T}^{*} \mathrm{M} \longrightarrow \operatorname{Hom}(\mathrm{E}, \mathrm{F}) \\
\rho\left(v^{*}\right):=\sum_{|\alpha|=k} A_{\alpha}(p)\left(v_{1}^{*}\right)^{\alpha_{1}} \cdots\left(v_{n}^{*}\right)^{\alpha_{n}} .
\end{array}
$$

Now, a normally hyperbolic operator is a second order differential operator whose principal symbol is given by the metric $g$,

$$
P=-\sum_{i, j=0}^{n-1} g^{i j}(x) \frac{\partial^{2}}{\partial x_{i} \partial x_{j}}+\sum_{j=0}^{n-1} a_{j}(x) \frac{\partial}{\partial x_{j}}+b(x) .
$$

On the other hand, a generalized d'Alembert operator is minus the composition of the following maps:

$$
C^{\infty}(\mathrm{M}, \mathrm{E}) \stackrel{\nabla}{\rightarrow} C^{\infty}\left(\mathrm{M}, \mathrm{T}^{*} \mathrm{M} \otimes \mathrm{E}\right) \stackrel{\nabla}{\rightarrow} C^{\infty}\left(\mathrm{M}, \mathrm{T}^{*} \mathrm{M} \otimes \mathrm{T}^{*} \mathrm{M} \otimes \mathrm{E}\right) \stackrel{\operatorname{tr} \otimes \mathrm{id}_{\mathrm{E}}}{\longrightarrow} C^{\infty}(\mathrm{M}, \mathrm{E}) .
$$

Lemma. If $S \in C^{\infty}(\mathrm{M}, \mathrm{E})$ and $f \in \mathscr{F}(\mathrm{M})$, then

$$
\square(f S)=f \square S+(\square f) S-2 \nabla_{\text {grad } f} S
$$

Proof.

$$
\begin{aligned}
\nabla(f S) & =d f \otimes S+f \nabla S \\
\nabla[\nabla(f S)] & =\nabla[d f \otimes S+f \nabla S] \\
& =(\nabla d f) \otimes S+f \nabla^{2} S+2 d f \otimes \nabla S \\
\left(\operatorname{tr} \otimes \mathrm{id}_{\mathrm{E}}\right) & \Rightarrow(\square f) S+f \square S+2(d f, \nabla S) \\
& =-(\square f) S-f \square S+2 \nabla_{\text {grad } f} S
\end{aligned}
$$

The notion of a generalized d'Alembert operator connects with differential operators from what follows

Theorem 1. Let $M$ be a Lorentzian manifold and let $P: C^{\infty}(\mathrm{M}, \mathrm{E}) \longrightarrow C^{\infty}(\mathrm{M}, \mathrm{E})$ be normally hyperbolic. Then there is a connection $\nabla$ on $\mathrm{E}$ and a unique $B \in C^{\infty}(\mathrm{M}, \operatorname{Hom}(\mathrm{E}, \mathrm{E}))$ such that

$$
P=\square+B
$$

where the d'Alembert is induced by the connection $\nabla$. 
Proof. Existence follows from uniqueness. Assume $\nabla$ satisfies the hypothesis of the theorem, and consider $B=P-\square^{\nabla}$, denoting the d'Alembertian is induced by $\nabla$. Then we have - omitting the summation symbol for simplicity

$$
\begin{aligned}
P(f S) & =-g^{i j} \frac{\partial^{2} f S}{\partial x^{i} \partial x^{j}}+A_{j} \frac{\partial f S}{\partial x^{j}}+B f S \\
& =\left\{-g^{i j}\left(\frac{\partial^{2} f}{\partial x^{i} \partial x^{j}} S\right)+A_{j}\left(\frac{\partial f}{\partial x^{j}} S\right)\right\}+\left\{-g^{i j}\left(f \frac{\partial^{2} S}{\partial x^{i} \partial x^{j}}\right)+A_{j}\left(f \frac{\partial S}{\partial x^{j}}\right)+B f S\right\}+ \\
& +2 \frac{\partial f}{\partial x^{i}} \frac{\partial S}{\partial x^{j}} \\
& =(\square f) S+f P S-2 \nabla_{\operatorname{grad} f} S,
\end{aligned}
$$

which, together with the result of the previous lemma, implies

$$
f\left(P S-\square^{\nabla} S\right)=P(f S)-\square^{\nabla}(f S) .
$$

Invoking again the previous lemma, the last equality is equivalent to

$$
\nabla_{\operatorname{grad} f} S=\frac{1}{2}[f P S-P(f S)+(\square f) S]
$$

and so $\nabla$ depends only on $P$ and $\square$, which in its turn depends only on the metric, since any vector field may be written as $X=\operatorname{grad}_{p} f$ for some $f$ at a certain point $p$. To prove existence, define $\nabla$ by the expression (1.11) and $B$ as before. A richer, though more complex proof on the existence of such a connection may be found in [10], lemma 1.5.5.

Hence, a generalized d'Alembert operator is extended to a normally hyperbolic operator, and we shall from now on omit the term generalized when refering to this class of operators; the Klein-Gordon operator $\left(\square+m^{2}\right)$ is then a particular example. 


\section{Chapter 2}

\section{Topics on the Theory of Distributions}

\subsection{Introduction}

In a particular sense, a distribution might be understood as a generalization of a function, and even some author prefer to call them "generalized function". On the behalf of this idea is what we call a regular distribution: let D be a certain set of functions, which we shall later call test functions; a distribution is then a continuous linear functional from $\mathrm{D}$ to $\mathbb{C}$, with the notion of continuity to be properly defined. A regular distribution, in its turn, is any distribution $T$ that may be written in terms of a function $f$ as

$$
T(g)=\int f(x) g(x) d x
$$

for all $g \in D$, with the integral obeying some conditions in order to make sense.

There are many situations in Physics where distributions arise naturally. For example, consider the classical case of a collection of electrical charges distributed throughout the space with a given density function $\rho=\rho(x)$. The electric field produced by this system is then given by

$$
E(r) \propto \int_{\mathbb{R}^{3}} \frac{\rho\left(r^{\prime}\right)}{\left\|r-r^{\prime}\right\|^{2}} d r^{\prime} .
$$

That is, we associate the idea of a charge distribution, in the sense of how the physical system is configured, to a linear functional given in terms of the function $\rho$, which carries in it the information of this configuration; this functional is, in agreement with the stated above, named a distribution in the mathematical way. In the context of Quantum Field Theory, distributions play a prominent role: for example, we may consider the Feynman propagator as defined from a distribution $(x+i \varepsilon)^{-1}$ in the limit $\varepsilon \longrightarrow 0+$. Another example would be the Klein-Gordon equation, which possesses distributional solutions, as shall be further explored later. In general, as proposed by Gårding and Wightman, Wightman 
functions and the very fields are constructed in terms of distributions: we regard the components of a field $\varphi$ as operator-valued maps $f \in \mathscr{S}\left(\mathbb{R}^{n}\right) \longmapsto \varphi_{1}(f), \ldots, \varphi_{n}(f)$, and then Wightman function, or vacuum expectation values - or even propagators, defined as $\left\langle\Psi_{0}, \varphi_{1}(f) \cdots \varphi_{n}(f) \Psi_{0}\right\rangle$, follow to be distributions on $\mathscr{S}\left(\mathbb{R}^{n}\right)$ as separately continuous linear functionals. However, we should mention that an axiomatic Quantum Field Theory as proposed by those two authors is beyond the scope of this work, having at most some parts presented as motivation and contextualization. The very idea of fields will not appear explicitly before the last section.

Throughout this chapter, we intend to introduce some concepts of the theory of distributions and tempered distribution, and to discuss in which situations we are able to define a product of distributions. In order to perform this discussion, it proves to be necessary to work with the Fourier Transform of a distribution, an extended notion of the Fourier Transform of a function. Besides, the concept of the Fourier Transform of a distribution proves also to be an important tool if one is concerned about some facts that follow from the Gårding-Whigtman axioms of Quantum Field Theory, as may be seen in [13]. It might be appropriate to clarify that we opted for denoting regular distributions and the functions that generate them by the same symbol; therefore, we may explicitly say whether we are dealing with $f \in \mathscr{S}$ or $f \in \mathscr{S}^{*}$, for example, where $\mathscr{S}^{*}$ shall denote the space of tempered distributions, to be defined ahead. Writing this chapter in any other way proved to be not only an useless effort, but, in the personal opinion of the author, also a search for hiding the very nature of distributions in the way we have presented them. A different system of notations is adopted in [7], but there the hole system of presentation is different.

\section{$2.2 \quad$ Distributions}

Consider the vector space $C^{\infty}\left(\mathbb{R}^{n}, \mathbb{C}\right)$. Adopting the notation

$$
\alpha \in \mathbb{N}^{n}, \quad \partial^{\alpha} \equiv \frac{\partial^{|\alpha|}}{\partial^{\alpha_{1}} \cdots \partial^{\alpha_{n}}}, \quad|\alpha|:=\sum_{j=1}^{n} \alpha_{j}
$$

where $\alpha$ is called a multi-index, and furthermore adding the notation $x^{\alpha} \equiv x_{1}^{\alpha_{1}} \cdots x_{n}^{\alpha_{n}}$ to denote the polynomials in the components of $x \in \mathbb{R}^{n}$, we define the family of seminorms

$$
\|f\|_{\alpha, \beta}:=\sup _{x \in \mathbb{R}^{n}}\left|x^{\alpha} \partial^{\beta} f(x)\right|
$$

for all multi-indices $\alpha, \beta$ - we recall that a seminorm is a functional $p$ defined on a vector space, obeying all the conditions a norm does, except for $p(x)=0 \Rightarrow x=0$. The subset of functions $f \in C^{\infty}\left(\mathbb{R}^{n}, \mathbb{C}\right)$ for which the family of seminorms is well defined (i.e., for which the supreme is finite) is a subspace of $C^{\infty}\left(\mathbb{R}^{n}, \mathbb{C}\right)$, which we call Schwartz space and represent by $\mathscr{S}\left(\mathbb{R}^{n}\right)$. Similarly, the subset of the $f \in C^{\infty}\left(\mathbb{R}^{n}, \mathbb{C}\right)$ with compact support is a subspace of $\mathscr{S}$, which we shall represent by $\mathscr{D}\left(\mathbb{R}^{n}\right)$ - though the notation $C_{0}^{\infty}$ is far more common. Whenever no misunderstanding is likely to happen, we shall 
omit the domains and write simply $\mathscr{S}$ and $\mathscr{D}$, and refer to the function over which the linear functional are evaluated as test functions.

We equip the space $\mathscr{S}$ of functions which, together with their derivatives, decay faster than any polynomial with a topology in which it is sequentially continuous w.r.t. the family of seminorms of above. Let $\left(f_{n}\right)_{n} \in \mathscr{S}$, we say $f_{n} \longrightarrow f \in \mathscr{S}$ if, for all $\alpha, \beta$ multi-indices, $\lim _{n \rightarrow \infty}\left\|f_{n}-f\right\|_{\alpha, \beta}=0$. We affirm $\mathscr{S}$ is a Fréchet space with the seminorms presented, one may see [14] for this statement. Consider now the topological dual of the space $\mathscr{S}$, the space $\mathscr{S}^{*}$ of continuous linear functional $T: \mathscr{S} \longrightarrow \mathbb{C}$. We call $\mathscr{S}^{*}$ the space of tempered distributions, whose notion of continuity may also be written down like follows.

Lemma 2. A linear functional $T$ on $\mathscr{S}$ is an element of $\mathscr{S}^{*}$ if, and only if there are constants $C, N>0$ such that

$$
|T(f)| \leq C \sum_{|\alpha|+|\beta| \leq N}\|f\|_{\alpha, \beta}
$$

for all multi-indices $\alpha, \beta$ and for $f \in \mathscr{S}$.

Proof. The inequality implies continuity. To prove the converse relation, suppose $T$ continuous such that the inequality is false; this means that for every constants $C, N>0$ there is a $f_{C, N} \equiv f \in \mathscr{S}$ such that the inequality does not hold. We construct the functions $g:=\frac{1}{|T(f)|} f$, and, since the equality (2.3) is false, we have

$$
\|g\|_{\alpha, \beta}=\frac{1}{|T(f)|}\|f\|_{\alpha, \beta}<\frac{1}{C} .
$$

Pick now $C=N=i$ to define a sequence $\left(g_{i}\right)_{i}$; by definition, we have, for $i>j$,

$$
\left\|g_{j}\right\|_{\alpha, \beta} \leq\left\|g_{i}\right\|_{\alpha, \beta}<\frac{1}{i}
$$

so this sequence converges to $0 \in \mathscr{S}$. If $T$ is supposed to be continuous, we must have $T\left(g_{j}\right) \longrightarrow 0 \in \mathbb{C}$; however, $\left|T\left(g_{j}\right)\right|=\frac{1}{\left|T\left(f_{j}\right)\right|}\left|T\left(f_{j}\right)\right|=1$.

In a similar way, we define on $\mathscr{D}$ the following notion of continuity - and therefore a topology. A sequence $\left(f_{n}\right)_{n} \in \mathscr{D}$ is sad to converge to an $f \in \mathscr{S}$ if there exist a compact subset $K$ such that supp $f_{n}$, supp $f \subset K$ and if the notion of convergence in $\mathscr{S}$ holds for $\left(f_{n}\right)_{n}$ and all its term-by-term derivatives. For a more complete construction of the topology in $\mathscr{S}$, see [15], but the one presented shall be enough within the scope of this work. In the same way as before, we define the topological dual space of $\mathscr{D}, \mathscr{D}^{*}$, which is called space of distributions. This nomenclature is coherent, as shows the next statement.

Lemma 3. Tempered distributions are distributions on its own right. I. e., $\mathscr{S}^{*} \subset \mathscr{D}^{*}$. 
Proof. It is evident that $\mathscr{D} \subset \mathscr{S}$, then a linear functional on $\mathscr{S}$ is also a linear functional on $\mathscr{D}$, we just have to check its continuity. Let $T \in \mathscr{S}^{*}$, and let $\left(f_{n}\right)_{n} \in \mathscr{D} \longrightarrow f \in \mathscr{D}$, which implies the convergence in $\mathscr{S}$. Then, $\lim _{n \rightarrow \infty}\left|T\left(f_{n}\right)-T(f)\right|=0$ in $\mathscr{S}$, which means $T$ is continuous as an element of $\mathscr{D}$ also.

We affirm that (2.3) has an equivalent in $\mathscr{D}^{*}$, the proof being quite similar. Some examples are presented.

\section{Examples:}

1. The gaussian function $x \in \mathbb{R}^{n} \longmapsto e^{-\lambda\|x\|^{2}} \in \mathbb{R}$ is in $\mathscr{S}\left(\mathbb{R}^{n}\right)$, but the exponential $x \longmapsto e^{-\|x\|}$ is not: although it decays faster than any polynomial, it is not differentiable at the origin. Construct now a bump function $\sigma: \mathbb{R}^{n} \longrightarrow \mathbb{C}$ such that $\sigma \equiv 1$ for $x$ in a connected subset $K$ of $\mathbb{R}^{n}$ and null outside a compact subset $K^{\prime} \supset K$. It is then possible to adjust the behave of $\sigma$ in between $K^{\prime}$ and $K$-i.e., in the complemet on $K$ w.r.t. $K^{\prime}$ in a way that $\sigma \in \mathscr{D}$.

2. There is a special and motivating kind of distribution called regular distribution. Let $g: \mathbb{R}^{n} \longrightarrow \mathbb{C}$ such that for all $f \in \mathscr{S}$ the integral

$$
\int_{\mathbb{R}^{n}} g(x) f(x) d x
$$

converges. Similarly, we may suppose $f \in \mathscr{D}$ and pick $g$ such that the integral above makes sense. In any case, we may think of $g$ as a linear functional on $\mathscr{S}$ or on $\mathscr{D}$ given by

$$
g(f):=\int_{\mathbb{R}^{n}} g(x) f(x) d x
$$

It is easy to show the continuity of $g$. Therefore, regular distributions are then distributions. As said earlier in the introduction, those are the most natural kind of distributions, and every construction presented in this chapter will be an attempt to generalize its properties.

3. The Dirac delta function $\delta_{x}$ is a distribution for each $x \in \mathbb{R}^{n}$, defined as $f \longmapsto$ $\delta_{x}(f):=f(x)$. At the origin, it may be conceived as the limit of a net of functions $\chi_{\varepsilon}: \mathbb{R} \longrightarrow \mathbb{C}$ given by

$$
\chi_{\varepsilon}(x):= \begin{cases}\frac{1}{\varepsilon} & \|x\| \leq \varepsilon / 2 \\ 0 & \text { otherwise }\end{cases}
$$

Consider now each $\chi_{\varepsilon}$ as a regular distribution, as presented in the previous example; let $F$ be the primitive of $f$, and then 


$$
\begin{aligned}
\lim _{\varepsilon \rightarrow 0} \chi_{\varepsilon}(f) & =\lim _{\varepsilon \rightarrow 0} \int f(x) \chi_{\varepsilon}(x) d x \\
& =\lim _{\varepsilon \rightarrow 0} \int_{\|x\| \leq \varepsilon} f(x) \chi_{\varepsilon}(x) d x \\
& =\lim _{\varepsilon \rightarrow 0} \frac{F(\varepsilon)-F(-\varepsilon)}{\varepsilon}=f(0) .
\end{aligned}
$$

It is possible to consider other limit sequences to $\delta_{x}-$ see [7].

4. Consider the function $\theta: \mathbb{R}^{n} \longrightarrow \mathbb{C}$

$$
\theta(x):= \begin{cases}1 & x_{j} \geq 0 \\ 0 & \text { otherwise }\end{cases}
$$

for some $1 \leq j \leq n$ and the regular distribution induced by it, represented by $H$. We call it the Heaviside distribution.

5. Not all linear functional on $\mathscr{D}$ are linear functionals on $\mathscr{S}$, although the opposite is true. For instance, consider

$$
e(f):=\int_{\mathbb{R}} f(x) e^{x^{4}} d x
$$

which does not makes sense for all $f \in \mathscr{S}$. This example was extracted from [7], section Distribuições e Distribuições Temperadas.

A fundamental concept concerning distributions is the support. For a function, its support is simply the closure of the set of points where the function is not null. For a distribution, the support is not a subset of the space of functions over which it is defined, but a subset of the domain of those functions: a point $x \in \mathbb{R}^{n}$ is sad to be in the support of a given distribution $T$ if for each neighbourhood $N$ of $x$ there exists a function $f \in \mathscr{D}$ with supp $f \subset N$ such that $T(f) \neq 0$.

Lemma 4. The support of a distribution is closed.

Proof. Consider $x \notin \operatorname{supp} T$ : it means that $x$ has an open neighbourhood $U_{0}$ such that $\forall f \in \mathscr{D}$ with supp $f \subset U_{0}, T(f)=0$. If $U_{0} \cap \operatorname{supp} T \neq \emptyset$, since we are dealing with $\mathbb{R}^{n}$ with its usual topology, we may shrink $U_{0}$ to an open subset $U^{\prime} \subset U_{0}, x \in U^{\prime}$ disjoint of supp $T$. Therefore the complement of supp $T$ is a neighbourhood of each one of its points, and so is open.

Equivalently, the support of $T$ is then held as the smaller closed set $K \in \mathbb{R}^{n}$ such that $\left.T\right|_{K^{C}}=0$.

If $f$ is a test function in $\mathscr{D}$ whose support is disjoint of the support of a distribution $T$ given, then $T(f)=0$. Let $x \in \operatorname{supp} f$; as $x \notin \operatorname{supp} T$, it has a neighbourhood $N$ such that for all $\psi$ with supp $\psi \subset N, T(\psi)=0$. Since supp $f$ is compact, consider a 
finite open covering $O_{1}, \ldots, O_{n}$ and a partition of unity subordinated to this covering in a way that we may write $f=\psi_{1}+\cdots+\psi_{n}$, again with $T\left(\psi_{j}\right)=0$. Then $T(f)=$ $T\left(\psi_{1}\right)+\cdots+T\left(\psi_{n}\right)=0$. However, it is not enough for $f$ to be null in the support of $T$ to ensure that $T(f)=0$ : namely, suppose $\mathscr{D}(\mathbb{R})$ and consider $T \in \mathscr{D}^{*}(\mathbb{R})$ as $T(f):=\delta_{0}\left(f^{\prime}\right)$, so we have supp $T=\{0\}$, but $T(f)$ may be different of 0 while $f(0)=0$.

Another important concept for distributions is the singular support: defining it by complementarity, a point $x \in \mathbb{R}^{n}$ is sad to be not in the singular support of $T$, denoted by $\operatorname{sing} \operatorname{supp} T$, if it has a neighbourhood $N$ such that there is $f \in \mathscr{D}$ (or in $\mathscr{S}$ ) with supp $f \subset N$ such that $T=f$ in $\mathscr{D}(N)$ (or in $\mathscr{S}(N)$ ). What that means is that the singular support of a distribution is a subset of $\mathbb{R}^{n}$ where this distribution is not regular. It may also be proved to be closed.

Example: The support of $\delta_{x}$ and its singular support are both $\{x\}$, since around at any other point it may be described in terms of the null distribution. The Heaviside distribution has support $\mathbb{R}^{+}$and singular support $\{0\}$. Another example, of great interest in the context of Quantum Field Theory, is the distribution

$$
u(x)=\frac{1}{x+i 0^{+}},
$$

i.e., the limit value of the sequence of regular distributions $u(x):=(x+i \varepsilon)^{-1}$ as $\varepsilon \longrightarrow$ $0+$,

$$
u(f)=\lim _{\varepsilon \longrightarrow 0+} \int_{\mathbb{R}} \frac{f(x)}{x+i \varepsilon} d x=\lim _{\varepsilon \longrightarrow 0+} \int_{\varepsilon}^{\infty} \frac{f(x)-f(-x)}{x} d x-i \pi \delta_{0}(f)
$$

whose singular support is $\{0\}-$ see [16] for the details.

Extending the definition concerning functions, we may define the derivative of a distribution as

$$
\partial^{\alpha} T(f):=(-1)^{|\alpha|} T\left(\partial^{\alpha} f\right) .
$$

The reason for this definition (and for the term $(-1)^{|\alpha|}$ ) lays on regular distributions. Suppose $T$ is induced by some $g$ and consider $f \in \mathscr{D}(\mathbb{R})$. Thus, integrating by parts,

$$
\begin{aligned}
\frac{\mathrm{d} g}{\mathrm{~d} x}(f) & =\int\left(\frac{\mathrm{d} g}{\mathrm{~d} x}(x)\right) f(x) d x \\
& =\left.f(x) g(x)\right|_{\mathbb{R}}-\int f(x)\left(\frac{\mathrm{d} f}{\mathrm{~d} x}(x)\right) d x
\end{aligned}
$$

As supp $f$ is in a compact subset of $\mathbb{R}$, the term $f g(x)$ is null. By induction and extension to $\mathbb{R}^{n}$, one obtains the result for regular distributions in $\mathbb{R}^{n}$. 
It is possible, however, to make the same definition from a more analytical way. The derivative of a distribution may be conceived as the limit

$$
\lim _{a \rightarrow 0} \frac{T_{a_{j}}-T}{a}
$$

where $T_{a_{j}}$ means the distribution $T$ translated in its $j$ th component by $a$. Hence,

$$
\begin{aligned}
\partial^{|\alpha|} T(f) & =\lim _{a \rightarrow 0} \frac{T_{a_{j}}(f)-T(f)}{a}=\lim _{a \rightarrow 0} \frac{T\left(f_{a_{j}}\right)-T(f)}{a} \\
& =T\left(\lim _{a \rightarrow 0} \frac{f_{a_{j}}-f}{a}\right)=-T\left(\frac{\partial f}{\partial x_{j}}\right)
\end{aligned}
$$

where $f_{a_{j}}(x)=f(x-(0, \ldots, 0, a, 0, \ldots, 0))$.

\section{Examples:}

1. The $n$th derivative of the delta distribution in $\mathscr{S}(\mathbb{R})$ is simply $(-1)^{n} f^{(n)}(0)$.

2. For the Heaviside distribution,

$$
H^{\prime}(f)=-H\left(f^{\prime}\right)=-\int_{\mathbb{R}} \theta(x) f^{\prime}(x) d x=-\int_{0}^{\infty} f^{\prime}(x) d x=f(0)-f(\infty)^{0}
$$

so that we identify $H^{\prime} \equiv \delta_{0}$.

There are some statements which are quite important and will be used in this chapter. We shall present, but not prove them; we refer to [14], section V.3 and its appendix.

Theorem 2 (Regularity theorem). If $T \in \mathscr{S}$, then there is a polynomially bounded function $g$ and a multi-index $\alpha$ such that

$$
T(f)=(-1)^{|\alpha|} \int g(x) \partial^{\alpha} f(x) d x .
$$

This theorem is proved in the reference as a corollary of another proposition, which also implies that $\mathscr{S}$ is weakly dense in $\mathscr{S}^{*}$. It is very interesting that such a demonstration involves the study of the quantum harmonic oscillator. Namely, it derives from the proof that the eigenstates of the Hamiltonian for the quantum harmonic oscillator form an orthonormal basis for $L^{2}(\mathbb{R})$.

\subsection{Fourier Transform of Distributions}

The Fourier transform of distributions plays an important role in the problem of defining the product of distributions. We shall recall its definition and some properties for functions before moving to $\mathscr{D}$ or $\mathscr{S}$. Hence, the Fourier Transform of a function 
$f \in \mathscr{S}$ and the Adjoint Fourier Transform are respectively defined as the functions $\mathscr{F}: \mathscr{S} \rightarrow \mathscr{S}$ and $\mathscr{F}^{*}: \mathscr{S} \rightarrow \mathscr{S}$ given by

$$
\begin{aligned}
\mathscr{F}(f)(k) & \equiv \hat{f}(k):=\frac{1}{(2 \pi)^{n / 2}} \int_{\mathbb{R}^{n}} f(x) e^{-i k \cdot x} d x \\
\mathscr{F}^{*}(f)(k) & \equiv \check{f}(k):=\frac{1}{(2 \pi)^{n / 2}} \int_{\mathbb{R}^{n}} f(x) e^{i k \cdot x} d x .
\end{aligned}
$$

We affirm $\mathscr{F}^{*}$ is the inverse of $\mathscr{F}$ and that both maps take values in $\mathscr{S}$ - see the appendix of this chapter. We define the Fourier transform of a distribution as the distribution applied to the transformed function, or, properly, as a function $\mathscr{F}: \mathscr{S}^{*} \longrightarrow$ $\mathscr{S}^{*}, T \mapsto \mathscr{F}(T)$ determined by

$$
\mathscr{F}(T)(f) \equiv \hat{T}(f):=T(\hat{f})
$$

for all $f \in \mathscr{S}$. Such a definition is inspired by the particular case of regular distributions, again. Consider $g \in \mathscr{D}$ as a regular distribution; then, by using the Parseval Identity (see the appendix) and the fact that the operations of conjugation and the Fourier transform commute in $\mathscr{D}$ - appendix, or [7], we have

$$
(\mathscr{F} g)(f)=\int \hat{g}(x) f(x) d x=\langle\overline{\mathscr{F}(g)}, f\rangle=\langle\bar{g}, \hat{f}\rangle=\int g(x) \hat{f}(x) d x=g(\mathscr{F} f) .
$$

The Fourier transform on $\mathscr{S}^{*}$ has, then, been defined in a natural way to extend the situation presented above. Such extension is, thereafter, the only weak continuous extension of the transform of regular distributions in $\mathscr{S}$ :

Theorem 3. The Fourier transform in the space of tempered distributions is a bijective map, and it is the only weakly continuous extension of the transform of regular distributions.

The proof of this theorem may be found in the appendix of this chapter.

\subsection{Further Operations with Distributions}

By further operations with distributions, extended from functions, we mean the product and the convolution. For the first, suppose $g$ a locally integrable function and $T$ a distribution. Generalizing the straightforward case of regular distributions, we define $(g T)(f):=T(f g)$ for all $f \in \mathscr{D}$. The natural question arising now is whether and how we would define the product of two distributions in general. This is not trivial to do, and we shall return to this problem later. For the convolution, we define the operation * : $\mathscr{S} \times \mathscr{S} \longrightarrow \mathscr{S}$ (equivalently for $\mathscr{D}$ ), as

$$
(f, g) \longmapsto(f * g)(x):=\frac{1}{(2 \pi)^{n / 2}} \int f(x-y) g(y) d y
$$


Therefore, this convolution $*$ between functions is associative and commutative. This will be an unproven statement in this work, but may be easily checked. The intrinsic relation between convolution of functions and the Fourier transform is shown in the next lemma, whose proof is in the appendix.

Lemma 5. Let $f, g \in \mathscr{S}$. Then,

(i) $\mathscr{F}[f g]=\hat{f} * \hat{g}$;

(ii) $(f, g) \mapsto f * g \in \mathscr{S}$;

(iii) $\mathscr{F}[f * g]=\hat{f} \hat{g}$;

(iv) $*$ is separately continuous. I.e., the map $g \mapsto f * g$ for each $g \in \mathscr{S}$ and for each $f \in \mathscr{S}$ held fixed is continuous.

This construction is now extended to the case when one of the elements is a distribution by

$$
(g * T)(f):=T(\tilde{g} * f)
$$

where $\tilde{g}(x):=g(-x)$. The motivation behind this extension $\mathscr{S} \longrightarrow \mathscr{S}^{*}$ is regular distributions: consider the regular distributions $f, g$, and so

$$
\begin{aligned}
(g * f)(h) & =\int(g * f)(x) h(x) d x=\int \frac{1}{(2 \pi)^{n / 2}}\left(\int g(x-y) f(y) d y\right) h(x) d x \\
& \propto \int g(x-y) h(x) d x f(y) d y \propto \int(\tilde{g} * h)(y) f(y) d y=f(\tilde{g} * h) .
\end{aligned}
$$

It is possible to notice that $g \longmapsto \tilde{f} * g$, being a continuous transformation in $\mathscr{S}$, guarantees that $T * f \in \mathscr{S}^{*}$. The properties of $*$ now extend to the following.

Lemma 6. For each $f \in \mathscr{S}$, the map $\mathscr{S}^{*} \longrightarrow \mathscr{S}^{*}$ given by $T \longmapsto T * f$ is weakly continuous, and it extends the convolution on $\mathscr{S}$ in the sense that it extends the notion of convolution of regular distributions. Besides that,

(i) $T * f$ is a polynomially bounded function of $C^{\infty}\left(\mathbb{R}^{n}, \mathbb{C}\right)$. Furthermore,

$$
\partial^{\beta}(T * f)=\left(\partial^{\beta} T\right) * f=T *\left(\partial^{\beta} f\right) ;
$$

(ii) $(T * f) * g=T *(f * g)$;

(iii) $\mathscr{F}[T * f]=\hat{f} \hat{T}$.

Proof. We follow the proof presented in [13]. A more explicit, but less analytic proof of part of this lemma may be found in [15], theorem 3 of chapter Microlocal Analysis, by Alexander Strohmaier. 
As $T \longmapsto T * f$ is defined in terms of a bounded map $*: \mathscr{S} \longrightarrow \mathscr{S}$, it is weakly continuous:

$$
\begin{aligned}
\|T * f\|_{\mathscr{S} *} & =\sup _{\|g\|_{\alpha, \beta} \leq 1}|(T * f)(g)|=\sup _{\|g\|_{\alpha, \beta} \leq 1}|T(\tilde{f} * g)| \leq \sup _{\|g\|_{\alpha, \beta} \leq 1}\|T\|_{\mathscr{S} *}\|\tilde{f} * g\|_{\gamma, \delta} \\
& =\|T\|_{\mathscr{S} *} \sup _{\|g\|_{\alpha, \beta} \leq 1}\|\tilde{f} * g\|_{\gamma, \delta} \leq C\|T\|_{\mathscr{S} *}\|f\|_{\alpha, \beta}
\end{aligned}
$$

The extension from regular distributions is proven above. The associativity in item (ii), item (iii) and the second part of item (i) all follow from the equivalent statements for $\mathscr{S}$, since $\mathscr{S}$ is weakly dense in $\mathscr{S}^{*}$ and since both $\partial, \mathscr{F}, *$ and the multiplication by a function are all weakly continuous in $\mathscr{S}^{*}$. For example, item (ii) is verified since the extension $g \in \mathscr{S} \longrightarrow g \in \mathscr{S}^{*}$ is well defined, and since so is $g * f \in \mathscr{S} \longrightarrow g * f \in \mathscr{S}^{*}$. It remains to prove that $T * f$ is polynomially bounded.

Let $T \in \mathscr{S}\left(\mathbb{R}^{n}\right)$. By the regularity theorem presented previously, there is a continuous bounded function $g$, some $r>0$ and a multi-index $\beta$ such that

$$
T\left(f_{y}\right)=\int g(x)\left(1+x^{2}\right)^{r}\left(\partial_{x}^{\beta} f\right)(y-x) d x
$$

where $f_{y}$ means the function $f$ with a translation by $y$ in its argument, $f_{y}(x)=f(x-y)$; the combination $\tilde{f}_{y}$ will then denote $\left(f_{y}\right)^{\sim}$, i.e. $\tilde{f}_{y}(x)=f(y-x)$. Thus, setting the change of variables $t:=y-x$,

$$
\begin{aligned}
\left|T\left(f_{y}\right)\right| & \leq \int\left|g(y-t) \|\left(1+(y-t)^{2}\right)\right|^{r}\left|\partial^{\beta} f(t)\right| d t \\
& \leq\|g\|_{\infty} \int\left|\left[1+(y-t)^{2}\right]\right|^{r}\left|\partial^{\beta} f(t)\right| d t \\
& \leq\left|1+y^{2}\right|^{r}\|g\|_{\infty} \int\left|\left(1+t^{2}\right)\right|^{r}\left|\partial^{\beta} f\right|(t) d t,
\end{aligned}
$$

but since $\partial^{\beta} f \in \mathscr{S}$, the above integral converges for each $y$, from what follows that the function $y \mapsto T_{\tilde{f} y}$ is polynomially limited. Using the expression above for $T_{\tilde{f} y}$ in terms of the regularity theorem, the same may be stated for the derivatives of $T_{\tilde{f} y}$ with respect to $y$, thus the function

$$
y \longmapsto T\left(f_{y}\right)
$$

is polynomially bounded. Suppose now $S \in \mathscr{S}^{*}$ is a regular distribution; then, for each $g \in \mathscr{S}$ 


$$
\begin{aligned}
(S * f)(g) & =S(\tilde{f} * g)=\int s(x)(g * \tilde{f})(x) d x \\
& =\int s(x)\left(\int g(y) \tilde{f}(x-y) d y\right) d x \\
& =\int \underbrace{\left(\int s(x) \tilde{f}_{y}(x) d x\right)}_{(*)} g(y) d y \\
& =S\left(\tilde{f}_{y}\right)(g), \quad S\left(\tilde{f}_{y}\right) \in \mathbb{C} \text { for each } \mathrm{y} .
\end{aligned}
$$

We thereafter see $y \longmapsto S\left(\tilde{f}_{y}\right)$ may be regarded as a function of $\mathbb{R}^{n} \longrightarrow \mathbb{C}$ if both $S$ and $f$ are held fixed, and $S * f \equiv S(\tilde{f})$. It follows from the regularity theorem that for each tempered distribution $T, T=\partial^{\beta} S$ for some $S$ and for some index $\beta$, so

$$
\begin{aligned}
(T * f)(g) & =T(\tilde{f} * g)=\partial^{\alpha} S(\tilde{f} * g)=(-1)^{|\alpha|} S\left(\partial^{\alpha} \tilde{f} * g\right) \\
& =(-1)^{|\alpha|} \int S(x)\left(\partial^{\alpha} \tilde{f} * g\right)(x) d x \\
& =(-1)^{|\alpha|} \int S(x) \int \partial^{\alpha} f(t-x) g(t) d t d x \\
& =\int \partial^{\alpha} S(x) g(t) f(t-x) d t d x \\
& =\int T\left(\tilde{f}_{t}\right) g(t) d t
\end{aligned}
$$

May no misunderstanding remain: for each $f \in \mathscr{S}, T \longmapsto T * f$ defines a map in $\mathscr{S}^{*}$. What this lemma shows is that this map is determined by a bounded function $\mathbb{R}^{n} \longrightarrow C, x \longmapsto T\left(\tilde{f}_{x}\right)$, which allows us to understand the convolution defining also a $\operatorname{map} T * f: \mathbb{R}^{n} \longrightarrow \mathbb{C}$ as

$$
(T * f)(x):=T\left(\tilde{f}_{x}\right) .
$$

In fact, we could have started with the latter definition and constructed the former one.

Lemma 7. Let $T$ be a tempered distribution, and let $f$ be a function in the Schwartz space. Then, the Fourier transform of their product, $\widehat{f T}$, is a polynomially bounded function of $\mathbb{R}^{n} \longrightarrow \mathbb{C}$ given by

$$
\widehat{f T}(y):=T\left(f \zeta_{y}\right)
$$


where

$$
\zeta_{y}: \mathbb{R}^{n} \longrightarrow \mathbb{C}, \quad \zeta_{y}(x):=e^{-i y \cdot x}
$$

Proof. Let $P$ be the parity operator $P f(x) \longrightarrow f(-x)$ and $U_{y}$ be the translation operator for each $y$, so that we have $\tilde{f}_{y}=P U_{y} f$ - this is just to bring an easier notation for this proof. According to last theorem and to the appropriate commutation relations - see [7],

$$
\begin{aligned}
\widehat{f T}(y) & =\mathscr{F}[f T](y)=[\hat{f} * \hat{T}](y) \\
& =\hat{T}\left(P U_{y} \mathscr{F} f\right)=T\left(\mathscr{F} P U_{y} \mathscr{F} f\right) \\
& =T\left(\mathscr{F}^{-1} U_{y} \mathscr{F} f\right) \\
& =T\left(\mathscr{F}^{-1} \mathscr{F} \zeta_{y} f\right)=T\left(\zeta_{y} f\right)
\end{aligned}
$$

Corollary. If $f \in \mathscr{S}$ is identically one on a neighbourhood of the support of the distribution $T$, then $\hat{T}(k)=T\left(f \zeta_{k}\right)$. A function $f$ like this will be eventually called a localization.

This dubious character of the convolution and the notions of both Fourier transform and convolution for distributions are fundamental for the development of product of two distributions, say $T$ and $S$, by what we mean another distribution $W \equiv T S$ such that the previous developments are extended. In better words, we saw that in the particular case where $S$ is a regular distribution, the product is well defined as $S T(f)=T(S f)$.

The first idealization of a product of distributions is given as follow:

Theorem 4. Let $T, S \in \mathscr{D}^{*}$ be such that sing supp $T \cap \operatorname{sing}$ supp $S=\emptyset$. Then there is a unique $W \equiv S T \in \mathscr{D}$ such that

(i) if $x \notin \operatorname{sing} \operatorname{supp}(S), S \equiv F$ a $C^{\infty}$ function in a neighbourhood of $x, W=F T$ in a neighbourhood on $x$. That is, if $S(f)=\int F(t) f(t) d t$ for all $f$ with support in open set about $x$, then $W(f)=T(F f)$;

(ii) if $x \notin \operatorname{sing} \operatorname{supp}(T), W=G S$ in the same way.

Proof. ${ }^{1}$ It should be noticed that there is no redundancy in the theorem above: it does not state the existence of two different distributions $W_{1}$ and $W_{2}$, one satisfying item (i) while the other satisfies item (ii); on the contrary, it is one unique distribution which satisfy both statements if the hypothesis is true.

\footnotetext{
${ }^{1}$ This proof contains probably too much details about partitions of unity. The reason is that the author did not know what they were and how to work with them until he had to study this theorem. Later the author decided to maintain all this details, at least in respect regarding his colleague Ricardo Costa de Almeida, who lost some time explaining them to him.
} 
There are two points to be proved: the first is that such a $W$ exists, while the second is that it is unique. We first assume the existence of such a distribution and prove its uniqueness in the following way: we suppose the existence of two distinct products for one given pair of distributions, then we show that in a neighbourhood of a point in the ball $B(0 ; 2 R) \equiv B(2 R)$ the products must be equal, in the sense they must have the same value whenever applied to a function whose support is in this neighbourhood of such a point. Then, we take a set of points in the ball $B(2 R)$ such that a collection of neighbourhoods of these points define a covering of the ball $B(R)$. Taking after that an appropriate set of functions, it is possible to show that for whichever given function in $\mathscr{D}$ with support in $B(R)$ there is a way to localize this function in order to conclude that the products of the distributions are equal when applied to this function. The next step, having proved that the products coincide for any $R>0$ and for any $f \in \mathscr{D}$ with supp $f \in B(R)$, is to extend the ball in a manner to produce a unique product of distributions which is also a distribution - a construction that requires an important property of the space $\mathscr{D}$. The last part shall be to prove that a certain candidate to product indeed satisfies the theorem.

Therefore, let $W_{1}$ and $W_{2}$, both satisfying the theorem, be defined as products of $S$ and $T$. Let also $R>0$ and $B(0 ; 2 R) \equiv B(2 R) \subseteq \mathbb{R}^{n}$. Since the singular supports of the distributions $S$ and $T$ are disjoint, for each $x \in B(2 R)$ there is $r=r(x)$ such that, for each $g \in \mathscr{D}$ with supp $g \subseteq B(x ; r(x)), W_{1}(g)=W_{2}(g)$ - once $x$ is not in (at least) one of the singular supports, both $W_{1}$ and $W_{2}$ satisfy (at least) one of the items of the theorem, so being equal in the neighbourhood $B(x, r(x))$ of $\mathrm{x}$.

Let now $A:=\left\{A_{j}\right\}_{j \in \Lambda}$ be a pre-compact open covering of $\mathbb{R}^{n}$ made of open balls, and let $\rho:=\left\{\rho_{j}\right\}_{j \in \Lambda}$ be the partition of unity associated to $A$ - which exists, since $\mathbb{R}^{n}$ is both Hausdorff and paracompact. For $R>0$, consider $f \in \mathscr{D}$ so that supp $f \subseteq B(R)$; then, for each $x \in \mathbb{R}^{n}$,

$$
\begin{aligned}
f(x) & =f(x) \sum_{j \in \Lambda} \rho_{j}(x)=\sum_{j \in \Lambda}\left(f \rho_{j}\right)(x) \Rightarrow \\
f & =\sum_{j \in \Lambda} f \rho_{j} \equiv \sum_{j \in \Lambda} f_{j},
\end{aligned}
$$

$f_{j}:=f \rho_{j}$ for all $j \in \Lambda$. The second sum above may be rewritten as follows: let $C \subset \Lambda, C^{\prime}:=\left\{j: \operatorname{supp} f \cap A_{j} \neq \emptyset\right\}$, and suppose $A$ is not redundant (i. e., for each $j \in \Lambda, \nexists j^{\prime} \in \Lambda, j^{\prime} \neq j$ such that $A_{j^{\prime}} \subset A_{j}$ ). Then, if $C^{\prime}$ is infinite, by the compactness of supp $f$ we may take $C \subseteq C^{\prime}$ finite. Thereafter, since for any $x \in \operatorname{supp} f, \rho_{j}(x)=0$ if $j \notin C$ (because in these circumstances the definition of $C$ implies that $x \notin \operatorname{supp} \rho_{j}$ ),

$$
f=\sum_{j \in C} f_{j}
$$

Now, in order to obtain a covering of $\overline{B(R)}$, we may extend $C$ to a $J \subset \Lambda$ such that $C \subseteq J$ and $\left\{A_{j}\right\}_{j \in J}$ is a finite open covering of $\overline{B(R)}$. By the last argument, 


$$
f=\sum_{j \in C} f_{j}=\sum_{j \in J} f_{j}
$$

For each $j \in J, f_{j}$ is a $C^{\infty}$ function, since both $f$ and $\rho_{j}$ are. We may conclude, according to the previous discussion, that $W_{1}\left(f_{j}\right)=W_{2}\left(f_{j}\right) \Rightarrow W_{1}(f)=W_{2}(f)$, and we obtain the existence of, at most, one product $W$ for given $T, S$ for some $R>0$.

To prove the existence of the product, for each $x \in B(R), x$ belongs to at most one of the singular supports of the distributions $T$ and $S$, so we may construct

$$
W_{R}(f)=\sum_{j \in J_{1} \subseteq J} T\left(F_{j} f_{j}\right)+\sum_{j \in J_{2} \subseteq J} S\left(G_{j} f_{j}\right)
$$

That is, in each open set $A_{j} \in\left\{A_{j}\right\}_{j \in J}$ at least one of the distributions $T$ and $S$ is regular; we take $J_{1}, J_{2} \subseteq J, J=J_{1} \cup J_{2}, J_{1}:=\left\{j: T\right.$ is regular in $\left.A_{j}\right\}, T$ being given in terms of the function $G_{j}$ in $A_{j}$ if $j \in J_{1}$, and $J_{2}:=\left\{j: S\right.$ is regular in $\left.A_{j}\right\}$ with $S$ being given in terms of the function $F_{j}$ in $A_{j}$ if $j \in J_{2}$. For $f \in \mathscr{D}$, we may verify that such an $W_{R}$ satisfies the conditions of the theorem: $T, S \in \mathscr{D}^{*}$ implies $W_{R} \in \mathscr{D}^{*}$; furthermore, if $x \in B(R)$, and if $x \notin \operatorname{sing}$ supp $S$ for example, in a neighbourhood $N \subseteq B(R)$ of $x S$ is regular, $f_{j}=0$ in the outside of a sub-covering of $N$ and thus

$$
W_{R}(f) \mid N=W_{R}(f)=\sum_{j \in J_{1} \subseteq J} T\left(F_{j} f_{j}\right)
$$

By symmetry, we may have the same for $S$. Finally, if $x$ is not in the singular support of both distributions,

$$
W_{R}(f) \mid N=W_{R}(f)=\sum_{j \in J_{1} \subseteq J} G_{j} F_{j} f_{j}+\sum_{j \in J_{2} \subseteq J} F_{j} G_{j} f_{j} .
$$

At last, we note that for each $R>0$ fixed we may construct a product of distributions. Since this product is unique, if we define $W_{R}$ and $W_{R}^{\prime}$ with $R<R^{\prime}$, both must agree on $\mathscr{D}(B(R))$; as for a functional on $\mathscr{D}\left(\mathbb{R}^{n}\right)$ to be continuous it is a sufficient condition that it is continuous in each $\mathscr{D}(B(R))$, we may put all the $W_{R}$ together to construct a product of distributions over the entire $\mathscr{D}$.

The first natural generalization to be made from the established notion of product of distributions is the construction of a product of distributions which may have a common non-empty singular support. That said, given $T, S \in \mathscr{D}$, we say there is a product $T S \equiv W \in \mathscr{D}$ if for each localization $f$ of $W$ and for each $k \in \mathbb{R}^{n}$, the integral

$$
\mathscr{F}\left[f^{2} T S\right](k)=\int_{\mathbb{R}^{n}} \mathscr{F}[f T](l) \mathscr{F}[f S](k-l) d l
$$

is absolutely convergent, for reasons to be justified in the next theorem, which also states the agreement with the previous definition. 


\section{Theorem 5.}

(i) The product of distributions with a (possibly) common singular support is well defined. I. e., there is at most one distribution $W$, given $T$ and $S$, such that the integral (2.10) above exists and converges absolutely;

(ii) If $T=f$ is a regular distribution, then $T S$ exists and $(T S)(g)=S(f g) \forall g$;

(iii) If $T S, S V, T(S V)$ and $(T S) V$ all exist, then the product is associative;

(iv) If the singular support of the distributions are indeed disjoint, then the definition (2.10) is in agreement with theorem (4);

(v) If both $T$ and $S$ have compact support, then the product exists if and only if $\hat{T} * \hat{S}$ converges absolutely and is a polynomially bounded function;

(vi) If for all $x \in \mathbb{R}^{n}$ there is $f \in \mathscr{D}$ with $f(x) \neq 0$ such that the right side of (2.10) is absolutely convergent and defines a polynomially bounded function, then the product exists;

(vii) If the product exists, then its support is in the support of each of the distributions.

Proof. The expression (2.10) means the same as

$$
\mathscr{F}\left[f^{2} T S\right](k)=(\widehat{f T} * \widehat{f S})(k)
$$

and it is defined therefore in terms of the convolution $\widehat{f T} * \widehat{f S}$ of polynomially limited functions, with polynomially-boundedness not enough to guarantee the convergence of this convolution. Notice that this is quite similar to $\mathscr{F}(f g)=\hat{f} * \hat{g}$.

For item (i), suppose $W_{1}$ and $W_{2}$ are two distributions satisfying (2.10) for a common pair $T, S$. Let $x \in \mathbb{R}^{n}$ and suppose $f$ and $g$ localizations around $x$, such that $\mathscr{F}\left[f^{2} W_{1}\right]=$ $\widehat{f T} * \widehat{f S}$ and $\mathscr{F}\left[g^{2} W_{1}\right]=(\widehat{g T} * \widehat{g S})$. We may then write $\mathscr{F}\left[f^{2} g^{2} W_{1}\right]=\mathscr{F}\left[f^{2} g^{2} W_{2}\right]$ around $x$ since, in general,

$$
\mathscr{F}\left[g f^{2} W\right]=(\widehat{g f T} * \widehat{f S})=(\widehat{f T} * \widehat{g f S})
$$

which is a direct consequence of $\hat{g} *(\widehat{f T} * \widehat{f S})=(\hat{g} * \widehat{f T}) * \widehat{f S}$ together with the hypothesis of convergence for the integrals. By repeating the procedure of the last theorem, we then obtain $W_{1}=W_{2}$.

We prove item (ii): let $f \in \mathscr{D}$ and $T \in \mathscr{D}^{*}$, and consider $f$ as an element of $\mathscr{D}^{*}$ then, for a localization $g$ around some $x \in \mathbb{R}^{n}$ we have

$$
(\widehat{g f} * \widehat{g T})(k)=\int \widehat{g f}(k-l) \widehat{g T}(l) d l,
$$


but this integral on the right side of the equality converges absolutely because $g f \in$ $\mathscr{D} \longmapsto \mathscr{F}(g f) \in \mathscr{S}$, so that while $\widehat{g T}$ has its growth polynomially limited, $\widehat{g f}$ fall down faster than any polynomial. Making this statement precise, we write

$$
\int|\widehat{g f}(k-l)| \cdot|\widehat{g T}(l)| d l \leq C \int|\widehat{g f}(k-l)| \cdot\left(1+l^{2}\right)^{N} d l<\infty
$$

which is valid for some $C, N>0$.

Suppose $T S, S V,(T S) V$ and $T(S V)$ all exist. Then

$$
\begin{aligned}
\mathscr{F}\left[f^{2}(T S) V\right](k) & =(\widehat{f(T S)} * \widehat{f V})(k) \quad f=: g^{2} \\
& =[(\widehat{g T} * \widehat{g S}) * \widehat{f V}](k) \\
& =\int(\widehat{g T} * \widehat{g S})(k-l) \widehat{f V}(l) d l \\
& =\int \widehat{g T}(k-l-t) \widehat{g S}(t) \widehat{f V}(l) d t d l \\
r:=t+y & \Rightarrow \int \widehat{g T}(k-r) \widehat{g S}(r-l) \widehat{f V}(l) d r d l \\
& =\int \widehat{g T}(k-r)(\widehat{g S} * \widehat{f V})(r) d r \\
& =[\widehat{g T} *(\widehat{g S} * \widehat{f V})](k) .
\end{aligned}
$$

To prove item (iv), suppose $x \notin \operatorname{sing} \operatorname{supp} T$. If $x \in \operatorname{sing}$ supp $S$, then item (ii) completes the proof. Due to the localization process, if $x$ lays in neither the singular supports, then the product of the distributions is a product of functions and the convolution is well defined.

For item (vii), suppose $x \notin \operatorname{supp} T$, and let also a neighbourhood $N$ of $x$ and a localization $f$; from $x \notin \operatorname{supp} T$, we may choose $N$ such that $T(f)=0$ and supp $f \subset N$. Now, for any $g \in \mathscr{D}, f T(g)=T(f g)=0 \Rightarrow f(T S)=(f T) S=0$. For any localization $h$ on $N, T S(f)=T S(f h)=(f T S)(h)$, so we have proved $T S(f)=0$ for all $f$ with support in $N$. According to the last theorem, we may expand this result to the whole space.

Examples: The Dirac delta distribution, for instance, is such that $\widehat{f} \delta(x)=\delta\left(f \zeta_{x}\right)=$ $f(0) \zeta_{x}(0)=f(0)$. If the product exists, then $\widehat{f^{2} \delta^{2}}(x)=\int \widehat{f \delta}(x-y) \widehat{f \delta}(y) d y=\int f^{2}(0) d y=$ $f^{2}(0) \int d y=\infty$. We conclude the absence of $\delta^{2}$.

The second possible generalization of product of distributions is related to certain directions we may take to achieve the points of $\mathbb{R}^{n}$. Consider, for instance, that to each point in $\mathbb{R}^{n}$ there is a cone associate, in such a way that whenever we take the limit 
to the vertex of the cone we get the starting point of $\mathbb{R}^{n}$, and suppose the direction in which the limit to $\mathbb{R}^{n}$ is taken is held fixed at each point. Furthermore, suppose also there are distributions defined in each one of those cones, and we require them to be asymptotically regular, in the sense that they are regular and tend to a (not necessarily regular) distribution in $\mathbb{R}^{n}$ when the limit is taken. In those circumstances, whenever the product of (regular) distributions is defined in the cone, it is possible to define a product of the limit distributions in $\mathbb{R}^{n}$. We shall make this idea precise.

Let $T \in \mathscr{S}^{*}\left(\mathbb{R}^{n}\right)$, let $C$ be a cone in $\mathbb{R}^{n}$ and let $F: \mathbb{R}^{n}+i C \longrightarrow \mathbb{C}$ be an analytic function. Consider a $\eta_{0} \in C$ fixed, and let $F\left(x-i \eta_{0}\right)$ define a regular distribution such that

$$
\int_{\mathbb{R}^{n}} F\left(x+i \eta_{0} t\right) f(x) d x \stackrel{t \rightarrow 0}{\longrightarrow} T(f)
$$

for all function $f \in \mathscr{S}\left(\mathbb{R}^{n}+i C\right)$. under these conditions, the distribution $T$ is called the boundary value of the distribution $\mathbf{F}$ and may be denoted by $B V(F)$. Now, consider that $F$ and also a $G$ are not only analytic, but polynomially bounded at infinity and as their imaginary parts tend to zero. If the boundary values of both $F$ and $G$ exist, then it can be shown that $B V(F) B V(G)=B V(F G)$, i. e., that the product of distributions in $\mathbb{R}^{n}$ exists and equal the boundary value of the product of regular distributions. Suppose $B V(F) B V(G)$ exists, and let $T_{F}(t)$ and $T_{G}(t)$ represent the regular distributions associated to $F$ and $G$ respectively, that is

$$
F(t) \equiv F\left(\eta_{0}, t\right)(f)=\int F\left(x+i \eta_{0} t\right) f(x) d x
$$

and similar to $G$. Finally, let also $\left(t_{k}\right)_{k} \in \mathbb{R}$ converge to zero, and

$$
\begin{aligned}
{\left[T_{F}\left(\eta_{0}, t^{\prime}{ }_{k^{\prime}}\right) T_{G}\left(\eta_{0}, t_{k}\right)\right](f) } & =G\left(t_{k}\right)\left(F\left(t^{\prime}{ }_{k^{\prime}}\right) f\right) \\
& =\int G\left(x+\eta_{0} t_{k}\right) F\left(x+i \eta_{o} t_{k^{\prime}}^{\prime}\right) f(x) d x \\
\Rightarrow \lim _{k^{\prime} \rightarrow \infty} \int G\left(x+\eta_{0} t_{k}\right) F\left(x+i \eta_{o} t^{\prime}{ }_{k^{\prime}}\right) f(x) d x & =B V(F)\left(G\left(t_{k}\right) f\right)=\left[T_{G} B V(F)\right](f) \\
\Rightarrow \lim _{k \rightarrow \infty}\left[T_{G} B V(F)\right](f) & =\lim _{k \rightarrow \infty} B V(F)\left(G\left(t_{k}\right) f\right) \\
& =B V(F)\left(\lim _{k \rightarrow \infty} G\left(t_{k}\right) f\right) \\
& =\left[\left(\lim _{k \rightarrow \infty} T_{G}\left(t_{k}\right)\right) B V(F)\right](f) \\
& =B V(F G)
\end{aligned}
$$

which proves that $B V(F) B V(G)$, if existing, equals to $B V(F G)$. To show that the product exists in the sense established in (2.10), we consider a localization $f$ of $B V(F G)$ and write 


$$
\begin{aligned}
& \int \widehat{f F}(k-l) \widehat{f G}(l) d l=\int F\left(f \zeta_{k-l}\right) G\left(f \zeta_{l}\right) d l \\
= & \int F\left(x+i \eta_{0} t\right) f(x) \zeta_{k-l}(x) G\left(y+i \eta_{0} t\right) f(y) \zeta_{l}(y) d x d y d l \\
= & \int F\left(x+i \eta_{0} t\right) G\left(y+i \eta_{0} t\right) f(x) f(y) e^{-i k x} e^{-i l(y-x)} d x d y d l \\
= & \int F(x+i \eta t) G(x+i \eta t) f^{2}(x) e^{-i k x} d x \\
= & \int(F G)(x+i \eta t) f^{2}(x) \zeta_{k}(x) d x \\
\stackrel{t \rightarrow \infty}{\longrightarrow} & B V(F G)\left(f^{2} \zeta_{k}\right)=\mathscr{F}\left[f^{2} B V(F G)\right]
\end{aligned}
$$

Thereafter, we conclude the product exists and agrees with (2.10).

With the previous idea of a direction in which a distribution is regular, or asymptotically regular at least, we may think of a point $(x, k) \in \mathbb{R}^{n} \times\left(\mathbb{R}^{n} \backslash\{0\}\right)$ where a given distribution $T \in \mathscr{D}\left(\mathbb{R}^{n}\right)$ has a locally polynomially bounded Fourier Transform in the cone around $k$, thus extending (2.10). Precisely, a point $(x, k) \in \mathbb{R}^{n} \times\left(\mathbb{R}^{n} \backslash\{0\}\right)$ is called a directed regular point of a distribution if there exist a neighbourhood $M$ of $k$ and a neighbourhood $N$ of $x$, besides a localization function $g \in \mathscr{D}, g \mid N \equiv 1$ such that for all $p \in M$ and all $\lambda \in \mathbb{R}_{0}^{+}$and for each given $m>0$, there is a constant $C=C(m)>0$ which satisfies

$$
|\widehat{g T}(\lambda p)| \leq C(1+\lambda)^{-m} .
$$

Therefore, a point $(x, k) \in \mathbb{R}^{n} \times\left(\mathbb{R}^{n} \backslash 0\right)$ is a regular directed point of a given distribution $T \in \mathscr{D}^{*}\left(\mathbb{R}^{n}\right)$ if and only if the localization $g T$ around $x$ defines a function $\widehat{g T}$ which falls faster than any power in a cone around $k$. When we introduced this idea of a cone for each point in $\mathbb{R}^{n}$ with a distribution defined within, it may seemed we were considering two different spaces: $\mathbb{R}^{n}$, in which the vertices of the cones would lay, and the family of spaces $C$. However, what has to be understood from this formalism is that there is a unique space, $\mathbb{R}^{n}$, and there might be directions in which a given distribution is regular, while it may not be regular in others. Notice that defining a family of directions for a point in $\mathbb{R}^{n}$ is the same of defining a cone around it.

In the next theorem, we may conceive a directed regular point as an extension of a regular point - in such a way that in the limit when the cone reduces to $\mathbb{R}^{n}$, that is, in the limit to the vertices of the cones, the directed regular points become regular points.

The complement in $\mathbb{R}^{n} \times\left(\mathbb{R}^{n} \backslash\{0\}\right)$ of the set of directed regular points of a distribution is called the wave front set of the distribution. If $T$ is the given distribution, we denote its wave front set by $W F(T)$.

Lemma 8. Let $T$ be a distribution. Then 
(i) $W F(T)$ is closed;

(ii) For each $x \in \mathbb{R}^{n}$, the set $W F_{x}(T):=\left\{k \in \mathbb{R}^{n}:(x, k) \in W F(T)\right\}$ is a cone;

(iii) $W F(T+S) \subseteq W F(T) \cup W F(S)$;

(iv) $\left\{x: W F_{X}(T) \neq \emptyset\right\}=\operatorname{sing} \operatorname{supp}(T)$;

(v) If $T$ is a tempered distribution whose Fourier Transform has support in a closed cone, then, for each $x, W F_{x}(T)$ is a subset of the cone;

(vi) Let $D$ be a diffeomorphism from $\mathbb{R}^{n} \longrightarrow \mathbb{R}^{n}$ and let $T \circ D$ be the distribution defined as $(T \circ D)(f)=T\left(J^{-1}\left(f \circ D^{-1}\right)\right)$ where $J$ is the Jacobian matrix. Defining $D_{*}$ : $\mathbb{R}^{n} \times\left(\mathbb{R}^{n} \backslash\{0\}\right) \longrightarrow \mathbb{R}^{n} \times\left(\mathbb{R}^{n} \backslash\{0\}\right)$ as the function that maps $(x, y) \longmapsto\left(D(x), J^{*} k\right)$. Then $W F(T \circ D)=D_{*}(W F(T))$.

Proof. Items (i) to (iii) follow from definition. See [13] for the others.

Examples: Once again, consider the Dirac delta function. We know sing supp $\delta=$ $\{0\}$, so that its wave front set, if not empty, has to be like $\{(0, k)\}$ for some set of $k \mathrm{~s}$ in $\mathbb{R}^{n} \backslash\{0\}$. In fact, for any $k \in \mathbb{R}^{n}$, the value of $\widehat{g \delta}(\lambda p)$ for $\lambda p$ in a neighbourhood of $k$ depends on the localization and does not fall at all, it is constant. We conclude that $W F(\delta)=\left\{(0, k): k \in \mathbb{R}^{n} \backslash\{0\}\right\}$.

The following theorem concludes our discussion about the produc of distributions.

Theorem 6. Hörmander's condition for the product of distributions. Let T and $S$ be two distributions, and suppose that the set $W F(T) \bigoplus W F(S):=\left\{\left(x, k_{1}+k_{2}\right) \in\right.$ $\left.\mathbb{R}^{n} \times \mathbb{R}^{n}:\left(x, k_{1}\right) \in W F(T),\left(x, k_{2}\right) \in W F(S)\right\}$ is a subset of $\mathbb{R}^{n} \times\left(\mathbb{R}^{n} \backslash\{0\}\right)$ - that $i s, k_{1}+k_{2} \neq 0$. Under these conditions, the product of the distributions exists and $W F(T S) \subseteq W F(T) \cup W F(S) \cup[W F(T) \bigoplus W F(S)]$.

Proof. See [13] or [17].

\subsection{Distributions on Manifolds}

Let $\mathrm{E} \longrightarrow \mathrm{M}$ be a $\mathbb{K}$-vector bundle over a smooth manifold $\mathrm{M}$ with a smooth volume density $d V$, and suppose it is equipped with a connection $\nabla$. For each section $\varphi \in$ $C^{\infty}(\mathrm{M}, \mathrm{E})$ and for each $k \in \mathbb{N}$ we define its k-norm over a subset $A \subseteq \mathrm{M}$ as

$$
\|\varphi\|_{k, A}:=\max _{j=0, \ldots, k} \sup _{x \in A}\left\|\left(\nabla^{j} \varphi\right)(x)\right\|
$$

where $\nabla^{j}$ must be understood as the composition

$$
C^{\infty}(\mathrm{M}, \mathrm{E}) \stackrel{\nabla}{\rightarrow} C^{\infty}\left(\mathrm{M}, \mathrm{T}^{*} \mathrm{M} \otimes \mathrm{E}\right) \stackrel{\nabla}{\rightarrow} \cdots \stackrel{\nabla}{\rightarrow} C^{\infty}(\mathrm{M}, \underbrace{\mathrm{T}^{*} \mathrm{M} \otimes \cdots \otimes \mathrm{T}^{*} \mathrm{M}}_{j} \otimes \mathrm{E}),
$$


and where $\left\|\left(\nabla^{j} \varphi\right)(x)\right\|$ means the norm in the fibre $\left.\left(\mathrm{T}^{*} \mathrm{M} \otimes \cdots \otimes \mathrm{T}^{*} \mathrm{M} \otimes \mathrm{E}\right)\right|_{x}$. Then, if the set $A$ is compact, the norm is necessarily well defined. The family of seminorms defined on $\mathscr{D}\left(\mathbb{R}^{n}\right)$ and the notion of convergence for test-functions can be transferred to section through these $k$ norms - which is itself actually a seminorm, but we may call k-norm even though. Let $\left(\varphi_{n}\right)_{n}, \varphi \in \mathscr{D}(\mathrm{M}, \mathrm{E})$, we say $\varphi_{n} \longrightarrow \varphi$ if there is a compact subset $K \subset \mathrm{M}$ such that $\operatorname{supp} \varphi_{n}, \operatorname{supp} \varphi \subset K$ for all $n$ and if $\left\|\varphi_{n}-\varphi\right\|_{k, K} \longrightarrow 0$. The set of sections in $C^{\infty}(\mathrm{M}, \mathrm{E})$ with compact support will be represented by $\mathscr{D}(\mathrm{M}, \mathrm{E})$, and its elements will be called test-sections. In the context of more general manifolds, the concept of distributions can be extended as a continuous $\mathbb{K}$-linear map $T: \mathscr{D}\left(\mathrm{M}, \mathrm{E}^{*}\right) \longrightarrow V$ in the sense that for all sequence $\left(\varphi_{n}\right)_{n} \longrightarrow \varphi \in \mathscr{D}(\mathrm{M}, \mathrm{E}), T\left(\varphi_{n}\right) \longrightarrow T(\varphi)$, and where $V$ is a finite-dimensional normed vector space over $\mathbb{K}=\mathbb{R}, \mathbb{C}$, depending on whether $\mathrm{E}$ is complex or real. We shall represent the space of $V$-valued distributions on $\mathrm{E}^{*}$ by $\mathscr{D}^{*}(\mathrm{M}, \mathrm{E}, V)$, even though it is defined over sections of the dual bundle $\mathrm{E}^{*}$. In what follows, we shall represent the $k$-norm omitting the explicit notation for the set $K$. The Dirac delta distribution may then be naturally extended to the present context exactly as expected: for $x \in \mathrm{M}, \delta_{x} \in \mathscr{D}^{*}\left(\mathrm{M}, \mathrm{E}, \mathrm{E}_{x}^{*}\right)$ is given by $\delta_{x}(\varphi):=\varphi(x)$; as for regular distributions on manifolds, if $f: \mathrm{M} \longrightarrow \mathrm{E}$ is locally integrable, then it defines a distribution through

$$
f(\varphi):=\int_{\mathrm{M}} f(x) \varphi(x) d V
$$

for all $\varphi \in \mathscr{D}\left(\mathrm{M}, \mathrm{E}^{*}\right)$.

Lemma 9. Let $T$ be a distribution on $\mathscr{D}\left(\mathrm{M}, \mathrm{E}^{*}\right)$ with values in a normed space $V$, and let $K$ be a compact subset of $\mathrm{M}$. Then, there are $k \in \mathbb{N}^{*}$ and $C>0$ such that, for all $\varphi \in \mathscr{D}\left(\mathrm{M}, \mathrm{E}^{*}\right)$ with support in $K$,

$$
\|T(\varphi)\| \leq C \cdot\|\varphi\|_{k} .
$$

Proof. The prove is quite equivalent to (2.3). Assume the inequality above is false for each pair $k, C$, so that we may find a non-trivial section $\varphi_{k} \in \mathscr{D}\left(\mathrm{M}, \mathrm{E}^{*}\right)$ such that

$$
\left\|T\left(\varphi_{k}\right)\right\| \geq k\left\|\varphi_{k}\right\|_{k} .
$$

Since $k \in \mathbb{N}^{*}$, we may define the distribution $\psi_{k}:=\varphi_{k} /\left\|T\left(\varphi_{k}\right)\right\|$, which satisfy supp $\psi_{k} \subset$ $K$ and

$$
\left\|\psi_{k}\right\|_{j} \leq\left\|\psi_{k}\right\|_{k}=\frac{1}{\left\|T\left(\varphi_{k}\right)\right\|}\left\|\varphi_{k}\right\|_{k} \leq \frac{1}{k}
$$

for all $j \leq k$. Hence, $\left(\psi_{j}\right)_{j}$ converges to 0 in $\mathscr{D}\left(\mathrm{M}, \mathrm{E}^{*}\right)$, and thus $T\left(\psi_{j}\right) \longrightarrow T(0)$. However, due to the very definition of $\psi_{j}$, we have $\left\|T\left(\psi_{j}\right)\right\|=\left\|T\left(\varphi_{j}\right)\right\| /\left\|T\left(\varphi_{j}\right)\right\|=1$. 
The space $\mathscr{D}^{*}(\mathrm{M}, \mathrm{E}, V)$ will be always endowed with a weak topology, i. e., let $\left(T_{n}\right)_{n}, T \in \mathscr{D}^{*}(\mathrm{M}, \mathrm{E}, V)$, and we say $T_{n} \longrightarrow T$ if for each $\varphi \in \mathscr{D}\left(\mathrm{M}, \mathrm{E}^{*}\right)$ we have $T_{n}(\varphi) \longrightarrow T(\varphi)$. Notice that this is not at all in conflict with the idea of convergence presented in the definition of a distribution: suppose $\mathscr{D}^{*}(\mathrm{M}, \mathrm{E}, V)$ has a topology such that $T\left(\varphi_{n}\right) \longrightarrow T(\varphi)$ whenever $\varphi_{n} \longrightarrow \varphi$ in $\mathscr{D}\left(\mathrm{M}, \mathrm{E}^{*}\right)$. Then, given $\left(T_{n}\right)_{n}, T \in \mathscr{D}^{*}(\mathrm{M}, \mathrm{E}, V)$ and $\varphi \in \mathscr{D}\left(\mathrm{M}, \mathrm{E}^{*}\right)$, we may construct a sequence $\left(\varphi_{n}\right)_{n} \in \mathscr{D}\left(\mathrm{M}, \mathrm{E}^{*}\right)$ such that $T\left(\varphi_{n}\right)=$ $T_{n}(\varphi)$. Then, the condition $T\left(\varphi_{n}\right) \longrightarrow T(\varphi)$ is equivalent to $T_{n}(\varphi) \longrightarrow T(\varphi)$.

Within this extension of distributions to manifolds, the support and the singular support of a distribution are defined just like they are for $\mathscr{D}^{*}\left(\mathbb{R}^{n}\right)$, except that they are now subsets of $\mathrm{M}$.

For the differential of a distribution $T \in \mathscr{D}(\mathrm{M}, \mathrm{E}, V)$, let $P: C^{\infty}(\mathrm{M}, \mathrm{E}) \longrightarrow C^{\infty}(\mathrm{M}, \mathrm{F})$ be a differential operator. This operator induces another one, which we call the formal adjoint $P^{*}: C^{\infty}\left(\mathrm{M}, \mathrm{F}^{*}\right) \longrightarrow C^{\infty}\left(\mathrm{M}, \mathrm{E}^{*}\right)$ such that

$$
\int_{\mathrm{M}} \psi(P \varphi) d V=\int_{\mathrm{M}}\left(P^{*} \psi\right) \varphi d V \quad \forall \varphi \in \mathscr{D}(\mathrm{M}, \mathrm{E}), \forall \psi \in \mathscr{D}\left(\mathrm{M}, \mathrm{F}^{*}\right)
$$

where the integration occurs over the natural pairing of the sections. By using the formal adjoint of a differential operator, it is possible to extend $P$ above to a linear differential operator acting on distributions, by defining

$$
\begin{gathered}
P: \mathscr{D}^{*}(\mathrm{M}, \mathrm{E}, V) \longrightarrow \mathscr{D}^{*}(\mathrm{M}, \mathrm{F}, V) \\
T \longmapsto P T, \quad(P T)(\varphi):=T\left(P^{*} \varphi\right)
\end{gathered}
$$

In the definition of the formal adjoint $P^{*}$, one should notice there is an implicit minus sign due to the integration by parts, so that in the case $P=\partial^{\alpha}$ we obtain the previous definition. The continuity of $P T$ follows straightforwardly: let $\varphi_{n} \longrightarrow \varphi$ in $\mathscr{D}(\mathrm{M}, \mathrm{E})$; since $P^{*}$ is a differential operator acting on sections, it is continuous and

$$
(P T)\left(\varphi_{n}\right)=T\left(P^{*} \varphi_{n}\right) \longrightarrow T\left(P^{*} \varphi\right)=(P T)(\varphi)
$$

Finally, from the properties of both $P^{*}$ and $T, P$, regarded as a map between distributions, is linear, and if we regard a section as a distribution, then it is equivalent to consider the action of $P$ over $\varphi$ as a distribution or as a section, i. e.,

$$
(P \psi)(\varphi)=\psi\left(P^{*} \varphi\right)=\int \psi\left(P^{*} \varphi\right) d V=\int(P \psi) \varphi d V=(P \psi)(\varphi) .
$$

Lemma 10. Let $\left(T_{n}\right)_{n}, T \in \mathscr{D}\left(\mathrm{M}, \mathrm{E}^{*}\right)$ such that $\left\|T_{n}-T\right\|_{0} \longrightarrow 0$. Considering the sections as distributions, $T_{n} \longrightarrow T$ in $\mathscr{D}^{*}(\mathrm{M}, \mathrm{E}, V)$ and, for every linear differential operator $P$ acting on the sections, $(P T)_{n} \longrightarrow P T$ as distributions, with $(P T)_{n} \equiv P T_{n}$.

Proof. See [10], lemma 1.1.10, for the first part of the proof. The convergence of $(P T)_{n}$ is then a consequence of the continuity of $P$ on sections, 


$$
P T_{n}(\varphi)=T_{n}\left(P^{*} \varphi\right) \longrightarrow T\left(P^{*} \varphi\right)=P T(\varphi)
$$

for each test-section $\varphi$.

\section{A Appendix: Topics on Fourier Transform}

In this appendix, we prove some statements about the Fourier transform of a function. Recall that for $f \in \mathscr{S}$,

$$
\begin{aligned}
\mathscr{F}(f)(k) & \equiv \hat{f}(k):=\frac{1}{(2 \pi)^{n / 2}} \int_{\mathbb{R}^{n}} f(x) e^{-i k \cdot x} d x \\
\mathscr{F}^{*}(f)(k) & \equiv \check{f}(k):=\frac{1}{(2 \pi)^{n / 2}} \int_{\mathbb{R}^{n}} f(x) e^{i k \cdot x} d x .
\end{aligned}
$$

While it is simple to notice that both integrals above are well defined, in the sense that both converge since $f \in \mathscr{S}$, it is not immediately obvious that $\mathscr{F}$ and $\mathscr{F}^{*}$ do map functions into $\mathscr{S}$, as it is also not evident that those two functions $\mathscr{F}$ and $\mathscr{F}^{*}$ are the inverse of each other. We try to clarify those points here. At first, however, it is convenient to prove the following statement:

Lemma 11. For all $k \in \mathbb{R}^{n}$ and for all $f \in \mathscr{S}$,

$$
\left((i k)^{\alpha} \partial^{\beta} \hat{f}\right)(k)=\mathscr{F}\left[\partial^{\alpha}(-i k)^{\beta} f(k)\right]
$$

for every pair of indexes $\alpha, \beta$

Proof.

$$
\begin{aligned}
\left(k^{\alpha} D^{\beta} \hat{f}\right)(k) & =\frac{k^{|\alpha|}}{(2 \pi)^{n / 2}} \partial^{\beta} \int f(x) e^{-i k \cdot x} d x \\
& =\frac{k^{|\alpha|}}{(2 \pi)^{n / 2}} \int \partial_{k}^{\beta} f(x) e^{-i k \cdot x} d x \\
& =\frac{k^{|\alpha|}}{(2 \pi)^{n / 2}} \int(-i x)^{|\beta|} f(x) e^{-i k \cdot x} d x \\
& =\frac{1}{(2 \pi)^{n / 2}} \int \frac{(-i x)^{|\beta|}}{(-i)^{|\alpha|}} f(x) \partial_{x}^{\alpha} e^{-i k \cdot x} d x \\
& =(-1)^{|\alpha|} \frac{1}{(2 \pi)^{n / 2}} \int \partial_{x}^{\alpha}\left[\frac{(-i x)^{|\beta|}}{(-i)^{|\alpha|}} f(x)\right] e^{-i k \cdot x} d x \\
& =(-i)^{|\alpha|} \mathscr{F}\left[\partial^{\alpha}(-i k)^{|\beta|} f(k)\right]
\end{aligned}
$$

where in the forth to the fifth line what has been done was to integrate by parts $\alpha$ times: because $f \in \mathscr{S}$, the terms not involving new integrals are null. 
Theorem 7. The Fourier transform $\mathscr{F}: \mathscr{S} \longrightarrow \mathscr{S}$ is a linear and continuous bijection, whose inverse is $\mathscr{F}^{*} \equiv \mathscr{F}^{-1}$.

Proof. The linearity of the functions follows immediately from their definitions. Since

$$
\begin{aligned}
\|\hat{f}\|_{\alpha, \beta} & =\sup _{k}\left\{\left|k^{|\alpha|}\left(\partial^{\beta} \hat{f}\right)(k)\right|\right\} \\
& =\sup _{k}\left\{\left|\mathscr{F}\left[\partial^{\alpha}(-i k)^{|\beta|} f(k)\right]\right|\right\} \\
& \leq \sup _{k} \frac{1}{(2 \pi)^{n / 2}} \int\left|\partial^{\alpha}(-i x)^{|\beta|} f(x)\right| d x \\
& <\infty
\end{aligned}
$$

the evaluation of the seminorms of the Fourier transform of a $f \in \mathscr{S}$ leads us to conclude that $\hat{f} \in \mathscr{S}$ for all $f \in \mathscr{S}$. That $\breve{f} \in \mathscr{S}$ for all $f$ is proved in an analogous way.

In order to prove the continuity of the Fourier transform, consider a $\lambda>0$ such that

$$
\int_{\mathbb{R}^{n}} \frac{1}{\left(1+x^{2}\right)^{\lambda}} d x<\infty
$$

Then, it follows that

$$
\begin{aligned}
\|\hat{f}\|_{\alpha, \beta} & \leq \int \frac{\left(1+x^{2}\right)^{-\lambda}}{\left(1+x^{2}\right)^{-\lambda}}\left|\partial^{\alpha}\left(-i x^{|\beta|}\right) f(x)\right| d x \\
& <\sup _{x}\{\left(1+x^{2}\right)^{\lambda} \partial^{\alpha} \underbrace{\left[x^{|\beta|} f(x)\right]}_{\in \mathscr{S}}\} \int \frac{d x}{\left(1+x^{2}\right)^{\lambda}} \\
& <\infty
\end{aligned}
$$

Therefore, for each pair $\alpha, \beta$ we have $\|\hat{f}\|_{\alpha, \beta}<\infty \Rightarrow \mathscr{F}$ is continuous - and, once again, the proof for the adjoint transform is analogous.

It remains to prove that $\mathscr{F}$ and $\mathscr{F}^{*}$ are both bijections and that they are, indeed, inverse operations. Therefore, it must be proved that, for all $f \in \mathscr{S}$,

$$
\begin{aligned}
& \mathscr{F} \mathscr{F}^{*}(f)=f \\
& \mathscr{F}^{*} \mathscr{F}(f)=f
\end{aligned}
$$

One may notice that the first assertion, $\mathscr{F} \mathscr{F} *(f)=f$, implies that $\mathscr{F}$ is surjective, while the second assertion implies that $\mathscr{F}$ is injective: suppose they are both true, and suppose $f \in \mathscr{S}$; then, on the one hand, there exists a function $f^{\prime} \in \mathscr{S}$ such that $\mathscr{F}\left[f^{\prime}\right]=f$ : namely, $f^{\prime}=\mathscr{F}^{*}(f)$, so $\mathscr{F}$ is surjective. On the other hand, suppose $f, g \in \mathscr{S}$ such that 
$\mathscr{F}[f]=\mathscr{F}[g]$; then, $\mathscr{F}^{*} \mathscr{F}[f]=\mathscr{F}^{*} \mathscr{F}[g] \Rightarrow f=g$, so $\mathscr{F}$ is injective. We shall prove the second assertion, the proof of the first being similar.

Consider $g \in \mathscr{D} \subset \mathscr{S}$ and let $C(\varepsilon) \subset \mathbb{R}^{n}$ be the cube of volume $(2 / \varepsilon)^{n}$ centered at the origin, with $\varepsilon>0$ being small enough so that the support of $g$ is in $C(\varepsilon)$. Now, let $K(\varepsilon):=\left\{\mathbf{k} \in \mathbb{R}^{n}: k_{j} /(\pi \varepsilon)\right.$ is an integer for each component $\left.j\right\}$, which is countable since it is the countable union of countable sets. So, we may write the function $g$ as

$$
\begin{aligned}
g(x) & =\sum_{k \in K(\varepsilon)}\left((\varepsilon / 2)^{n / 2} e^{i k \cdot x}, g\right)(\varepsilon / 2)^{n / 2} e^{i k \cdot x} \\
& =\sum_{k \in K(\varepsilon)} \frac{\hat{g}(k) e^{i k \cdot x}}{(2 \pi)^{n / 2}}(\pi \varepsilon)^{n},
\end{aligned}
$$

the Fourier expansion of $g$ in $C(\varepsilon)$, which converges since $g$ is continuously differentiable. Once $\mathbb{R}^{n}$ is the disjoint union of cubes of volume $(\pi \varepsilon)^{n}$ centered at each point of $K(\varepsilon)$, the final expression for $g$ is the Riemann sum for the integral of $\hat{g}(k) e^{i k \cdot x} /(2 \pi)^{n / 2}$. However, because $\hat{g} \in S$ and so $g$ is continuously differentiable, this sum converges, as stated before, and converges to the integral, what leads us to finally conclude that $\mathscr{F}^{*} \mathscr{F}(g)=g$.

Suppose now $f \in \mathscr{S}$, and let $\left(f_{n}\right)_{n} \in \mathscr{D}$ be a sequence converging to $f$ - which exists since $\mathscr{D}$ is dense in $\mathscr{S}$. Then, by the linearity of $\mathscr{F} * \mathscr{F}$,

$$
\mathscr{F}^{*} \mathscr{F}(f)=\mathscr{F}^{*} \mathscr{F}\left(f_{n}\right)-\mathscr{F}^{*} \mathscr{F}\left(f_{n}-f\right) .
$$

But $\mathscr{F}^{*} \mathscr{F}$ was proved to be continuous, so we conclude that in the limit $n \rightarrow \infty$, the right side of the above equation reduces to

$$
\lim _{n \rightarrow \infty} \mathscr{F}^{*} \mathscr{F}\left(f_{n}\right)=\lim _{n \rightarrow \infty} f_{n}=f .
$$

Thus, $\mathscr{F}^{*} \mathscr{F}(f)=f$.

Other important statements about the Fourier transform of a function in the Schwartz space are the called Parseval's Identity and Plancherel's Identity

Theorem 8 (Parseval's Identity). For each function $f \in \mathscr{S},\langle f, f\rangle=\langle\hat{f}, \hat{f}\rangle$.

Proof. The proof of this statement follows the same outline of the proof of the previous theorem. Suppose $f$ a function with compact support, and for some $\varepsilon$ small enough

$$
f(x)=\sum_{k \in K(\varepsilon)}\left\langle(\varepsilon / 2)^{n / 2} \zeta_{k}, f\right\rangle(\varepsilon / 2)^{n / 2} e^{i k \cdot x}
$$

Admitting $\left\{(\varepsilon / 2)^{n / 2} e^{i k \cdot x}\right\}_{k \in K(\varepsilon)}$ as a basis for $L^{2}(C(\varepsilon))$, then 


$$
\begin{aligned}
\int_{\mathbb{R}^{n}}|f(x)|^{2} d x & =\int_{C(\varepsilon)}|f(x)|^{2} d x \\
& =\sum_{k \in K(\varepsilon)}\left|\left\langle(\varepsilon / 2)^{n / 2} \zeta_{k}, f\right\rangle\right|^{2} \\
& =\sum_{k \in K(\varepsilon)}|\hat{f}(k)|^{2}(\pi \varepsilon)^{2} \\
& \rightarrow \int_{\mathbb{R}^{n}}|\hat{f}(k)|^{2} d k
\end{aligned}
$$

The theorem is now extended to the Schwartz space provided $\mathscr{D}$ is dense in $\mathscr{S}$ and both the Fourier transform and the norm in $L^{2}\left(\mathbb{R}^{n}\right)$ are continuous.

Corollary (Plancherel's Identity). The Fourier transform maintains the product of each pair of functions in the Schwartz space invariant, i. e., $\langle f, g\rangle=\langle\hat{f}, \hat{g}\rangle \quad \forall f, g \in S$.

Proof. According to the Parseval's Identity, this corollary is true if $f=g$. Consider then the case $f=g+h$ and take $\langle f, f\rangle$ :

$$
\begin{aligned}
\langle f, f\rangle & =\langle g+h, g+h\rangle=\langle g, g\rangle+\langle h, h\rangle+\langle g, h\rangle+\langle h, g\rangle \\
& =\langle\mathscr{F}[g+h], \mathscr{F}[g+h]\rangle=\langle\hat{g}+\hat{h}, \hat{g}+\hat{h}\rangle \\
& =\langle\hat{g}, \hat{g}\rangle+\langle\hat{h}, \hat{h}\rangle+\langle\hat{g}, \hat{h}\rangle+\langle\hat{h}, \hat{g}\rangle
\end{aligned}
$$

from which we see that

$$
\begin{gathered}
\langle g, h\rangle+\langle h, g\rangle=\langle\hat{g}, \hat{h}\rangle+\langle\hat{h}, \hat{g}\rangle \\
h \rightarrow i h \\
-i\langle g, h\rangle+i\langle h, g\rangle=-i\langle\hat{g}, \hat{h}\rangle+i\langle\hat{h}, \hat{g}\rangle
\end{gathered}
$$

and so, summing the last equation with the one above multiplied by $i$,

$$
\begin{aligned}
-i\langle g, h\rangle+i\langle h, g\rangle & =-i\langle\hat{g}, \hat{h}\rangle+i\langle\hat{h}, \hat{g}\rangle \\
+ & \\
i\langle g, h\rangle+i\langle h, g\rangle & =i\langle\hat{g}, \hat{h}\rangle+i\langle\hat{h}, \hat{g}\rangle \\
\Rightarrow i\langle h, g\rangle & =i\langle\hat{h}, \hat{g}\rangle
\end{aligned}
$$


therefore proving this corollary. One could also prove this statement by means of the polarization identity

$$
\langle f, g\rangle=\frac{1}{4} \sum_{j=0}^{3} i^{-j}\left\langle f+i^{j} g, f+i^{j} g\right\rangle .
$$

For the relation between the Fourier transform and the convolution of test functions, we have the following:

Lemma. Let $f, g \in \mathscr{S}$. Then,

(i) $\mathscr{F}[f g]=\hat{f} * \hat{g}$;

(ii) $(f, g) \mapsto f * g \in \mathscr{S}$;

(iii) $\mathscr{F}[f * g]=\hat{f} \hat{g}$;

(iv) $*$ is separately continuous. I.e., the map $g \mapsto f * g$ for each $g \in \mathscr{S}$ and for each $f \in \mathscr{S}$ held fixed is continuous.

Proof. (i) For each $y \in \mathbb{R}^{n}$ held fixed, we define $\zeta_{y}: \mathbb{R}^{n} \longrightarrow \mathbb{C}, \zeta_{y}(x):=e^{-i y \cdot x}$ and compute

$$
\begin{aligned}
\left\langle\mathscr{F}\left[\zeta_{-y} \bar{f}\right], \bar{g}\right\rangle & =\int\left(\overline{(2 \pi)^{-n / 2} \int e^{-i(\lambda-y) \cdot x \overline{f(x)}} d x}\right) \hat{g}(\lambda) d \lambda \\
& =\int \overline{\mathscr{F}[\bar{f}](\lambda-y)} \hat{g}(\lambda) d \lambda \\
& =\int \hat{f}(y-\lambda) \hat{g}(\lambda) d \lambda \\
& =(\hat{f} * \hat{g})(y)
\end{aligned}
$$

which, according to the Parseval's Identity, is equal to

$$
\begin{aligned}
\left\langle\zeta_{y} \bar{f}, g\right\rangle & =\int e^{-i y \cdot x} f(x) g(x) d x \\
& =\mathscr{F}[f g](y)
\end{aligned}
$$

so proving (i).

(ii) That $f * g \in \mathscr{S}$ now follows directly from the previous items: the convolution may be regarded as a composition of Fourier transforms of functions in $\mathscr{S}$, and since the Fourier transform in $\mathscr{S}$ is a bijection as proved previously, this item has been proved. 
(iii) The procedure is quite the same of item (i):

$$
\begin{aligned}
\left\langle\mathscr{F}^{-1}\left[\zeta_{y} \mathscr{F} \bar{f}\right], g\right\rangle & =\int \overline{F^{-1}[\mathscr{F} \bar{f}](\lambda-y)} g(\lambda) d \lambda \\
& =\int f(y-\lambda) g(\lambda) d \lambda \\
& =(f * g)(y)=\left\langle\zeta_{y} \mathscr{F} \bar{f}, g\right\rangle=F[\hat{f} \hat{g}](y)
\end{aligned}
$$

so proving (iii).

(iv) Follows from the continuity of the Fourier transform in $\mathscr{S}$ and the argument right above. 


\section{Chapter 3}

\section{The classical theory of wave equations on manifolds}

\subsection{Introduction}

In Physics, wave equations provide a description of a wide range of phenomena, from the motion of a string of a musical instrument to the 'dynamics' of fundamental particles. In the context of Quantum Field Theory, we are frequently interested in solving the KleinGordon equation, a particular wave equation which describes bosonic particles, and which is also related to the Dirac equation for fermions. Before dealing with quantum theories, we shall analyse the classical wave equation, in the beginning of this chapter strictly in neighbourhoods of points in a spacetime - that is, we shall consider here M a timeoriented Lorentzian manifold, and, as the domain of our constructions to come, a neighbourhood of a point of M. Later, we shall move the results established to the whole space through the study of the Cauchy problem yet to be defined.

Therefore, the aim of this part is to consider equations of the form

$$
P u=f
$$

where $u$ is a function or a distribution representing some physical object, as a bosonic field for instance, and $P$ corresponds to the wave-propagation operator. For example, if the considered equation describes the dynamics of the states of a quantum system, the dynamic information is then contained entirely in the operator $P$. For given $P$ and $f$, where $f$ may be a function or a distribution, we call $u$ the solution of the equation. It will intrinsically carry some information with respect to the space; however, it is natural to conceive $P$ being given, somehow, in terms of the metric, the main object describing the form of the manifold, as may be seen in the next section.

The first step in the study of generalized wave equations will concern fundamental solutions: and so we shall look for distributions $F$ obeying $P F=\delta_{x}$ for some $x \in \mathrm{M}$, with the point in this passage being the possibility of obtaining distributional solutions $u$ to (3.2) from $F$. It is this distribution $F$ we call a fundamental solution. Next, we shall 
define the Riesz distribution, and, given its properties, it shall be tempting to wonder whether it may produce fundamental solutions. We shall see why it actually may not, while a series of Riesz distributions might provide a way to the construction of solutions. Therefore, we shall have to deal with cutoff methods for the convergence of such a series and with the consequent error produced. We shall show that it is possible to construct exact solutions to the wave equation in terms of the approximated ones. The problem with the method presented here is that it is given in terms of the Riemannian exponential map through the Riesz distribution, and so it makes sense only locally.

This part of the text was based mainly in [10], which explores the subject from a quite general framework by using vector bundles structures. However, [15], specifically the third chapter - which was written by Nicolas Ginoux, one of the authors of [10], provides a basic, natural and intuitive introduction to the topic, and hence most the physical motivations and arguments provided in the present text were based on it. As for examples, [18] and [19] provide physical situations to which the general formalism to be presented applies.

\subsection{The Wave Equations and Fundamental Solutions}

Initially, a a wave equation we understand an equation of the form

$$
\frac{\partial^{2} u}{\partial t^{2}}-\left(\frac{\partial^{2} u}{\partial x_{1}^{2}}+\frac{\partial^{2} u}{\partial x_{2}^{2}}+\frac{\partial^{2} u}{\partial x_{3}^{2}}\right)=0,
$$

the regular wave equation in three dimensions, with $u: \mathbb{R} \times \mathbb{R}^{3} \longrightarrow \mathbb{R}$. Using the d'Alembert operator, this equation may be restated as

$$
\square u=0 .
$$

Therefore, the question of whether or not we may generalize a wave equations to be defined in some manifold consists on working out a generalization of the d'Alembert operator on $\mathbb{R} \times \mathbb{R}^{3}$.

Definition 1. Let $\mathrm{E} \longrightarrow \mathrm{M}$ be a vector bundle over a time-oriented Lorentzian manifold M. Let also $P: C^{\infty}(\mathrm{M}, \mathrm{E}) \longrightarrow C^{\infty}(\mathrm{M}, \mathrm{E})$ be a normally hyperbolic operator acting on sections of $\mathrm{E}$, as defined in (1.10). We call

$$
P u=f
$$

the wave equation associated to $P$ for a given $f \in \mathscr{D}(\mathrm{M}, \mathrm{E})$ and for $u \in \mathscr{D}(\mathrm{M}, \mathrm{E})$, to be understood either in terms of sections or in terms of distributions.

Let $x \in \mathrm{M}$; a fundamental solution for $P$ at $x \in \mathrm{M}$ is a distribution $F \in$ $\mathscr{D}^{*}\left((\mathrm{M}, \mathrm{E}), \mathrm{E}_{x}^{*}\right)$ such that

$$
P F=\delta_{x} .
$$


In other words, $F$ is called a fundamental solution for $P$ at $x$ if for every $\varphi \in \mathscr{D}\left(\mathrm{M}, \mathrm{E}^{*}\right)$

$$
[P F(x)](\varphi)=F(x)\left(P^{*} \varphi\right)=\varphi(x)
$$

where $P^{*}$ is the formal adjoint to $P$.

But what fundamental solutions of the generalized equation 3.2 do have to do with solutions of the wave equation? The answer is that it is possible to obtain sections solving the wave equation from fundamental solutions. Suppose there is a fundamental solution $F$ at $x$, for each $x \in \mathrm{M}$, for a given normally hyperbolic operator $P$, and suppose also this fundamental solutions depends continuously on the point $x$, in the sense that the function $x \longmapsto F(x)(u) \in \mathrm{E}_{x}^{*}$ is continuous for each $u \in \mathscr{D}(\mathrm{M}, \mathrm{E})$ fixed; fix now a $f \in \mathscr{D}\left(\mathrm{M}, \mathrm{E}^{*}\right)$ and consider

$$
u(\varphi):=\int_{M} f(x) F(x)(\varphi) d V
$$

for each $\varphi \in \mathscr{D}\left(\mathrm{M}, \mathrm{E}^{*}\right)$. Then,

$$
\begin{aligned}
P u(\varphi) & =u\left(P^{*} \varphi\right)= \\
& =\int_{\mathrm{M}} f(x) F(x)\left(P^{*} \varphi\right) d V \\
& =\int_{\mathrm{M}} f(x)[P F(x)](\varphi) d V \\
& =\int_{\mathrm{M}} f(x) \varphi(x) d V \\
& =f(\varphi)
\end{aligned}
$$

and we have thus obtained back again the wave equation, but now in a distributional sense. Therefore, if we find a fundamental solution for $P$ for all $x \in \mathrm{M}$, we will find a solution for the wave equation associated to this operator. This intrinsic relation between these two objects will be used throughout this chapter and, when dealing with globalization, we shall use it in the opposite direction, i.e., we shall prove the existence of global fundamental solutions by proving global existence of solutions for the wave equation.

A useful object in the development of fundamental solutions is the Riesz distribution, which by itself takes us pretty close to solving the problem in generic manifolds. However, since it obeys a recursive relation other than what we wish, building fundamental solution demands some extra work.

\subsection{Riesz Distribution}

Consider a n-dimensional vector space $V$ over $\mathbb{R}$ with a non-degenerate pseudo-inner product $\langle\cdot, \cdot\rangle: V \times V \longrightarrow \mathbb{R}$ of index one; it is straightforward that $V$ with $\langle\cdot, \cdot\rangle$ is 
isometric to $\mathbb{R}^{n}$ with the Minkowski pseudo-inner product given by the interval of Special Relativity; we shall use the notation $\langle\cdot, \cdot\rangle$ for the (pseudo-)inner product in whatever vector space we consider as long as no misunderstanding is possible. Define the function

$$
\begin{aligned}
& \gamma: V \longrightarrow \mathbb{R} \\
& \gamma(v):=-\langle v, v\rangle
\end{aligned}
$$

which enabled us to extend the usual classes of vectors in Minkowski space to $V$, defining spacelike, timelike and light or nulllike vectors as in Minkowski case.

For each $\alpha \in \mathbb{C}$ with $\operatorname{Re}(\alpha)>n$, the Riesz distribution is defined in $V$ in terms of the complex-valued function

$$
\begin{gathered}
R_{ \pm}(\alpha): V \longrightarrow \mathbb{C} \\
R_{ \pm}(\alpha)(x):=\left\{\begin{array}{cc}
C(\alpha, n) \gamma(x)^{(\alpha-n) / 2} & x \in J_{ \pm}(0) ; \\
0 & \text { otherwise }
\end{array}\right.
\end{gathered}
$$

where $C(\alpha, n)$ is a constant w.r.t. $x$ given by

$$
C(\alpha, n):=\frac{2^{1-\alpha} \pi^{(2-n) / 2}}{(\alpha / 2-1) ![(\alpha-n) / 2-1] !}
$$

and with $z \longmapsto(z-1)$ ! being the Gamma function, which obeys $z !=z(z-1)$ !. The condition on $\alpha \operatorname{Re}(\alpha)>n$ implies the functions $R_{ \pm}$are well-defined for each $x \in V$, and it is of $C^{k}$ class as long as $\operatorname{Re}(\alpha)>n+2 k$. Precisely, $R_{ \pm}(\alpha)$ stands for two different distributions; the one with support in the future leaf of the causal cone around the origin, $R_{+}$, is called advanced Riesz distribution, while $R_{-}$, whose support lays within the past leaf of the causal cone is named retarded Riesz distribution.

Our main interest in this function is due to the following properties it obeys.

Lemma 12. For each $\alpha \in \mathbb{C}$ with $\operatorname{Re} \alpha>n$, the functions $R_{ \pm}(\alpha)$ satisfy

$$
\square R_{ \pm}(\alpha+2)=R_{ \pm}(\alpha) .
$$

Besides this, $R_{ \pm}(\alpha)$ may be analytically extended to all $\alpha \in \mathbb{C}$ as a family of distributions. I. e., for each test function $\varphi: \mathbb{C} \longrightarrow \mathbb{C}$ the map $\alpha \longmapsto R_{ \pm}(\alpha)(\varphi)$ may be analytically extended to the whole $\mathbb{C}$. Finally, it also obeys

$$
\text { supp } R_{ \pm}(\alpha) \subset J_{ \pm}(0) \quad \forall \alpha \in \mathbb{C}
$$

and

$$
R_{ \pm}(0)=\delta_{0}
$$

The combination of expressions 3.7 and ?? results in

$$
\square R_{ \pm}(2)=\delta_{0},
$$

a fundamental solution for the usual d'Alembertian operator around the origin. 
Proof. Equation (3.7) follows from two other expressions:

$$
\begin{aligned}
& \gamma R_{ \pm}(\alpha)=\alpha(\alpha-n+2) R_{ \pm}(\alpha+2) \\
& (\operatorname{grad} \gamma) R_{ \pm}(\alpha)=2 \alpha \operatorname{grad} R_{ \pm}(\alpha+2)
\end{aligned}
$$

Assuming them to be both true, we have

$$
\begin{aligned}
-\square R_{ \pm}(\alpha+2) & =\sum_{j=0}^{n-1} \varepsilon_{j} \frac{\partial^{2} R_{ \pm}(\alpha+2)}{\partial x_{j}^{2}} \\
& =\sum_{j} \varepsilon_{j} \frac{\partial}{\partial x_{j}}\left\{\frac{1}{2 \alpha}\left(\frac{\partial}{\partial x_{j}} \gamma\right) R_{ \pm}(\alpha)\right\} \\
& =\sum_{j} \varepsilon_{j} \frac{1}{2 \alpha}\left\{\frac{\partial^{2} \gamma}{\partial x_{j}^{2}} R_{ \pm}(\alpha)+\frac{\partial \gamma}{\partial x_{j}} \frac{\partial R_{ \pm}(\alpha)}{\partial x_{j}}\right\} \\
& =\sum_{j} \varepsilon_{j} \frac{1}{2 \alpha}\left\{\frac{\partial^{2} \gamma}{\partial x_{j}^{2}} R_{ \pm}(\alpha)+\frac{\partial \gamma}{\partial x_{j}} \frac{1}{2(\alpha-2)}\left(\frac{\partial \gamma}{\partial x}\right) R_{ \pm}(\alpha-2)\right\} \\
& =\sum_{j} \varepsilon_{j} \frac{1}{2 \alpha}\left\{\frac{\partial^{2} \gamma}{\partial x_{j}^{2}} R_{ \pm}(\alpha)+\frac{1}{2(\alpha-2)}\left(\frac{\partial \gamma}{\partial x_{j}}\right)^{2} R_{ \pm}(\alpha-2)\right\} \\
& =\sum_{j} \varepsilon_{j} \frac{1}{2 \alpha}\left\{2 R_{ \pm}(\alpha)+\frac{1}{2(\alpha-2)}\left(2 x_{j}\right)^{2} R_{ \pm}(\alpha-2)\right\} \\
& =\frac{1}{2 \alpha}\left\{-2 n R_{ \pm}(\alpha)-\frac{2}{\alpha-2} \gamma R_{ \pm}(\alpha-2)\right\} \\
& =\frac{1}{\alpha}\left\{-n R_{ \pm}(\alpha)-\frac{1}{\alpha-2}(\alpha-2)(\alpha-2-n+2) R_{ \pm}(\alpha)\right\} \\
& \frac{1}{\alpha}\left\{-n R_{ \pm}(\alpha)-(\alpha-n) R_{ \pm}(\alpha)\right\}=-R_{ \pm}(\alpha) .
\end{aligned}
$$

where $\left(e_{j}\right)_{j}$ in an orthonormal basis for $V$, and $\varepsilon:=\left\langle e_{j}, e_{j}\right\rangle$. It remains to prove the identities which were used. Starting from

$$
\gamma R_{ \pm}(\alpha)=\alpha(\alpha-n+2) R_{ \pm}(\alpha+2)
$$

we see both sides are null when applied to a point outside $J_{ \pm}(0)$, so, ignoring this situation, 


$$
\begin{aligned}
\left(\gamma R_{ \pm}(\alpha)\right)(x) & =C(\alpha, n) \gamma(x)^{(\alpha-n+2) / 2} \\
& =C(\alpha, n) \frac{R_{ \pm}(\alpha+2)}{C(\alpha+2, n)}
\end{aligned}
$$

and $C(\alpha, n) / C(\alpha+2, n)=\alpha(\alpha+2-n)$ is then a straightforward calculation.

Using again another property of the constants $C(\alpha, n)$ (which may be found in [15]), the second equality holds, for $x$ outside the causal cone around 0 , by considering $R_{ \pm}(\alpha)$ as a distribution rather than as a function, from

$$
\begin{aligned}
\partial_{i} \gamma \cdot R_{ \pm}(\alpha)(\varphi) & =C(\alpha, n) \int_{J_{ \pm}(0)} \gamma(x)^{(\alpha-n) / 2} \partial_{i} \gamma \varphi(x) d x \\
& =\frac{2 C(\alpha, n)}{(\alpha-n+2)} \int \partial_{i} \gamma(x)^{(\alpha-n+2) / 2} \varphi(x) d x \\
& =-2 \alpha C(\alpha+2, n) \int \gamma(x)^{(\alpha-n+2) / 2} \partial_{i} \varphi(x) d x \\
& =-2 \alpha R_{ \pm}(\alpha+2)\left(\partial_{i} \varphi\right) \\
& =2 \alpha \partial_{i} R_{ \pm}(\alpha+2)(\varphi)
\end{aligned}
$$

for some basis $\left\{\mathbf{e}_{i}\right\}_{i}$ describeing the gradient and a compact support test function $\varphi$. The extension of $R_{ \pm}(\alpha)$ to the entire complex plane follows now from (3.7). For $\operatorname{Re} \alpha>n-2$, we may define

$$
R_{ \pm}(\alpha):=\square R_{ \pm}(\alpha+2)
$$

which is not a definition if we return to the previous case $\operatorname{Re} \alpha>n$, and therefore it is coherent with the previous established development. Applying this relation recursively, we define a single analytic function in all $\mathbb{C}$, since $R_{ \pm}(\alpha)$ is analytic in $\operatorname{Re} \alpha>n$ and through the recursive extension of $R_{ \pm}(\alpha)$ the functions agree in open subsets of $\mathbb{C}$. Lastly, the analyticity of the distribution follows from the analyticity of the function. This lemma thus enables us to define $R_{ \pm}$over the whole complex plane, but as a distribution rather than as a function.

The assertion about the support of the distribution follows from its definition for $\operatorname{Re} \alpha>n$ : as $\square$ is a differential operator, the support of $R_{ \pm}(\alpha)$ is invariant under its action, in the sense that supp $\left(R_{ \pm}(\alpha) \mid \operatorname{Re}(\alpha)>n-2\right) \subset \operatorname{supp}\left(R_{ \pm}(\alpha) \mid \operatorname{Re}(\alpha)>n\right)$.

The last statement, $R_{ \pm}(0)=\delta_{0}$, is not proved completely here. Its proof may be found in [10], proposition 1.2.4. Indeed, we shall assume part of the conditions for the proof.

Let $K \subset V$ be a compact subset, and let $\sigma: V \longrightarrow \mathbb{R}$ be an appropriate bump function such that $\sigma \equiv 1$ in $K$. Let now $\varphi \in \mathscr{D}(V, \mathbb{C})$ with support in $K$. Then we write 


$$
\varphi(x)=\varphi(0)+\sum_{j=1}^{n} x^{j} \varphi_{j}(x)
$$

for some appropriate choice of functions $\varphi_{j}$. Then,

$$
\begin{aligned}
R_{ \pm}(0)(\varphi) & =R_{ \pm}(0)(\sigma \varphi)=R_{ \pm}(0)\left(\sigma \varphi(0)+\sum_{j} x^{j} \sigma \varphi_{j}\right) \\
& =\varphi(0) \underbrace{R_{ \pm}(0)(\sigma)}_{=: c_{K}}+\sum_{j} \underbrace{\left(x^{j} R_{ \pm}(0)\right)}_{=0}\left(\sigma \varphi_{j}\right) \\
& =c_{K} \varphi(0)
\end{aligned}
$$

Notice $x^{j} R_{ \pm}(0)=0$ due to $(\operatorname{grad} \gamma) R_{ \pm}(\alpha)=2 \alpha \operatorname{grad} R_{ \pm}(\alpha+2)$. Besides that, although $\sigma$ depends on the choice of $K, c_{K}$ actually does not: let $K^{\prime} \supset K$ be compact; then

$$
c_{K^{\prime}} \varphi(0)=R_{ \pm}(0)(\varphi)=c_{K} \varphi(0) .
$$

Now, we only have to show $c=1$.

The following claim is presented in the reference [10] and will be assumed here: if $\operatorname{Re} \alpha>1$, then

$$
R_{+}(\alpha)(\varphi)=\frac{1}{(\alpha-1) !} \int_{0}^{\infty} r^{\alpha-1} f(r) d r
$$

where $f$ verifies $f(0)=\varphi(0)$, and with a similar equation regarding $R_{-}$. The latter being assumed, then

$$
\begin{aligned}
c \varphi(0) & =R_{+}(0)(\varphi)=R_{+}(2)(\square \varphi) \\
& =\int_{0}^{\infty} r f^{\prime \prime}(r) d r=-\int_{0}^{\infty} f^{\prime}(r) d r \\
& =f(0)=\varphi(0) .
\end{aligned}
$$

The extension of $R_{ \pm}(\alpha)$ from a particular finite-dimensional vector space $V$ to a manifold is performed locally. I. e., consider a point $p \in \mathrm{M}$, and suppose $p$ admits a starshaped neighbourhood $\Omega \subset \mathrm{M}$ of $p^{1}$. The Riemannian exponential map then provides

\footnotetext{
${ }^{1}$ Given $p \in \mathrm{M}$, we say a certain neighbourhood $N$ of $p$ is star-shaped if $\forall x \in N$ there is a geodesics connecting $p$ to $x$ entirely contained in $N$
} 
a diffeomorphism $\Omega \approx \exp _{p}^{-1} \Omega \subset T_{p} \Omega$, so to enable us to extend the Riesz distribution to $\Omega$ by pulling it back to $T_{p} \Omega$ and applying what has just been developed. We recall $\exp _{p}: \mathrm{M} \longrightarrow \mathrm{T}_{p} \mathrm{M}$ and define, by extending $\left(\mu_{x} \varphi\right) \circ \exp _{x}$ by zero outside $\exp _{x}^{-1} \Omega$ since its support is in $\exp _{x}^{-1} \Omega$,

$$
\begin{gathered}
R_{ \pm}^{\Omega}(\alpha, x): T_{p} \Omega \longrightarrow \mathbb{C} \\
R_{ \pm}^{\Omega}(\alpha, x):=\mu_{x} \exp _{x}^{*} R_{ \pm}(\alpha) \\
R_{ \pm}^{\Omega}(\alpha, x)(\varphi):=R_{ \pm}(\alpha)\left[\left(\mu_{x} \varphi\right) \circ \exp _{x}\right] \quad \forall \varphi \in \mathscr{D}(\Omega, \mathbb{C}) .
\end{gathered}
$$

where $\mu_{x}: \Omega \longrightarrow \mathbb{R}$ is the volume-form function defined by $d V=\mu_{x}\left(\exp _{x}^{-1}\right)^{*} d x^{\prime}, d x^{\prime}$ the volume density in $T_{x} \Omega$.With this construction, which we call the locally defined Riesz distribution with sign + standing for advanced and - for retarded, $R_{ \pm}^{\Omega}(\alpha, x)$ naturally inherits the following properties from $R_{ \pm}(\alpha)$ :

Lemma 13. Recall the function $\Gamma_{x}: \Omega \longrightarrow \mathbb{R}$ as given in (1.8), $\Gamma_{x}:=\gamma \circ \exp _{x}^{-1}$. For each $\alpha \in \mathbb{C}$ and for each $x \in \Omega$ such that $\Omega$ is star-shaped w.r.t. $x$,

(i) if $\operatorname{Re} \alpha>n$ where $n$ is the dimension of the (finite-dimensional) manifold M, $R_{ \pm}^{\Omega}(\alpha, x)$ is a continuous function given by

$$
R_{ \pm}^{\Omega}(\alpha, x)(y)=\left\{\begin{array}{l}
C(\alpha, n) \Gamma_{x}^{(\alpha-n) / 2}(y) \quad y \in J_{ \pm}^{\Omega}(x) \\
0 \quad \text { otherwise; }
\end{array}\right.
$$

(ii) $R_{ \pm}^{\Omega}(0, x)=\delta_{x}$;

(iii) if $\alpha \neq 0$, then $\square R_{ \pm}^{\Omega}(\alpha+2, x)=\left(\frac{\square \Gamma_{x}-2 n}{2 \alpha}+1\right) R_{ \pm}^{\Omega}(\alpha, x)$.

Proof. Recall $\Gamma_{x}: \Omega \longrightarrow \mathbb{R}$ is defined as $\Gamma_{x}:=\gamma \circ \exp _{x}^{-1}$. Equations (3.11) and the fact that for $\operatorname{Re} \alpha>n$ the Riesz distribution $R_{ \pm}(\alpha)$ corresponds to a continuous function implies that

$$
\begin{aligned}
R_{ \pm}^{\Omega}(\alpha, x)(\varphi) & =R_{ \pm}(\alpha)\left[\left(\mu_{x} \varphi\right) \circ \exp _{x}\right] \\
& =\int_{T_{x} \Omega} R_{ \pm}(\alpha)(y)\left[\left(\mu_{x} \varphi\right) \circ \exp _{x}\right](y) d y \\
& =C(\alpha, n) \int \gamma(y)^{(\alpha-n) / 2}\left[\left(\mu_{x} \varphi\right) \circ \exp _{x}\right](y) d y \\
& =C(\alpha, n) \int_{J_{ \pm}(0)} \gamma(y)^{(\alpha-n) / 2}\left(\mu_{x} \circ \exp _{x}\right)(y)\left(\varphi \circ \exp _{x}\right)(y) d y \\
& =C(\alpha, n) \int_{J_{ \pm}(0)}\left(\Gamma^{(\alpha-n) / 2} \circ \exp _{x}\right)\left(\varphi \circ \exp _{x}\right)\left(\mu_{x} \circ \exp _{x}\right)(y) d y \\
& =C(\alpha, n) \int_{J_{ \pm}^{\Omega}(x)} \Gamma_{x}^{(\alpha-n) / 2} \varphi d V
\end{aligned}
$$


Now, item (ii) follows easily from:

$$
\begin{aligned}
R_{ \pm}^{\Omega}(0, x) & =R_{ \pm}(0)\left[\left(\mu_{x} \varphi\right) \circ \exp _{x}\right]=\delta_{0}\left[\left(\mu_{x} \varphi\right) \circ \exp _{x}\right] \\
& =\left[\left(\mu_{x} \varphi\right) \circ \exp _{x}\right](0)=\left(\mu_{x} \varphi\right)\left(\exp _{x}(0)\right) \\
& =\mu_{x}(x) \varphi(x)=\varphi(x)=\delta_{x}(\varphi)
\end{aligned}
$$

To prove item (iii), suppose $\alpha$ with $\operatorname{Re} \alpha>n+2$, and remember the relation $\operatorname{div} f X=f \operatorname{div} X+\langle\operatorname{grad} f, X\rangle$ where $f$ is a function and $X$ is a field, and notice that $\left\langle\operatorname{grad} \Gamma_{x}, \operatorname{grad} \Gamma_{x}\right\rangle=-4 \Gamma_{x}$ (for the latter one, see [10] lemma 1.3.19 item 1). Considering the equalities

$$
\begin{aligned}
& 2 \alpha \operatorname{grad} R_{ \pm}^{\Omega}(\alpha+2, x)=\operatorname{grad}\left(\Gamma_{x}\right) R_{ \pm}^{\Omega}(\alpha, x) \\
& \Gamma_{x} R_{ \pm}^{\Omega}(\alpha, x)=\alpha(\alpha-n+2) R_{ \pm}^{\Omega}(\alpha+2, x)
\end{aligned}
$$

which shall not be proved in this work (which are equivalent to the previous relations for $\gamma$; a full proof may be found in [10], proposition 1.4.2), then

$$
\begin{aligned}
\square R_{ \pm}^{\Omega}(\alpha+2, x) & =-\operatorname{div}\left(\operatorname{grad} R_{ \pm}^{\Omega}(\alpha+2, x)\right) \\
& =-\operatorname{div}\left(\frac{1}{2 \alpha} \operatorname{grad}\left(\Gamma_{x}\right) R_{ \pm}^{\Omega}(\alpha, x)\right) \\
& =\frac{1}{2 \alpha}\left(\square \Gamma_{x} \cdot R_{ \pm}^{\Omega}(\alpha, x)-\left\langle\operatorname{grad}\left(\Gamma_{x}\right), \operatorname{grad} R_{ \pm}^{\Omega}(\alpha, x)\right\rangle\right) \\
& =\frac{1}{2 \alpha}\left(\square \Gamma_{x} \cdot R_{ \pm}^{\Omega}(\alpha, x)+\right. \\
& \left.-\frac{1}{2(\alpha-2)}\left\langle\operatorname{grad}\left(\Gamma_{x}\right), \operatorname{grad}\left(\Gamma_{x}\right) R_{ \pm}^{\Omega}(\alpha-2, x)\right\rangle\right) \\
& =\frac{1}{2 \alpha}\left(\square \Gamma_{x} \cdot R_{ \pm}^{\Omega}(\alpha, x)+\frac{4 \Gamma_{x}}{2(\alpha-2)} R_{ \pm}^{\Omega}(\alpha-2, x)\right) \\
& =\frac{1}{2 \alpha} \square \Gamma_{x} \cdot R_{ \pm}^{\Omega}(\alpha, x)+\frac{(\alpha-2)(a-n)}{\alpha(\alpha-2)} R_{ \pm}^{\Omega}(\alpha, x) \\
& =\left(\frac{\square \Gamma_{x}-2 n}{2 \alpha}+1\right) R_{ \pm}^{\Omega}(\alpha, x)
\end{aligned}
$$

Analyticity of the Riesz distribution $R_{ \pm}(\alpha)$ now yields the extension of item (iii) to the complex plan - while $\alpha \neq 0$.

If we are to consider the regular d'Alembertian operator on Minkowski space, the property of the Riesz distribution that $\square R_{ \pm}(2)=\delta_{0}$ provides a fundamental solution, while in general Lorentzian Manifolds the extra term $\frac{\square \Gamma_{x}-2 n}{2 \alpha}$ does not allow us to consider the case $\alpha=0$. 


\subsection{The Formal Solution}

We shall start the construction of fundamental solutions to 3.2locally, considering a $x \in \mathrm{M}$ and a geodesically star-shaped neighborhood $\Omega$ of $x$ to be the subset where the wave equation is to be considered. Suppose the distribution ${ }^{2}$

$$
\widetilde{\mathscr{R}}_{ \pm}(x):=\sum_{k=0}^{\infty} V_{x}^{k} R_{ \pm}^{\Omega}(2+2 k, x),
$$

with smooth $V_{x}^{k} \in C^{\infty}\left(\Omega, \mathrm{E} \otimes \mathrm{E}_{x}^{*}\right)$, defined as

$$
\widetilde{\mathscr{R}}_{ \pm}(x)(\varphi)=\sum_{k=0}^{\infty} R_{ \pm}^{\Omega}(2+2 k, x)\left(V_{x}^{k} \cdot \varphi\right)
$$

for $\varphi \in \mathscr{D}\left(\Omega, \mathrm{E}^{*}\right)$, where we regard $R_{ \pm}^{\Omega}(2+2 k, x)$ as the defined distribution and $V_{x}^{k} \cdot \varphi$ means the natural pairing of $V_{x}^{k}$ and $\varphi$ w.r.t. the $\mathrm{E}$ component in the tensor product $\mathrm{E} \otimes \mathrm{E}_{x}^{*}$. Such a construction does not only is appropriate to the present context, since we are looking for an operator $F$ acting on sections $\varphi \in \mathscr{D}\left(\mathrm{M}, \mathrm{E}^{*}\right)$, as it makes sense completely. According to $(3.11), R_{ \pm}^{\Omega}(2+2 k, x)$ is defined over $\mathscr{D}(\Omega, \mathbb{C})$, so we may regard $R_{+}^{\Omega}(2+2 k, x)$ as a distribution in $\mathscr{D}(\Omega, \mathrm{E}, \mathrm{M})$ by applying $R_{+}^{\Omega}(2+2 k, x)$ to the complex component of $V_{x}^{k} \cdot \varphi$ and leaving the $\mathrm{E}_{x}^{*}$ component untouched. Furthermore, we shall suppose $\widetilde{\mathscr{R}}_{ \pm}(x)$ provides a fundamental solution. The next step is to calculate $P$ acting on it; now, it is equivalent to consider the action of a differential operator over a distribution and over the function defining the distribution, in case it exists. Following the properties of Riesz distribution,

$$
\begin{aligned}
P \widetilde{\mathscr{R}}_{ \pm}(x)=\delta_{x} & =P \sum_{k=0}^{\infty} V_{x}^{k} R_{ \pm}^{\Omega}(2+2 k, x)=\sum_{k=0}^{\infty} P\left\{V_{x}^{k} R_{ \pm}^{\Omega}(2+2 k, x)\right\} \\
& =\sum_{k=0}^{\infty}\left\{V_{x}^{k} \square R_{ \pm}^{\Omega}(2+2 k, x)+\right. \\
& \left.+\left(P V_{x}^{k}\right) R_{ \pm}^{\Omega}(2+2 k, x)-2 \nabla_{\operatorname{grad} R_{ \pm}^{\Omega}} V_{x}^{k}\right\} \\
& =V_{x}^{0} \square R_{ \pm}^{\Omega}(2, x)-2 \nabla_{\operatorname{grad} R_{ \pm}^{\Omega}(2, x)} V_{x}^{0}+ \\
& +\sum_{k=1}^{\infty}\left\{V_{x}^{k} \square R_{ \pm}^{\Omega}(2+2 k, x)+\left(P V_{x}^{k-1}\right) R_{ \pm}^{\Omega}(2 k, x)-2 \nabla_{\operatorname{grad} R_{ \pm}^{\Omega}} V_{x}^{k}\right\} \\
& =V_{x}^{0} \square R_{ \pm}^{\Omega}(2, x)-2 \nabla_{\operatorname{grad} R_{ \pm}^{\Omega}(2, x)} V_{x}^{0}+
\end{aligned}
$$

\footnotetext{
${ }^{2}$ There is no reason initially for the series to converge. Hence, 3.12 may not define a distribution. It will not turn out to be a problem, since we shall introduce cut-off functions. For a while, we shall ignore this problem.
} 


$$
\begin{aligned}
& +\sum_{k=1}^{\infty}\left\{V_{x}^{k}\left(\frac{\square \Gamma_{x}-2 n}{4 k}+1\right) R_{ \pm}^{\Omega}(2 k, x)+\left(P V_{x}^{k-1}\right) R_{ \pm}^{\Omega}(2 k, x)+\right. \\
& \left.-\frac{2}{4 k} \nabla_{\operatorname{grad} \Gamma_{x} \cdot R_{ \pm}^{\Omega}(2 k, x)} V_{x}^{k}\right\} \\
& =V_{x}^{0} \square R_{ \pm}^{\Omega}(2, x)-2 \nabla_{\operatorname{grad} R_{ \pm}^{\Omega}(2, x)} V_{x}^{0}+ \\
& +\sum_{k=1}^{\infty} \frac{1}{2 k}\left\{V_{x}^{k}\left[\square \frac{1}{2} \Gamma_{x}-n+2 k\right]+2 k\left(P V_{x}^{k-1}\right)-\nabla_{\operatorname{grad}_{x}} V_{x}^{k}\right\} R_{ \pm}^{\Omega}(2 k, x) \\
& =\delta_{x}=R_{ \pm}^{\Omega}(0, x)
\end{aligned}
$$

which implies the differential equations

$$
\begin{gathered}
V_{x}^{0} \square R_{ \pm}^{\Omega}(2, x)-2 \nabla_{\operatorname{grad} R_{ \pm}^{\Omega}(2, x)} V_{x}^{0}-R_{ \pm}^{\Omega}(0, x)=0 \\
V_{x}^{k}\left[\square \frac{1}{2} \Gamma_{x}-n+2 k\right]+2 k\left(P V_{x}^{k-1}\right)-\nabla_{\operatorname{grad}_{x}} V_{x}^{k}=0 \quad k \geq 1
\end{gathered}
$$

However, the first equation may be introduced in the second one: we admit $2 k P V_{x}^{k-1}=0$ for $k=0$ and write

$$
\begin{aligned}
& V_{x}^{0}\left(\square \frac{1}{2} \Gamma_{x}-n\right) R_{ \pm}^{\Omega}(\alpha, x)-\nabla_{g r a d} \Gamma_{x} R_{ \pm}^{\Omega}(\alpha, x) \\
\Rightarrow & \nabla_{2 \alpha \operatorname{grad} R_{ \pm}^{\Omega}(\alpha, x)} V_{x}^{0}-\alpha\left(\square R_{ \pm}^{\Omega}(\alpha+2, x)-R_{ \pm}^{\Omega}(\alpha, x)\right) V_{x}^{0}=0 \\
\Rightarrow & 2 \nabla_{g r a d R_{ \pm}^{\Omega}(\alpha, x)} V_{x}^{0}-\left(\square R_{ \pm}^{\Omega}(\alpha+2, x)-R_{ \pm}^{\Omega}(\alpha, x)\right) V_{x}^{0}=0 \\
\Rightarrow & 2 \nabla_{\operatorname{grad} R_{ \pm}^{\Omega}(0, x)} V_{x}^{0}-\left(\square R_{ \pm}^{\Omega}(2, x)-R_{ \pm}^{\Omega}(0, x)\right) V_{x}^{0}=0 \quad(\text { as } \alpha \rightarrow 0)
\end{aligned}
$$

and hence yields the equation obtained above from (3.12) when treating $k=0$ separately in the special case $V_{x}^{0}=\mathrm{id}_{\mathrm{E}}$. We have concluded that equation (3.12) provides a fundamental solution to the wave equation iff the coefficients $V_{x}^{k} \in C^{\infty}\left(\mathrm{M}, \mathrm{E} \otimes \mathrm{E}_{x}^{*}\right)$ satisfy the differential equation

$$
\nabla_{\operatorname{grad} \Gamma_{x}} V_{x}^{k}-\left[\square \frac{1}{2} \Gamma_{x}-n+2 k\right] V_{x}^{k}=2 k P V_{x}^{k-1}, \quad k \geq 0,
$$

with boundary condition $V_{x}^{0}=\mathrm{id}_{\mathrm{E}}$. The smooth coefficients $V_{x}^{k}$ which satisfy the so called transport equation (3.14) are called Hadamard coefficients for $P$. One could ask whether it is a significant loss of generality to endow the first equation of (3.13), regardind $k=0$, in the second one, therefore restricting the possible solutions 
of $(3.13 \mathrm{a})$ to $\mathrm{id}_{\mathrm{E}}$. However, the recursive character of $(3.13 \mathrm{~b})$ w. r. t. $k$ demands such constraint, and no reasonable solution to (3.14) is left aside in this way. Of course, this statement only makes sense if we are able to demonstrate not only the existence, but also the uniqueness of Hadamard coefficients.

Theorem 9. (Existence and Uniqueness of Hadamard coefficients) Let $\Omega \subset \mathrm{M}$ be a geodesically convex open subset. Let $P$ be a globally hyperbolic operator induced by the connection $\nabla$, and let $\Pi_{x}^{y}$ denote the parallel transport induced by $\nabla$ from $\mathrm{E}_{x} \longrightarrow \mathrm{E}_{y}$. Then, there are unique Hadamard coefficients $V^{k} \in C^{\infty}\left(\Omega \times \mathrm{M}, \mathrm{E} \otimes \mathrm{E}^{*}\right)$ for $P$, with $k \geq 0$, which are given by

$$
\begin{gathered}
V_{x}^{0}(y) \equiv V^{0}(x, y)=\mu_{x}^{-1 / 2}(y) \Pi_{y}^{x} \\
V^{k}(x, y)=-k \mu_{x}^{-1 / 2}(y) \int_{0}^{1} \mu_{x}^{-1 / 2}(\Phi(y, t)) t^{k-1} \Pi_{x}^{\Phi(y, t)}\left(P_{2} V^{k-1}\right)(x, \Phi(y, t)) d t
\end{gathered}
$$

for all $(x, y) \in \Omega \times \mathrm{M}$, where $\Phi: \Omega \times[0,1] \longrightarrow \Omega, \Phi(x, y):=\exp _{x}\left(t \exp _{x}^{-1}(y)\right)$ and $P_{2}$ denotes the action of $P$ over the second argument.

In particular, for $x=y$, for any normally hyperbolic $P$

$$
\begin{aligned}
& V^{0}(x, x)=\operatorname{id}_{\mathrm{E}_{x}} \\
& V^{k}(x, x)=-P V^{k-1}(x, x) \quad k \geq 1
\end{aligned}
$$

Proof. First, we shall suppose $P$ has well-defined Hadamard coefficients $V_{x}^{k}$, and we prove they are indeed given in terms of the expressions presented in the theorem, hence we shall conclude the uniqueness of the coefficients. After this, we shall take these expressions and show they define Hadamard coefficients, which will imply the existence.

Uniqueness: beginning by proving (3.15a), we shall rewrite the transport equation in order to obtain a geodesics equation. Let $x \in \Omega$, and let $C(x)=\exp _{x}(C(0))$ be the light-cone of $x$; for $y \in \Omega \backslash C(x)$, we have $\Gamma_{x}(y) \neq 0$ and we use identities

$$
\left\{\begin{array}{l}
\frac{1}{2} \square \Gamma_{x}-n=-\nabla_{\operatorname{grad} \Gamma_{x}} \ln \mu_{x}^{1 / 2} \\
\nabla_{\operatorname{grad} \Gamma_{x}} \ln \rho^{k}=-2 k,
\end{array}\right.
$$

where $\rho(x):=\sqrt{\left|\Gamma_{x}\right|}$, in order to write 


$$
\begin{aligned}
& \nabla_{\operatorname{grad} \Gamma_{x}} V_{x}^{k}-\left[\square \frac{1}{2} \Gamma_{x}-n+2 k\right] V_{x}^{k}=2 k P V_{x}^{k-1} \Rightarrow \\
& \nabla_{\operatorname{grad} \Gamma_{x}} V_{x}^{k}+\nabla_{\operatorname{grad} \Gamma_{x}}\left(\ln \mu_{x}^{1 / 2}\right) V_{x}^{k}+\nabla_{\operatorname{grad} \Gamma_{x}}\left(\ln \rho^{k}\right) V_{x}^{k}=2 k P V_{x}^{k-1} \\
\Rightarrow & \nabla_{\operatorname{grad} \Gamma_{x}} V_{x}^{k}+\nabla_{\operatorname{grad} \Gamma_{x}}\left(\ln \mu_{x}^{1 / 2}+\ln \rho^{k}\right) V_{x}^{k}= \\
= & \nabla_{\operatorname{grad} \Gamma_{x}} V_{x}^{k}+\nabla_{\operatorname{grad} \Gamma_{x}}\left[\ln \left(\mu_{x}^{1 / 2} \rho^{k}\right)\right] V_{x}^{k}=2 k P V_{x}^{k-1} \times \mu_{x}^{1 / 2} \rho^{k} \\
\Rightarrow & \mu_{x}^{1 / 2} \rho^{k} \nabla_{\operatorname{grad} \Gamma_{x}} V_{x}^{k}+\nabla_{\operatorname{grad} \Gamma_{x}}\left(\mu_{x}^{1 / 2} \rho^{k}\right) V_{x}^{k}= \\
= & \nabla_{\operatorname{grad} \Gamma_{x}}\left(\mu_{x}^{1 / 2} \rho^{k} V_{x}^{k}\right)=2 k \mu_{x}^{1 / 2} \rho^{k} P V_{x}^{k-1}
\end{aligned}
$$

Hence, for $k=0$, we have $\nabla_{\operatorname{grad} \Gamma_{x}}\left(\mu_{x}^{1 / 2} \rho^{k} V_{x}^{0}\right)=0$, which means that $\mu_{x}^{1 / 2} V_{x}^{0}$ is parallel trasported by $\nabla$ throughout a geodesics starting at $x$, from what we conclude $\mu_{x}^{1 / 2}(y) V_{x}^{0}(y)=\Pi_{y}^{x}$.

For $k \geq 1$, consider once again a point $y \in \Omega \backslash C(x)$, and let $\alpha(t)=\exp _{x}\left(t \cdot \exp _{x}^{-1} y\right)$ be a geodesics from $x$ to $y$, which we reparametrize as $\beta(t)=\exp _{x}\left(e^{2 t} \cdot \eta\right)$, with $\eta:=$ $\exp _{x}^{-1}(y)$. This results yields, according to Gauss' lemma - see [9],

$$
\begin{aligned}
\langle\dot{\beta}(t), \dot{\beta}(t)\rangle & =\left\langle 2 e^{2 t} \dot{\alpha}\left(e^{2 t}\right), 2 e^{2 t} \dot{\alpha}\left(e^{2 t}\right)\right\rangle \\
& =4 e^{4 t}\langle\eta, \eta\rangle=-4 \gamma\left(e^{2 t} \eta\right) \\
& =-4 \gamma \circ \exp _{x}^{-1} \circ \exp _{x}\left(e^{2 t} \eta\right) \\
& =-4 \Gamma_{x}(\beta(t))=\left\langle\operatorname{grad}_{c(t)} \Gamma_{x}, \operatorname{grad}_{c(t)} \Gamma_{x}\right\rangle .
\end{aligned}
$$

Thus, being $c:[0,1] \longrightarrow \Omega$ an integral curve of the vector field $\operatorname{grad} \Gamma_{x}$, we may solve (3.16) exactly by using the variation of parameters method:

$$
\begin{gathered}
\left(\mu_{x}^{1 / 2} \rho^{k} V_{x}^{k}\right)(\beta(t))=\Pi_{\beta(t)}^{x}\left\{\int_{t}^{\infty} d t^{\prime} \Pi_{x}^{\beta\left(t^{\prime}\right)}\left[\mu_{x}^{1 / 2} \rho^{k} 2 k P V_{x}^{k-1}\right]\left(\beta\left(t^{\prime}\right)\right)\right\} \\
=2 k \Pi_{\beta(t)}^{x}\left\{\int_{t}^{\infty} d t^{\prime}\left(\mu_{x}^{1 / 2} \circ \beta\right)\left(t^{\prime}\right)\left(\rho^{k} \circ \beta\right)\left(t^{\prime}\right) \Pi_{x}^{\beta\left(t^{\prime}\right)}\left(P V_{x}^{k-1}\right)\left(\beta\left(t^{\prime}\right)\right)\right\}, \\
\left(\left(\rho^{k} \circ \beta\right)(t)=\left(\rho^{k} \circ \exp _{x}\right)\left(e^{2 t} \eta\right)=\left|\gamma\left(e^{2 t} \eta\right)\right|^{k / 2}=\right. \\
\left.=e^{2 k t}|\gamma(\eta)|^{k / 2}=e^{2 k t}\left|\gamma \circ \exp _{x}^{-1}(y)\right|^{k / 2} \neq 0 \text { since } y \notin C(x)\right), \\
\Rightarrow e^{2 k t}|\gamma(\eta)|^{k / 2}\left(\mu_{x}^{1 / 2} V_{x}^{k}\right)(c(t))
\end{gathered}
$$




$$
\begin{aligned}
& =2 k|\gamma(\eta)|^{k / 2} \Pi_{c(t)}^{x}\left\{\int_{t}^{\infty} d t^{\prime}\left(\mu_{x}^{1 / 2} \circ \beta\right)\left(t^{\prime}\right) e^{2 k t^{\prime}} \Pi_{x}^{\beta\left(t^{\prime}\right)}\left(P V_{x}^{k-1}\right)\left(\beta\left(t^{\prime}\right)\right)\right\} \\
& \text { dividing by }|\gamma(\eta)|^{k / 2} \Rightarrow e^{2 k t}\left(\mu_{x}^{1 / 2} V_{x}^{k}\right)(\beta(t))= \\
& =-2 k \Pi_{\beta(t)}^{x}\left\{\int_{0}^{e^{2 t}} \frac{d u}{2 u} \mu_{x}^{1 / 2}\left(\exp _{x}(u \cdot \eta)\right) u^{k} \Pi_{x}^{\exp _{x}(u \cdot \eta)}\left(P V_{x}^{k-1}\right)\left(\exp _{x}(u \cdot \eta)\right)\right\} \\
& =-k \Pi_{\beta(t)}^{x}\left\{\int_{0}^{e^{2 t}} d u \mu_{x}^{1 / 2}(\Phi(u, \eta)) u^{k-1} \Pi_{x}^{\Phi(u, \eta)}\left(P V_{x}^{k-1}\right)(\Phi(u, \eta))\right\}
\end{aligned}
$$

where $u\left(t^{\prime}\right):=e^{2 t^{\prime}}, u(0)=1$. Uniqueness of Hadamard coefficients then follow, since if there were a sequence $W_{x}^{k}$ of Hadamard coefficients other than $V_{x}^{k}$, we would have $W_{x}^{0}=V_{x}^{0}$, and, by the recurrence relation in $\mathrm{k}, W_{x}^{k}=V_{x}^{k}$ henceforth.

Existence: it is now easier to prove the existence of Hadamard coefficients from expressions (3.15a) and (3.15b). Since they indeed define smooth sections in $C^{\infty}(\Omega, \mathrm{E} \otimes$ $\left.\mathrm{E}_{x}^{*}\right)$, it is only left to prove the transport equation of the form

$$
\nabla_{\operatorname{grad} \Gamma_{x}}\left(\mu_{x}^{1 / 2} \rho^{k} V_{x}^{k}\right)=2 k \mu_{x}^{1 / 2} \rho^{k} P V_{x}^{k-1}
$$

for all $k \geq 0$. For $k=0$,

$$
\nabla_{\operatorname{grad} \Gamma_{x}}\left(\mu_{x}^{1 / 2} \rho^{0} V_{x}^{0}\right)=\nabla_{\operatorname{grad} \Gamma_{x}}\left(\Pi^{x}\right)=0 .
$$

On the other hand, for $k \geq 1$, since

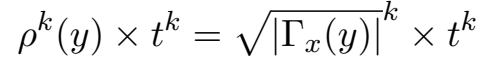

$$
\begin{aligned}
& ={\sqrt{\left|\Gamma_{x}(y)\right| t^{2}}}^{k} \\
& ={\sqrt{\left|\gamma \circ \exp _{x}^{-1}(y)\right| t^{2}}}^{k} \\
& ={\sqrt{\mid \gamma \circ t \exp _{x}^{-1}(y)}}^{k} \\
& ={\sqrt{\mid \gamma \circ \exp _{x}^{-1} \circ \exp _{x} \circ t \exp _{x}^{-1}(y)}}^{k}
\end{aligned}
$$

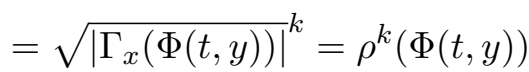

we have 


$$
\begin{aligned}
& \nabla_{\operatorname{grad} \Gamma_{x}}\left(\mu_{x}^{1 / 2} \rho^{k} V_{x}^{k}\right)= \\
& =-k \nabla_{\operatorname{grad} \Gamma_{x}}\left\{\Pi^{x} \int_{0}^{1} \mu_{x}^{1 / 2}(\Phi(u, \cdot)) u^{k-1} \rho^{k}(\cdot) \Pi_{x}^{\Phi(u, \cdot)}\left(P V_{x}^{k-1}\right)\left[\Phi\left(e^{2 t}, \cdot\right)\right] d u\right\} \\
& =-k \nabla_{\operatorname{grad} \Gamma_{x}}\left\{\Pi^{x} \int_{0}^{1} \mu_{x}^{1 / 2}(\Phi(u, \cdot)) \rho^{k}(\Phi(u, \cdot)) \Pi_{x}^{\Phi(u, \cdot)}\left(P V_{x}^{k-1}\right)\left[\Phi\left(e^{2 t}, \cdot\right)\right] \frac{d u}{u}\right\} \\
& =-k \nabla_{\operatorname{grad} \Gamma_{x}}\left\{\Pi^{x} \int_{0}^{1}\left[\mu_{x}^{1 / 2} \rho^{k} \Pi_{x}^{\Phi(u, \cdot)}\left(P V_{x}^{k-1}\right)\right]\left[\Phi\left(e^{2 t}, \cdot\right)\right] \frac{d u}{u}\right\} \\
& u=e^{2 t} \Rightarrow-2 k \nabla_{\operatorname{grad} \Gamma_{x}}\left\{\Pi^{x} \int_{-\infty}^{0}\left[\mu_{x}^{1 / 2} \rho^{k} \Pi_{x}^{\Phi\left(e^{2 t}, \cdot\right)}\left(P V_{x}^{k-1}\right)\right]\left[\Phi\left(e^{2 t}, \cdot\right)\right] d t\right\} \\
& =\left.2 k \Pi^{x} \frac{d}{d l}\right|_{l=0}\left\{\int_{-\infty}^{0}\left[\mu_{x}^{1 / 2} \rho^{k} \Pi_{x}^{\Phi\left(e^{2 t}, \cdot\right)}\left(P V_{x}^{k-1}\right)\right]\left[\Phi\left(e^{2 l}, \Phi\left(e^{2 t}, \cdot\right)\right)\right] d t\right\} \\
& \Rightarrow=t+l \Rightarrow \\
& \left.\Rightarrow 2 k \Pi^{x} \frac{d}{d l}\right|_{l=0}\left\{\int_{-\infty}^{l}\left[\mu_{x}^{1 / 2} \rho^{k} \Pi_{x}^{\Phi\left(e^{2(\tau-l)}, \cdot\right)}\left(P V_{x}^{k-1}\right)\right]\left[\Phi\left(e^{2 \tau}, \cdot\right)\right] d \tau\right\} \\
& =2 k \Pi^{x}\left[\mu_{x}^{1 / 2} \rho^{k} \Pi_{x}^{\Phi\left(e^{2(\tau-l)}, \cdot\right)}\left(P V_{x}^{k-1}\right)\right]\left[\Phi\left(e^{0}, \cdot\right)\right] \\
& =2 k \Pi^{x}\left[\mu_{x}^{1 / 2} \rho^{k} \Pi_{x}^{\Phi\left(e^{2(\tau-l)}, \cdot\right)}\left(P V_{x}^{k-1}\right)\right](\cdot)
\end{aligned}
$$

The expression above is nothing but the transport equation in the form (3.17) for a fixed $x \in \Omega$, and it remains to consider $x$ varying over $\Omega$ : therefore, let $U \subset \Omega$, geodesic-convex, be a neighborhood of $p \in \Omega$, so the Riesz distributions are defined for all $x \in U$, and from expressions (3.15a) (3.15b) we conclude the Hadamard coefficients $V^{k} \in C^{\infty}(U \times$ $\left.\Omega, \mathrm{E}^{*} \otimes \mathrm{E}\right)$ depends smoothly on $\mathrm{x}$.

\subsection{The Existence of "True" Fundamental Solutions}

We have proved for the series (3.12) that the coefficients $V_{x}^{k}$ exist and are the unique smooth functions in $C^{\infty}\left(\Omega \times \Omega, \mathrm{E}^{*} \otimes \mathrm{E}\right)$ whenever (3.12) is a fundamental solution to the wave equation, with $\Omega \subset \mathrm{M}$ a geodesic-convex neighborhood of a certain $p \in \mathrm{M}$. However, there is in principle no reason why the presented series should be well defined as a distribution, since its convergence is not guaranteed by any property of the Hadamard coefficients nor by the Riesz distributions. What we shall do next is to introduce cutoff functions in the series in order to establish a local convergence. Since (3.12) may provide a exact solution, this cutoff might result in a solution up to an error, which can be proved to be a smooth function and used in the construction of a new and well defined fundamental solution - which, in the sense of its definiteness, we called it true solution. 
Therefore, in order to guarantee the continuity of $\widetilde{\mathscr{R}}_{ \pm}(x)$, pick a $N>n / 2-$ this is just to ensure $R_{ \pm}^{\Omega}(2+2 k, x)$ is continuous for each $k \geq N$, according to lemma (13); let $\left(\varepsilon_{j}\right)_{j} \in(0,1]$ and let the smooth bump function $\sigma: \mathbb{R} \rightarrow \mathbb{R}$ be such that supp $\sigma \subset[-1,1]$ and

$$
\sigma(x) \begin{cases}=1 & \forall x \in[-1 / 2,1 / 2] ; \\ \in[0,1] & \forall x \in[-1,-1 / 2] \cup[1 / 2,1] .\end{cases}
$$

We rewrite the previous series as

$$
\begin{aligned}
\mathscr{R}_{ \pm}^{\sigma}(x) & :=\sum_{k=0}^{\infty} V_{x}^{k} R_{ \pm}^{\Omega}(2+2 k, x) \\
& =\sum_{k=0}^{N-1} V_{x}^{k} R_{ \pm}^{\Omega}(2+2 k, x)+\sum_{k=N}^{\infty} \sigma\left(\frac{\Gamma_{x}}{\varepsilon_{k}}\right) V_{x}^{k} R_{ \pm}^{\Omega}(2+2 k, x)
\end{aligned}
$$

which is possible due to the following lemma.

Lemma 14. (i) For each $l \in \mathbb{N}$ and each $\beta \geq l+1$, there is a constant $C=C(l, \beta)$ such that, for all $\varepsilon \in(0,1]$,

$$
\left\|\frac{\mathrm{d}^{l} \sigma}{\mathrm{d} x^{l}}\right\|_{\mathscr{F}(\mathbb{R})} \leq \varepsilon C\|\sigma\|_{C^{l}(\mathbb{R})} .
$$

(ii) Let $\Omega^{\prime} \subset \subset \Omega$ (i.e., $\Omega^{\prime} \subset \Omega$ and $\overline{\Omega^{\prime}} \subset \Omega$ ) be open and relatively compact; then there is a sequence $\left(\varepsilon_{k}\right)_{k} \in(0,1]$ such that, for each $k_{0} \geq 0$, the expression

$$
\begin{gathered}
(x, y) \longmapsto \sum_{k=N+k_{0}}^{\infty} \sigma\left(\frac{\Gamma_{x}(y)}{\varepsilon_{k}}\right) V_{x}^{k}(y) R_{ \pm}^{\Omega}(2+2 k, x)(y) \\
=\left\{\begin{array}{lr}
\sum_{k=N+k_{0}}^{\infty} C(2+2 k) \sigma\left(\frac{\Gamma_{x}(y)}{\varepsilon_{k}}\right) V_{x}^{k}(y) \Gamma_{x}(y)^{k+1-n / 2} & y \in J_{ \pm}^{\Omega}(x) \\
0 & \text { otherwise }
\end{array}\right.
\end{gathered}
$$

defines a smooth section in $\overline{\Omega^{\prime}} \times \overline{\Omega^{\prime}} \backslash \Gamma_{0}^{-1}$ and it is continuous in $\overline{\Omega^{\prime}} \times \overline{\Omega^{\prime}}$, where $C$ is the constant given in item (i). In particular,

$$
\sum_{k=N}^{\infty} \sigma\left(\frac{\Gamma_{x}(y)}{\varepsilon_{k}}\right) V_{x}^{k}(y) R_{ \pm}^{\Omega}(2+2 k, x)(y)
$$

converges.

Proof. See [10], section 2.4. 
Therefore, after the introduction of the cutoff functions we may regard $\widetilde{\mathscr{R}}_{ \pm}(x)$ as a distribution; for the change in $\widetilde{\mathscr{R}}_{ \pm}(x)$ after the cutoff introduction, we shall represent it by $\mathscr{R}_{ \pm}^{\sigma}(x)$, with the following properties:

Lemma 15. For each $x \in \Omega$,

$$
\begin{aligned}
& \text { supp } \mathscr{R}_{ \pm}^{\sigma}(x) \subset J_{ \pm}^{\Omega}(x) \\
& \text { sing supp } \mathscr{R}_{ \pm}^{\sigma}(x) \subset C_{ \pm}^{\Omega}(x)
\end{aligned}
$$

Proof. Considering item (ii) of lemma 14, we know that for every $\alpha \in \mathbb{C} \backslash\{0,-2,-4, \ldots\} \cup$ $\{n-2, n-4, \ldots\}, \operatorname{supp} R_{ \pm}^{\Omega}(\alpha, x) \subset J_{ \pm}^{\Omega}(x)$, which ensures us the first property. The second one follows from sing supp $R_{ \pm}^{\Omega}(\alpha, x) \subset C_{ \pm}^{\Omega}(x)$ in the same circumstances for $\alpha$ and from the discontinuity of the expression in the preceding lemma around the borders of $J_{ \pm}^{\Omega}(x)$. One should note that the conic structure of both $J_{ \pm}^{\Omega}(x)$ and $C_{ \pm}^{\Omega}(x)$ is implicitly used in the extension of these statements from $R_{ \pm}^{\Omega}(\alpha, x)$ to $\mathscr{R}_{ \pm}^{\sigma}(x)$.

Theorem 10. With the conditions of lemma 14, it is possible to take the sequence $\left(\varepsilon_{k}\right)_{k}$ in a manner that there exist $K_{ \pm} \in C^{\infty}\left(\overline{\Omega^{\prime}} \times \overline{\Omega^{\prime}}, \mathrm{E}^{*} \otimes \mathrm{E}\right)$ with

$$
P_{(2)} \mathscr{R}_{ \pm}^{\sigma}(x)-\delta_{x}=K_{ \pm}(x)
$$

Proof. We want to show the equality between distributions

$$
\begin{aligned}
& P_{(2)}\left\{\sum_{k=0}^{N-1} V_{x}^{k}(y) R_{ \pm}^{\Omega}(2+2 k, x)(y)+\sum_{k=N}^{\infty} \sigma\left(\frac{\Gamma_{x}(y)}{\varepsilon_{k}}\right) V_{x}^{k}(y) R_{ \pm}^{\Omega}(2+2 k, x)(y)\right\} \\
& =K_{ \pm}(x, y)+\delta_{x}
\end{aligned}
$$

where, once again, $P_{(2)}$ is acting on the variable $y \in \Omega$. From the properties of Hadamard coefficients (3.13), we have

$$
\sum_{k=0}^{N-1} P_{(2)}\left\{V_{x}^{k}(y) R_{ \pm}^{\Omega}(2+2 k, x)(y)\right\}=\left[P_{(2)} V_{x}^{N-1}(y)\right] R_{ \pm}^{\Omega}(2 N, x)+\delta_{x}
$$

It is remaining to prove the statement for the series starting at $k=N$ :

$$
\begin{aligned}
& P_{(2)}\left\{\sum_{k=N}^{\infty} \sigma\left(\frac{\Gamma_{x}(y)}{\varepsilon_{k}}\right) V_{x}^{k}(y) R_{ \pm}^{\Omega}(2+2 k, x)(y)\right\} \\
& =\sum_{k=N}^{\infty} P_{(2)}\left\{\sigma\left(\frac{\Gamma_{x}(y)}{\varepsilon_{k}}\right) V_{x}^{k}(y) R_{ \pm}^{\Omega}(2+2 k, x)(y)\right\} \\
& =\sum_{k=N}^{\infty}\left\{\square\left[\sigma\left(\frac{\Gamma_{x}(y)}{\varepsilon_{k}}\right) R_{ \pm}^{\Omega}(2+2 k, x)(y)\right] V_{x}^{k}(y)-2 \nabla_{\operatorname{grad} \sigma R_{ \pm}^{\Omega}} V_{x}^{k}(y)+\right. \\
& \left.+\left[P_{(2)} V_{x}^{k}(y)\right] \sigma\left(\frac{\Gamma_{x}(y)}{\varepsilon_{k}}\right) R_{ \pm}^{\Omega}\right\}
\end{aligned}
$$


where we have represented $\sigma \equiv \sigma\left(\frac{\Gamma_{x}(y)}{\varepsilon_{k}}\right)$ and $R_{ \pm}^{\Omega} \equiv R_{ \pm}^{\Omega}(2+2 k, x)$, omitting their arguments for the sake of notation. It should be noted that the introduction of the operator $P_{(2)}$ within the summation is not a trivial consequence of its linearity, since such a property applies when dealing with the action of the operator on linear combinations of arguments - therefore finite summations; the veracity of this statement is a consequence of the fact that if a sequence $\left(T_{n}\right)_{n}$ of regular distributions converge as functions, then it converges as distributions, and, in particular, the same applies for $\left(P T_{n}\right)_{n}$. Thereafter,

$$
\begin{aligned}
& P_{(2)}\left\{\sum_{k=N}^{\infty} \sigma\left(\frac{\Gamma_{x}(y)}{\varepsilon_{k}}\right) V_{x}^{k}(y) R_{ \pm}^{\Omega}(2+2 k, x)(y)\right\} \\
& =\sum_{k=N}^{\infty}\left\{\square\left[\sigma\left(\frac{\Gamma_{x}(y)}{\varepsilon_{k}}\right)\right] V_{x}^{k}(y) R_{ \pm}^{\Omega}(2+2 k, x)(y)+\right. \\
& +\sigma\left(\frac{\Gamma_{x}(y)}{\varepsilon_{k}}\right) V_{x}^{k}(y) \square\left[R_{ \pm}^{\Omega}(2+2 k, x)(y)\right]-2\left[\sigma \nabla_{\operatorname{grad} R_{ \pm}^{\Omega}}+R_{ \pm}^{\Omega} \nabla_{\operatorname{grad} \sigma}\right] V_{x}^{k}(y)+ \\
& \left.+\left[P_{(2)} V_{x}^{k}(y)\right] \sigma\left(\frac{\Gamma_{x}(y)}{\varepsilon_{k}}\right) R_{ \pm}^{\Omega}(2+2 k, x)-2\left\langle\operatorname{grad} \sigma, \operatorname{grad} R_{ \pm}^{\Omega}\right\rangle V_{x}^{k}\right\}= \\
& =\Sigma_{1}+\Sigma_{2}+\Sigma_{3}
\end{aligned}
$$

with

$$
\begin{aligned}
\Sigma_{1} & :=\sum_{k=N}^{\infty} \square\left[\sigma\left(\frac{\Gamma_{x}(y)}{\varepsilon_{k}}\right)\right] V_{x}^{k}(y) R_{ \pm}^{\Omega}(2+2 k, x)(y) \\
\Sigma_{2} & :=-2 \sum_{k=N}^{\infty} \nabla_{\operatorname{grad} \sigma}\left[V_{x}^{k}(y) R_{ \pm}^{\Omega}(2+2 k, x)(y)\right] \\
\Sigma_{3} & :=\sum_{k=N}^{\infty} \sigma\left(\frac{\Gamma_{x}(y)}{\varepsilon_{k}}\right)\left\{\left[P_{(2)} V_{x}^{k}(y)\right] R_{ \pm}^{\Omega}(2+2 k, x)(y)+\right. \\
& \left.-2 \nabla_{\operatorname{grad} R_{ \pm}^{\Omega}} V_{x}^{k}+V_{x}^{k}(y) \square\left[R_{ \pm}^{\Omega}(2+2 k, x)(y)\right]\right\}
\end{aligned}
$$

The expression $\Sigma_{2}$ contains the inner product involving the gradients; one should also note that the differential operators $\square, \nabla$ and grad, induced by $P_{(2)}$, act only on the variable $y \in \Omega$. Now, by using property $(3.13 \mathrm{~b})-$ or, even better, the calculus that drove us to it, we obtain for $\Sigma_{3}$

$$
\Sigma_{3}=\sum_{k=N}^{\infty} \sigma\left(\frac{\Gamma_{x}(y)}{\varepsilon_{k}}\right)\left\{\left[P_{(2)} V_{x}^{k}(y)\right] R_{ \pm}^{\Omega}(2+2 k, x)-\left[P_{(2)} V_{x}^{k-1}\right] R_{ \pm}^{\Omega}(2 k, x)\right\}
$$

(we redefine the index in the right hand side term:) 


$$
\begin{aligned}
& =-\sigma\left(\frac{\Gamma_{x}(y)}{\varepsilon_{N}}\right)\left\{P_{(2)}\left[V_{x}^{N-1} R_{ \pm}^{\Omega}(2 N, x)\right]\right\}+ \\
& +\underbrace{\sum_{k=N}^{\infty}\left\{\sigma\left(\frac{\Gamma_{x}(y)}{\varepsilon_{k}}\right)+\sigma\left(\frac{\Gamma_{x}(y)}{\varepsilon_{k+1}}\right)\right\}\left\{\left[P_{(2)} V_{x}^{k}(y)\right] R_{ \pm}^{\Omega}(2+2 k, x)(y)\right\}}_{\Sigma_{4}}
\end{aligned}
$$

and

$$
\begin{aligned}
P_{(2)} \mathscr{R}_{ \pm}^{\sigma}(x)-\delta_{x} & =\Sigma_{1}+\Sigma_{2}+\Sigma_{4}+ \\
& +\left[1-\sigma\left(\frac{\Gamma_{x}(y)}{\varepsilon_{N}}\right)\right] \times \underbrace{\left\{\left[P_{(2)} V_{x}^{N-1}(y)\right] R_{ \pm}^{\Omega}(2 N, x)(y)\right\}} \\
& =\left\{\begin{array}{l}
C(2 N, n)\left[P_{(2)} V_{x}^{N-1}(y)\right] \Gamma_{x}(y)^{N-n / 2} \\
\text { or } 0, \text { according to lemma } 14
\end{array}\right.
\end{aligned}
$$

Finally, since $\sigma \circ \Gamma$ is smooth, the gradients, d'Alembert operators and the difference $\sigma\left(\Gamma / \varepsilon_{k}\right)-\sigma\left(\Gamma / \varepsilon_{k+1}\right)$ are all smooth sections, and the last would be the proof that both $\Sigma_{1}, \Sigma_{2}$ and $\Sigma_{4}$ converge w.r.t. the distribution norms defined previously. Due to its pure computational character, we opted for not to present the rest of the demonstration, which may be found in [10], chapter 2, lemma 2.4.3.

The smooth errors $K_{ \pm}$obtained when truncating the series $\widetilde{\mathscr{R}}_{ \pm}(x)$ give rise to a distribution

$$
\begin{aligned}
\mathscr{K}_{ \pm}: \overline{\Omega^{\prime}} & \longrightarrow\left\{C^{0}\left(\overline{\Omega^{\prime}}, \mathrm{E}^{*}\right) \rightarrow \mathrm{E}^{*}\right\} \\
{\left[\mathscr{K}_{ \pm}(x)\right](\varphi) } & :=\int_{\overline{\Omega^{\prime}}} K_{ \pm}(x, y) \varphi(y) d V
\end{aligned}
$$

or, equivalently, to an operator

$$
\begin{gathered}
\mathscr{K}_{ \pm}: C^{0}\left(\overline{\Omega^{\prime}}, \mathrm{E}^{*}\right) \longrightarrow C^{\infty}\left(\overline{\Omega^{\prime}}, \mathrm{E}^{*}\right) \\
{\left[\mathscr{K}_{ \pm}(\varphi)\right](\cdot):=\int_{\overline{\Omega^{\prime}}} K_{ \pm}(\cdot, y) \varphi(y) d V}
\end{gathered}
$$

from which it is possible to construct the mentioned true fundamental solutions.

Lemma 16. The operator $\mathscr{K}_{ \pm}$is bounded and, for each $k \in \mathbb{N}, C^{k}\left(\overline{\Omega^{\prime}}, \mathrm{E}\right)$ in the sense that if $u \in C^{k}\left(\overline{\Omega^{\prime}}, \mathrm{E}\right)$ then so is $\mathscr{K}_{ \pm} u$. The support of $\mathscr{K}_{ \pm}$is such that

$$
\operatorname{supp}\left(\mathscr{K}_{ \pm} \varphi\right) \subset J_{\mp}^{\overline{\Omega^{\prime}}}(\operatorname{supp} \varphi) .
$$


Proof. For a $k \in \mathbb{N}$ and $\varphi \in C^{0}\left(\overline{\Omega^{\prime}}, \mathrm{E}^{*}\right)$,

$$
\begin{aligned}
\left\|\mathscr{K}_{ \pm} \varphi\right\|_{C^{k}\left(\overline{\Omega^{\prime}}\right)} & =\left\|\int_{\overline{\Omega^{\prime}}} K_{ \pm}(\cdot, y) \varphi(y) d V\right\|_{C^{k}\left(\overline{\Omega^{\prime}}\right)} \\
& \leq \int_{\overline{\Omega^{\prime}}}\left\|K_{ \pm}(\cdot, y) \varphi(y)\right\|_{C^{k}\left(\overline{\Omega^{\prime}}\right)} d V \\
& \leq \underbrace{\int_{\overline{\Omega^{\prime}}}\left\|K_{ \pm}(\cdot, y)\right\|_{C^{k}\left(\overline{\Omega^{\prime}}\right)} d V}_{=: C_{k}} \cdot\|\varphi\|_{C^{0}\left(\overline{\Omega^{\prime}}\right)} \\
& =C_{k} \cdot\|\varphi\|_{C^{0}\left(\overline{\Omega^{\prime}}\right)} .
\end{aligned}
$$

Besides that, suppose $x \in \overline{\Omega^{\prime}}$ such that $K_{ \pm}(x, y) \varphi(y)=0$; then either $\varphi(y)=0$ or $K_{ \pm}(x, y)=0$ (or both), that is, $P_{(2)} \mathscr{R}_{ \pm}^{\sigma}(x)-\delta_{x}=0$. Since supp $\mathscr{R}_{ \pm}^{\sigma}(x) \subset J_{ \pm}^{\bar{\Omega}^{\prime}}(x)$, we have supp $K_{ \pm}(x, y) \subset J_{ \pm}^{\overline{\Omega^{\prime}}}(x)$ and therefore the integrand is not null if $y \in J_{ \pm}^{\overline{\Omega^{\prime}}}(x) \cap$ $\operatorname{supp} \varphi$. This is equivalent to $\operatorname{supp} \mathscr{K}_{ \pm} \subset J_{ \pm}^{\overline{\Omega^{\prime}}}(\operatorname{supp} \varphi)$.

Note that as the $C^{k}$-norms were defined they have not to be defined for $k=\infty$, so the statement $\mathscr{K}_{ \pm}: C^{0}\left(\overline{\Omega^{\prime}}, \mathrm{E}^{*}\right) \longrightarrow C^{\infty}\left(\overline{\Omega^{\prime}}, \mathrm{E}^{*}\right)$ makes sense as $\mathscr{K}_{ \pm}: C^{0}\left(\overline{\Omega^{\prime}}, \mathrm{E}^{*}\right) \longrightarrow$ $C^{k}\left(\overline{\Omega^{\prime}}, \mathrm{E}^{*}\right)$ for each $k \in \mathbb{N}$.

Now, for a given bounded operator $O$ in a Banach space, $\mathbb{1}+O$ is invertible iff $\|O\|<1$. That is the main idea beneath the following lemma.

Lemma 17. Let $\Omega^{\prime} \subset \subset \Omega$ be a relatively compact causal domain and assume $\operatorname{vol}\left(\overline{\Omega^{\prime}}\right)\left\|K_{ \pm}\right\|_{C^{0}}<$ 1. Then, for each $k \in \mathbb{N}$, the operator $\mathbb{1}+\mathscr{K}_{ \pm}: C^{k}\left(\overline{\Omega^{\prime}}, \mathrm{E}^{*}\right) \longrightarrow C^{k}\left(\overline{\Omega^{\prime}}, \mathrm{E}^{*}\right)$ is an isomorphism whose inverse is bounded and given by the Neumann series

$$
\left(\mathbb{1}+\mathscr{K}_{ \pm}\right)^{-1}=\sum_{j=0}^{\infty}(-1)^{j} \mathscr{K}_{ \pm}^{j},
$$

which converges in all k-norms. Furthermore,

$$
\operatorname{supp}\left(\mathbb{1}+\mathscr{K}_{ \pm}(x)\right)^{-1} \mathscr{R}_{ \pm}^{\sigma}(x) \subset J_{\mp}^{\overline{\Omega^{\prime}}} \operatorname{supp} \mathscr{R}_{ \pm}^{\sigma}(x) .
$$

Proof. The operator $\mathscr{K}_{ \pm}: C^{0}\left(\overline{\Omega^{\prime}}, \mathrm{E}^{*}\right) \longrightarrow C^{k}\left(\overline{\Omega^{\prime}}, \mathrm{E}^{*}\right)$ is bounded w.r.t. each $C^{k}$-norm, so $\mathbb{1}+\mathscr{K}_{ \pm}: C^{k}\left(\overline{\Omega^{\prime}}, \mathrm{E}^{*}\right) \longrightarrow C^{k}\left(\overline{\Omega^{\prime}}, \mathrm{E}^{*}\right)$ is also bounded for each $k$. Suppose $k=0$, and so

$$
\begin{aligned}
\left\|\mathscr{K}_{ \pm} \varphi\right\|_{C^{0}\left(\overline{\Omega^{\prime}}\right)} & \leq \operatorname{vol}\left(\overline{\Omega^{\prime}}\right)\left\|K_{ \pm}\right\|_{C^{0}\left(\overline{\Omega^{\prime}}\right)}\|\varphi\|_{C^{0}\left(\overline{\Omega^{\prime}}\right)} \\
& =(1-\eta)\|\varphi\|_{C^{0}\left(\overline{\Omega^{\prime}}\right)}
\end{aligned}
$$

where $\eta:=1-\operatorname{vol}\left(\overline{\Omega^{\prime}}\right)\left\|K_{ \pm}\right\|_{C^{0}\left(\overline{\Omega^{\prime}}\right)}$ is positive due to the assumption of the lemma. This means that $\left\|\mathscr{K}_{ \pm} \varphi\right\|_{C^{0}\left(\overline{\Omega^{\prime}}\right)}<1$ and so the Neumann series $\sum_{j=0}^{\infty}(-1)^{j} \mathscr{K}_{ \pm}^{j}$ converges w.r.t. the $C^{0}$-norm to $\left(\mathbb{1}+\mathscr{K}_{ \pm}(x)\right)^{-1}$. For $k \neq 0$, consider the norm 


$$
\|\varphi\|_{2}:=\|\varphi\|_{C^{0}}+\frac{\eta}{2 \operatorname{vol}\left(\overline{\Omega^{\prime}}\right)\left\|K_{ \pm}\right\|_{C^{k}}}\|\varphi\|_{C^{0}} .
$$

Evaluating $\mathscr{K}_{ \pm}$with respect to $\|\cdot\|_{2}$ yields

$$
\begin{aligned}
\left\|\mathscr{K}_{ \pm} \varphi\right\|_{2} & =\left\|\mathscr{K}_{ \pm} \varphi\right\|_{C^{0}}+\frac{\eta}{2 \operatorname{vol}\left(\overline{\Omega^{\prime}}\right)\left\|K_{ \pm}\right\|_{C^{k}}}\left\|\mathscr{K}_{ \pm} \varphi\right\|_{C^{0}} \\
& \leq(1-\eta)\|\varphi\|_{C^{0}\left(\overline{\Omega^{\prime}}\right)}+\frac{\eta}{2 \operatorname{vol}\left(\overline{\Omega^{\prime}}\right)\left\|K_{ \pm}\right\|_{C^{k}}}(1-\eta)\|\varphi\|_{C^{0}} \\
& =(1-\eta)\|\varphi\|_{C^{0}\left(\overline{\Omega^{\prime}}\right)}+\frac{\eta}{2 \operatorname{vol}\left(\overline{\Omega^{\prime}}\right)\left\|K_{ \pm}\right\|_{C^{k}}} \operatorname{vol}\left(\overline{\Omega^{\prime}}\right)\left\|K_{ \pm}\right\|_{C^{k}}\|\varphi\|_{C^{0}} \\
& =\left(1-\frac{\eta}{2}\right)\|\varphi\|_{C^{0}} \leq\left(1-\frac{\eta}{2}\right)\|\varphi\|_{2},
\end{aligned}
$$

which means that with respect to $\|\cdot\|_{2}$, for each $k \in \mathbb{N}, \mathscr{K}_{ \pm}$has norm less than one, and the Neumann series converges.

Regarding the support of the operator, let $\varphi$ be as usual, and we write

$$
\left(\mathbb{1}+\mathscr{K}_{ \pm}\right)^{-1} \varphi=\varphi-\left(\mathbb{1}+\mathscr{K}_{ \pm}\right)^{-1} \mathscr{K}_{ \pm} \varphi
$$

which may be checked if one multiplies both sides by $\left(\mathbb{1}+\mathscr{K}_{ \pm}\right)$. It is then a direct consequence of this equality together with supp $\varphi \subset J_{ \pm}^{\overline{\Omega^{\prime}}}(\operatorname{supp} \varphi)$ that

$$
\begin{aligned}
\operatorname{supp} \varphi & =\operatorname{supp}\left\{\left(\mathbb{1}+\mathscr{K}_{ \pm}\right)^{-1} \varphi+\left(\mathbb{1}+\mathscr{K}_{ \pm}\right)^{-1} \mathscr{K}_{ \pm} \varphi\right\} \\
& \Rightarrow \operatorname{supp}\left\{\left(\mathbb{1}+\mathscr{K}_{ \pm}\right)^{-1} \mathscr{K}_{ \pm} \varphi\right\} \subset J_{ \pm}^{\overline{\Omega^{\prime}}}(\operatorname{supp} \varphi)
\end{aligned}
$$

It provides us with the definition of the distribution

$$
\left[F_{ \pm}^{\Omega^{\prime}}(\varphi)\right](x):=\left(\mathbb{1}+\mathscr{K}_{ \pm}\right)^{-1} \mathscr{R}_{ \pm}^{\sigma}(x)
$$

which we shall call the advanced true fundamental solution, $F_{+}^{\Omega^{\prime}}(x)$, and $F_{-}^{\Omega^{\prime}}(x)$ the retarded true fundamental solution around $x \in \Omega^{\prime}$, once we have proved the coherence of this nomenclature and their following properties.

Lemma 18. Each point $x$ of the Lorentzian manifold $M$ has an arbitrarily small causal neighbourhood $\Omega^{\prime}$ whose elements posses both the advanced and the retarded fundamental solutions $F_{ \pm}^{\Omega^{\prime}}(x)$ for $P$, satisfying

(i) $\operatorname{supp} F_{ \pm}^{\Omega^{\prime}}(x) \subset J_{ \pm}^{\Omega}(x)$ for all $x$;

(ii) the map $x \longmapsto F_{ \pm}^{\Omega^{\prime}}(x)(\varphi)$ for each fixed $\varphi$ is a smooth section in $\mathrm{E}^{*}$. 
Proof. A fundamental solution can be obtained now by defining

$$
x \longmapsto\left[F_{ \pm}^{\Omega^{\prime}}(x)\right](\varphi):=\left(\mathbb{1}+\mathscr{K}_{ \pm}\right)^{-1}\left[\mathscr{R}_{ \pm}^{\sigma}(x)(\varphi)\right] .
$$

We first have to show that $F_{ \pm}^{\Omega^{\prime}}$ indeed define distributions. Therefore, suppose a sequence $\varphi_{n} \longrightarrow \varphi$ in $\mathscr{D}\left(\Omega^{\prime}, \mathrm{E}^{*}\right)$; according to the previous lemma $\left(\mathbb{1}+\mathscr{K}_{ \pm}\right)^{-1}$ is continuous, ans since $\mathscr{R}_{ \pm}^{\sigma}(x)$ is a distribution, we have $\left(\mathbb{1}+\mathscr{K}_{ \pm}\right)^{-1}\left[\mathscr{R}_{ \pm}^{\sigma}(x)\left(\varphi_{n}\right)\right] \longrightarrow$ $\left(\mathbb{1}+\mathscr{K}_{ \pm}\right)^{-1}\left[\mathscr{R}_{ \pm}^{\sigma}(x)(\varphi)\right]=F_{ \pm}^{\Omega^{\prime}}(x)(\varphi)$. The statement that $F_{ \pm}^{\Omega^{\prime}}(x)$ provides a fundamental solution is now completely justified by

$$
\begin{aligned}
{\left[P F_{ \pm}^{\Omega^{\prime}}(x)\right](\varphi) } & =\left[F_{ \pm}^{\Omega^{\prime}}(x)\right]\left(P^{*} \varphi\right) \\
& =\left(\mathbb{1}+\mathscr{K}_{ \pm}(x)\right)^{-1}\left[\mathscr{R}_{ \pm}^{\sigma}(x)\left(P^{*} \varphi\right)\right] \\
& =\left(\mathbb{1}+\mathscr{K}_{ \pm}(x)\right)^{-1}\left[P \mathscr{R}_{ \pm}^{\sigma}(x)(\varphi)\right] \\
& =\left(\mathbb{1}+\mathscr{K}_{ \pm}(x)\right)^{-1}\left[\left(\delta_{x}+K_{ \pm}(x)\right)(\varphi)\right] \\
& =\left(\mathbb{1}+\mathscr{K}_{ \pm}(x)\right)^{-1}\left[\left(\mathbb{1}+\mathscr{K}_{ \pm}(x)\right)(\varphi)\right] \\
& =\varphi(x) \\
\Rightarrow P F_{ \pm}^{\Omega^{\prime}}(x) & =\delta_{x}
\end{aligned}
$$

For item (i), let $x \in \Omega^{\prime}$ and consider $\varphi \in \mathscr{D}\left(\Omega^{\prime}, \mathrm{E}^{*}\right)$ with supp $\varphi \cap J_{ \pm}^{\Omega^{\prime}}(x)=\emptyset$; therefore $x \notin J_{ \pm}^{\Omega^{\prime}}(\operatorname{supp} \varphi) \Rightarrow x \notin \operatorname{supp} F_{ \pm}^{\Omega^{\prime}}$. Finally, item (ii) follows from $\mathbb{1}+\mathscr{K}_{ \pm}(x)$ defining an isomorphism between sections and from the character or $\mathscr{R}_{ \pm}^{\sigma}(x)$.

The relation between the fundamental solution $F_{ \pm}^{\Omega^{\prime}}(x)$ defined in (3.19) and the formal series $\widetilde{\mathscr{R}}_{ \pm}(x)$ in (3.12) in terms of how good this cutoff approximation might be now follows.

Theorem 11. Suppose the formal solution $\widetilde{\mathscr{R}}_{ \pm}(x)$ is truncated at the $(N+k)$ th term for some $k \in \mathbb{N}$, where $N$ is the constant adopted by the beginning of this section. Then, there is a constant $C=C(k)$ such that

$$
\left\|\left(F_{ \pm}^{\Omega^{\prime}}(x)-\mathscr{R}_{ \pm}^{\sigma}(x)\right)(y)\right\| \leq C(k)\left|\Gamma_{x}(y)\right|^{k}
$$

for each pair $(x, y) \in \bar{\Omega} \times \bar{\Omega}$.

Proof. The demonstration of this theorem demands two auxiliary lemmas presented in [10], lemmas 2.5.3 and 2.5.4. We shall combine them in a single statement, which shall not be proved here.

Statement: Let $f: \mathbb{R}^{n} \longrightarrow \mathbb{R}$ be $C^{3 k+1}$ for some $k \in \mathbb{N}$. If $f(v)=0$ for all space-like $v \in \mathbb{R}^{n}$, then there exists $h: \mathbb{R}^{n} \longrightarrow \mathbb{R}$ such that $f=h \cdot \gamma^{k}$. 
Letting $R_{ \pm}^{N+k}(x)$ represent the formal solution truncated at the $(N+k)$ th term

$$
\begin{aligned}
& {\left[F_{ \pm}^{\Omega^{\prime}}(x)-R_{ \pm}^{N+k}(x)\right](y)=} \\
& =\left[F_{ \pm}^{\Omega^{\prime}}(x)-R_{ \pm}^{N+3 k+1}(x)\right]+\sum_{j=N+k}^{N+3 k} V_{x}^{k}(y) R_{ \pm}^{\Omega}(\alpha+2, x)(y) \\
& =\left[F_{ \pm}^{\Omega^{\prime}}(x)-R_{ \pm}^{N+3 k+1}(x)\right]+\sum_{j=N+k}^{N+3 k} \Gamma_{x}^{k}(y) \underbrace{V_{x}^{k}(y) C_{j} R_{ \pm}^{\Omega^{\prime}}(2+2(j-k), x)(y)}_{=: h_{j}(x, y)}
\end{aligned}
$$

is obtained by applying repeatedly the relation ${ }^{3}$

$$
\Gamma_{x} R_{ \pm}^{\Omega}(\alpha, x)=C_{j}(\alpha, n) R_{ \pm}^{\Omega}(\alpha+2, x) .
$$

Since $2+2(j-k) \geq 2+2(N+\not k-\not k) \geq 2+2 n \geq n, h_{j}$ is continuous. Assume $\left[F_{ \pm}^{\Omega^{\prime}}(x)-\right.$ $\left.R_{ \pm}^{N+3 k+1}(x)\right](y)$ is $C^{3 k+1}$. Since supp $\left(F_{ \pm}^{\Omega^{\prime}}(x)-R_{ \pm}^{N+3 k+1}(x)\right) \subset J_{ \pm}^{\Omega^{\prime}}$, according to the statement above, there exists $h$ such that

$$
\left[F_{ \pm}^{\Omega^{\prime}}(x)-R_{ \pm}^{N+3 k+1}(x)\right](y)=\Gamma_{x}^{k}(y) h(x, y)
$$

Then,

$$
\left[F_{ \pm}^{\Omega^{\prime}}(x)-R_{ \pm}^{N+3 k+1}(x)\right](y)=\left[h(x, y)+\sum_{j=N+k}^{N+3 k} h_{j}(x, y)\right] \Gamma_{x}(y)^{k}
$$

and taking $C_{k}$ to be the norm of the right-hand side term in brackets completes the proof.

It is still remaining to show that $(x, y) \longmapsto\left[F_{ \pm}^{\Omega^{\prime}}(x)-R_{ \pm}^{N+k}(x)\right](y)$ is $C^{k}\left(\Omega^{\prime} \times \Omega^{\prime}, \mathrm{E}^{*}\right)$. We have

$$
\begin{aligned}
& {\left[\mathscr{R}_{ \pm}^{\sigma}(x)-\mathscr{R}_{ \pm}^{N+k}(x)\right](y)=} \\
& =-\sum_{j=N}^{N+k-1}\left(V_{x}^{k} R_{ \pm}^{\Omega}(\alpha+2, x)\right)+\sum_{j=N}^{N+k-1} \sigma\left(\frac{\Gamma_{x}(y)}{\varepsilon_{j}}\right) V_{x}^{k}(y) R_{ \pm}^{\Omega}(\alpha+2, x)+ \\
& +\sum_{j=N+k}^{\infty} \sigma\left(\frac{\Gamma_{x}(y)}{\varepsilon_{j}}\right) V_{x}^{k}(y) R_{ \pm}^{\Omega}(\alpha+2, x) .
\end{aligned}
$$

According to the already invoked fact that the last term in the right-hand-side, the infinite sum, is $C^{k},\left[\mathscr{R}_{ \pm}^{\sigma}(x)-\mathscr{R}_{ \pm}^{N+k}(x)\right](y)$ is $C^{k}$ since the finite sums is smooth -

\footnotetext{
${ }^{3}$ This equation has already been used in this text; it is proved in [10], proposition 1.4.2 item 3 .
} 
that because $\left(\sigma\left(\Gamma_{x}(y) / \varepsilon_{j}\right)-1\right)$ vanishes on a neighbourhood of $\Gamma^{-1}(0)$ where $R_{ \pm}^{\Omega^{\prime}}(2=$ $2 j, x)(y)$ is not smooth.

It is also possible to prove that $\left[F_{ \pm}^{\Omega^{\prime}}(x)-\mathscr{R}_{ \pm}^{\sigma}(x)\right](y)$ is $C^{k}$, and the proof of the theorem will be completed from

$$
\left[F_{ \pm}^{\Omega^{\prime}}(x)-\mathscr{R}_{ \pm}^{N+k}(x)\right](y)=\left[F_{ \pm}^{\Omega^{\prime}}(x)-\mathscr{R}_{ \pm}^{\sigma}(x)+\mathscr{R}_{ \pm}^{\sigma}(x)-\mathscr{R}_{ \pm}^{N+k}(x)\right](y) .
$$

Motivated by $F_{ \pm}^{\Omega^{\prime}}(x)-\mathscr{R}_{ \pm}^{\sigma}(x)=\left[\left(\mathbb{1}+\mathscr{K}_{ \pm}\right)^{-1}-\mathbb{1}\right] \mathscr{R}_{ \pm}^{\sigma}(x)$, this is done by showing that the operator $-\left(\mathbb{1}+\mathscr{K}_{ \pm}\right)^{-1} \circ \mathscr{K}_{ \pm}$has an integral kernel, and then splitting the difference between the fundamental solution $F$ and the formal solution with cut-off in three: a sum for $0 \leq j \leq N-1$, a second for $N \leq j \leq N+k-1$ and a third one for $N+k \leq j \leq \infty$, all of them involving this integral kernel of the operator. The last step would then be to prove that each one of this terms defines a $C^{k}$-section - the details may be found in [10], mainly in theorem 2.5.1.

\subsection{Non-homogeneous wave equations}

The analysis of equations of the form $P u=f$ proves to be quite important to the process of globalization of the formalism just presented, as it may be seen in the next section. We shall explore this topic quite superficially.

Let $\varphi \in \mathscr{D}\left(\mathrm{M}, \mathrm{E}^{*}\right), f \in \mathscr{D}(\mathrm{M}, \mathrm{E})$ and let $F_{ \pm}^{\Omega}(x)$ be the fundamental solution for $P$ in some appropriate $\Omega$ around $x$. Then, let $\cdot$ denote the natural pairing in $\mathrm{E}_{x}^{*} \otimes \mathrm{E}_{x}$, and set

$$
u_{ \pm}(\varphi):=\int_{\Omega} F_{ \pm}^{\Omega}(x)(\varphi) \cdot f(x) d V .
$$

Since $F_{ \pm}^{\Omega}(\cdot)(\varphi)$ is sequentially continuous, then so is $u_{ \pm}$, so the expression above does defines a distribution. We may state about it the following.

Lemma 19. Each point in $M$ possesses a relatively compact causal neighbourhood $\Omega$ such that for all $f \in \mathscr{D}(\Omega, \mathrm{E})$ there is $u_{ \pm}$like above such that

(i) $P u_{ \pm}=f$;

(ii) supp $u_{ \pm} \subset J_{ \pm}^{\Omega}(\operatorname{supp} f)$;

(iii) $u_{ \pm} \in C^{\infty}(\Omega, \mathrm{E})$.

Proof. (i) Let $\varphi \in \mathscr{D}\left(\mathrm{M}, \mathrm{E}^{*}\right)$.

$$
\begin{aligned}
P u_{ \pm}(\varphi) & =u_{ \pm}\left(P^{*} \varphi\right)=\int F_{ \pm}^{\Omega}(x)\left(P^{*} \varphi\right) \cdot f(x) d V \\
& =\int P F_{ \pm}^{\Omega}(x)(\varphi) \cdot f(x) d V=\int \varphi(x) \cdot f(x) d V \\
& =f(\varphi)
\end{aligned}
$$


(ii) Assume supp $\varphi \cap J_{ \pm}^{\Omega}(\operatorname{supp} f)$, which equivalent to $J_{\mp}^{\Omega}(\operatorname{supp} \varphi) \cap \operatorname{supp} f$. Since $\operatorname{supp} F_{ \pm}^{\Omega}(\cdot)(\varphi) \subset J_{\mp}^{\Omega}(\operatorname{supp} f), \operatorname{supp} F_{ \pm}^{\Omega}(\cdot)(\varphi) \cap \operatorname{supp} f=\emptyset$, so the integrand in the definition of $u_{ \pm}$is null. Therefore, supp $u_{ \pm}$lays within $J_{ \pm}^{\Omega}(\operatorname{supp} f)$.

\subsection{Globalization}

Until now, we have developed the theory of wave propagation in Lorentzian manifolds considering only small regions of space, geodesically star-shaped neighbourhoods $\Omega$ of a certain point $x$ in terms of which we wrote the Riemannian exponential map $\exp _{x}$, used implicitly in the function $\Gamma$ - and, thus, in the Fundamental solution $F_{ \pm}^{\Omega^{\prime}}$, to connect this region of the manifold to a vector space inherited by the vector bundle structure. In the next natural attempt to follow, one could suppose that globalization would come from glueing local solutions together by using an appropriate collection of partitions of unity. However, such a construction would not make sense entirely: by picking up some point of the manifold belonging to two geodesically star-shaped neighbourhoods $N_{x}$ and $N_{y}$ of certain $x$ and $y$, it would not be clear which equation to solve and where.

Even if not that straightforward, the globalization process is possible, though quite technical still, and will be performed in this section. We hereby anticipate that, due to this technicality level, some parts will not be completely developed within this text and then will be rather indicated. We start by showing the Cauchy problem is well defined: let $P$ be a normally hyperbolic operator and let $S \subset \mathrm{M}$ be a Cauchy surface whose unit normal timelike future directed vector field we denote by $\mathfrak{n}$; we call the problem of finding a solution $u$ to the equation $P u=f$ for a given $f$ on $\mathrm{M}$ with initial conditions

$$
\begin{aligned}
u & =u_{0} \\
\nabla_{\mathfrak{n}} u & =u_{1}
\end{aligned}
$$

along $S$, for given $u_{0}, u_{1} \in \mathscr{D}(S, \mathrm{E})$, the Cauchy problem. Therefore, we first aim at establishing whether it admits a solution, beginning with the trivial case.

Lemma 20. Let $M$ be a globally hyperbolic manifold with a given vector bundle structure $\mathrm{E}$ defined on it. If $u$ is a solution for the Cauchy problem with $f=u_{o}=u_{1}=0$, then $u=0$.

The proof of this lemma, although quite simple and elegant, demands another result.

Lemma 21. Let $\nabla$ denote the connection inducing $P$ and let $\Omega$ be like in lemma 17. For each $x \in \Omega$, let $F_{ \pm}^{\Omega}$ be the exact solution to the wave equation at $x$, as before. Finally, let $u \in C^{\infty}(\Omega, \mathrm{E})$ be a solution to $P u=f$ with boundary conditions $u_{0}$ and $u_{1}$. Then, for each $\varphi \in \mathscr{D}\left(\Omega, \mathrm{E}^{*}\right)$, by denoting by $\psi$ the distribution $\omega \in \mathscr{D}(\Omega, \mathrm{E}) \longmapsto \psi_{ \pm}(\omega):=$ $\int_{\Omega} \varphi(x) F_{ \pm}^{\Omega}(x)(\omega) d V$, we have

$$
\int_{\Omega} \varphi \cdot u d V=\int_{S}\left\{\left[\nabla_{\mathfrak{n}}\left(\psi_{+}-\psi_{-}\right)\right] \cdot u-\left[\left(\psi_{+}-\psi_{-}\right) \cdot\left(\nabla_{\mathfrak{n}} u\right)\right]\right\} d S .
$$


Proof. First, we analyse

$$
\int_{I_{-}^{\Omega(S)}} \varphi \cdot u d V=\int_{I_{-}^{\Omega}(S)}\left(P^{*} \psi_{+}\right) \cdot u d V=\int_{I_{-}^{\Omega(S)}}\left(P^{*} \psi_{+}\right) \cdot u-\psi_{+} \cdot(P u) d V .
$$

Let $W \in C^{\infty}(\mathrm{M}, \mathrm{TM} \otimes \mathbb{K})$ be the vector field obeying $\langle W, X\rangle=\left(\nabla_{X} \psi\right) \cdot u-\psi \cdot\left(\nabla_{X} u\right)$ for all $X \in C^{\infty}(\mathrm{M}, \mathrm{TM})$ (see [10], lemma 3.2.1); then, by Gauss' theorem,

$$
\begin{aligned}
\int_{I_{-}^{\Omega(S)}}\left(P^{*} \psi\right) \cdot u-\psi \cdot(P u) d V & =-\int_{I_{-}^{\Omega}(S)} \operatorname{div} W d V=\int_{I_{-}^{\Omega}(S)}\langle W, \mathfrak{n}\rangle d S \\
& =\int_{I_{-}^{\Omega(S)}} \nabla_{\mathfrak{n}} \psi_{+} \cdot u-\psi_{+} \cdot \nabla_{n} u d V
\end{aligned}
$$

and so

$$
\int_{I_{-}^{\Omega(S)}} \varphi \cdot u d V=\int_{I_{-}^{\Omega}(S)} \nabla_{\mathfrak{n}} \psi_{+} \cdot u-\psi_{+} \cdot \nabla_{n} u d V
$$

The demonstration is then completed by repeating the calculations for $\psi_{-}$, with the integral being evaluated in $I_{-}^{\Omega}$ and summing the two expressions.

Corollary. supp $u \subset J^{\Omega}\left(\right.$ supp $\left.u_{0} \cup \operatorname{supp} u_{1}\right)$.

Proof. Let $\varphi \in \mathscr{D}\left(\Omega, \mathrm{E}^{*}\right)$, and thus supp $F_{ \pm}^{\Omega}(\varphi) \subset J_{ \pm}^{\Omega}(\operatorname{supp} \varphi)$. Suppose $u$ is such that $\operatorname{supp} u_{j} \cap J_{ \pm}^{\Omega}(\operatorname{supp} \varphi)=\emptyset$ for $j=0,1$, which is the same as $J_{ \pm}^{\Omega}\left(\operatorname{supp} u_{j}\right) \cap \operatorname{supp} \varphi=\emptyset$. Then, by the statement of the lemma $\int_{\Omega} \varphi \cdot u d V=0$, and the distribution $u$ is null whenever the support of the test function is disjoint of $J^{\Omega}\left(\operatorname{supp} u_{0} \cup \operatorname{supp} u_{1}\right)$.

This is all we need to prove lemma 20 .

Proof. (Of lemma 20) Since M is globally hyperbolic, it admits a foliation by Cauchy surfaces $\mathbb{R} \times S,(t, S) \equiv S_{t}$ a Cauchy surface and $S_{0} \equiv S$. Let $p$ be a point in M, let $\tau \in \mathbb{R}$ be such that $p \in S_{\tau}$, and suppose w.l.g. $\tau>0$; we shall prove $u(p)=0$ by proving $u=0$ in each Cauchy surface $J_{-}^{M}(p) \cap S_{t}$ for $t \in[0, \tau]$.

We define

$$
t_{0}:=\sup \left\{t \in[0, \tau]:\left.u\right|_{J_{-}^{\mathrm{M}}(p) \cap S_{t}}=0\right\}
$$

which makes sense due to the boundary conditions established in the hypothesis of the lemma - i.e., $t_{0}$ is at least 0 . Assume $t_{0}<\tau$ (otherwise the thesis follows). Set $u_{0}:=\left.u\right|_{S_{t_{0}}}$ and $u_{1}:=\left.\nabla_{\mathfrak{n}} u\right|_{S_{t_{0}}}$. If $t_{0}=0$, then $u_{0}=u_{1}=0$ by hypothesis. If $t_{0}>0, u_{0}=u_{1}=0$ in $J_{-}^{M}(p) \cup S_{t_{0}}$ still since $u=0$ on $J_{-}^{\mathrm{M}}(p) \cap S_{t} \forall t \in\left[0, t_{0}\right]$.

Pick $x \in J_{-}^{M}(p) \cup S_{t_{0}}$, and so $x$ has a relatively compact causal neighbourhood $\Omega$ satisfying lemma 17 and such that $J_{-}^{M}(p) \cap S_{t_{0}}$ is a Cauchy surface w.r.t. $\Omega$. The 
fact that the sections $u_{0}$ and $u_{1}$ are null in $J_{-}^{M}(p) \cap S_{t}$ for all $t \in\left[0, t_{0}\right]$ implies in particular that $u$ is null in $J_{-}^{M}(p) \cap J_{+}^{\Omega}\left(S_{t_{0}} \cap \Omega\right)$, due to the previous corollary. As the set $J_{-}^{\mathrm{M}}(p) \cap S_{t_{0}}$ is compact, it may be covered by a finite family $\left\{\Omega_{j}\right\}_{j=1, \cdots, N}$, and $u=0$ on $\left(\Omega_{1} \cup \cdots \cup \Omega_{N}\right) \cap J_{-}^{\mathrm{M}}(p) \cap J_{+}^{M}\left(S_{t_{0}}\right)$. But $\left(\Omega_{1} \cup \cdots \cup \Omega_{N}\right) \cap J_{+}^{M}\left(S_{t_{0}}\right)$ is an open set, so there is $\varepsilon>0$ such that $S_{t} \in\left(\Omega_{1} \cup \cdots \cup \Omega_{N}\right) \cap J_{+}^{M}\left(S_{t_{0}}\right)$ for all $t \in\left[t_{0}, t_{0}+\varepsilon\right)$, and so $u=0$ in $S_{t}$, contradicting the fact that $t_{0}$ is maximal, so we may conclude $t_{0}=\tau$.

Lemma 22. Let $\Omega \subset \mathrm{M}$ be an appropriate subset of $M$ like in lemma 17. Then, for each $f \in \mathscr{D}(\Omega, \mathrm{E})$ and for each pair $u_{0}, u_{1} \in \mathscr{D}(S \cap \Omega, \mathrm{E})$ of boundary conditions there is a unique solution $u \in C^{\infty}(\Omega, \mathrm{E})$ to the local Cauchy problem in $\Omega$. Furthermore,

$$
\text { supp } u \subset J^{M}(\underbrace{\operatorname{supp} u_{0} \cup \operatorname{supp} u_{1} \cup \operatorname{supp} f}_{=: K}) .
$$

Proof. Uniqueness follows from lemma 20. Since $\mathrm{M}$ is globally hyperbolic, consider its usual foliation and its induced metric $-\beta d t^{2}+g^{\prime}$. Let $u_{0}, u_{1} \in \mathscr{D}(S \cap \Omega, \mathrm{E})$ and $f \in C^{\infty}(\Omega, \mathrm{E})$. We consider the bundle E trivialized over $\Omega$ and therefore its sections are to be understood as $\mathbb{K}^{n}$ valued, with $n$ the rank of E. Write

$$
P=\frac{1}{\beta} \frac{\partial^{2}}{\partial t^{2}}+Y
$$

where $Y$ is a differential operator of order at most one with respect to $t$. Suppose the differential equation $P u=f$ admits a power series solution

$$
u(t, x)=\sum_{j=0}^{\infty} t^{j} u_{j}(x)
$$

for some set of smooth sections $\left\{u_{j}\right\}_{j}$, with $u_{0}$ and $u_{1}$ the sections given above. Putting those two assumptions together entails

$$
\begin{aligned}
P u & =\left(\frac{1}{\beta} \frac{\partial^{2}}{\partial t^{2}}+Y\right) \sum_{j=0} t^{j} u_{j}(x)=\frac{1}{\beta} \sum_{j=2} j(j-1) t^{j-2} u_{j}(x)+Y u \\
& =\frac{2}{\beta} u_{2}+\frac{1}{\beta} \sum_{j=3} j(j-1) t^{j-2} u_{j}(x)+Y u
\end{aligned}
$$

and, thus, for $t=0$,

$$
P u(0, x)=\frac{2}{\beta} u_{2}(x)+Y\left(u_{0}+t u_{1}\right)(0, x)=f
$$

due to the order of $Y$. We may as well differentiate the expression $P u=f$ w.r.t. $t$ to obtain 


$$
\begin{aligned}
\frac{\partial f}{\partial t} & =\frac{1}{\beta} \sum_{j=3} j(j-1)(j-2) t^{j-3} u_{j}-\frac{1}{\beta^{2}} \frac{\partial \beta}{\partial t} \sum_{j=2} j(j-1) t^{j-2} u_{j}(x)+ \\
& +\left(\frac{\partial}{\partial t} \circ Y\right)\left(t u_{1}+t^{2} u_{2}\right)
\end{aligned}
$$

so we may conclude that each term $u_{j}$ is recursively determined by the $j-1$ previous terms and by $f$ up to its $(j-1)$ times derivative.

Now, drop the assumption of a power series solution, but keep the recursive relation obtained. Since there is no reason why a series of those terms should converge, hence defining a smooth section, we shall make use of some cut-off to obtain a meaningful power series. Let $\sigma: \mathbb{R} \longrightarrow \mathbb{R}$ be a bump function such that $\sigma \equiv 1$ in $\left[-\frac{1}{2}, \frac{1}{2}\right]$ and $\sigma \equiv 0$ in outside $[-1,1]$, and let $\left\{\varepsilon_{j}\right\}_{j}$ be a sequence of real numbers such that $0<\varepsilon<1 \forall j$. Then, for each $k$ and for each $j>k$ it is possible to prove the existence of a constant $c_{1}=c_{1}(k)$ such that

$$
\left\|\sigma\left(t / \varepsilon_{j}\right) t^{j} u_{j}(x)\right\|_{C^{k}(\Omega)} \leq c_{1}(k)\left\|\sigma\left(t / \varepsilon_{j}\right) t^{j}\right\|_{C^{k}(\mathbb{R})}\left\|u_{j}\right\|_{C^{k}(S)}
$$

due to the previous lemma 14 (see [10], lemma 1.1.11 for details). Furthermore, also due to lemma 14 , for $l<k$ we have a $c_{2}=c_{2}(l, j)$ such that

$$
\left\|\frac{\mathrm{d}^{l} \sigma}{\mathrm{d} x^{l}}\right\|_{\mathscr{F}(\mathbb{R})} \leq \varepsilon_{j} c_{2}\|\sigma\|_{C^{l}(\mathbb{R})}
$$

which implies

$$
\left\|\sigma\left(t / \varepsilon_{j}\right) t^{j} u_{j}(x)\right\|_{C^{k}(\Omega)} \leq \varepsilon_{j} c(k, j)\|\sigma\|_{C^{k}(\mathbb{R})}\left\|u_{j}\right\|_{C^{k}(S)} .
$$

We may now choose $\varepsilon_{j}$ such that the right hand side of last inequality is less or equal to $2^{-j}$ for $k<j$. This is enough for

$$
\hat{u}(t, x):=\sum_{j=0}^{\infty} \sigma\left(\frac{t}{\varepsilon_{j}}\right) t^{j} u_{j}(x)
$$

to be a smooth section with compact support, which, by construction, lays within $J^{M}(K)$. Define now

$$
v(t, x):=\left\{\begin{array}{l}
(P \hat{u}-f)(t, x) \quad \text { for } t \geq 0 \\
0 \text { otherwise. }
\end{array}\right.
$$

which is a smooth section, since, due to the construction of the terms $u_{j}, P \hat{u} \equiv f$ up to infinite order on $S$. We must now find a way to expand our solution to M. 
According to the analysis of inhomogeneous wave equations, we know we can solve equation $P \tilde{u}=v$ for some section $\tilde{u}$ with past compact support; besides, supp $\tilde{u} \subset$ $J_{+}^{\mathrm{M}}(\operatorname{supp} v) \subset J_{+}^{\mathrm{M}}(\operatorname{supp} \hat{u} \cup \operatorname{supp} f) \subset J^{\mathrm{M}}(K)$. It can be proved about $\tilde{u}$ that $\tilde{u}=0$ on $I_{-}^{\Omega}(S)$ - this is a consequence of the restriction of $\tilde{u}$ having past compact support and satisfying $P \tilde{u}=0$ on $I_{-}^{\Omega}(S)$; by theorem 3.3 .1 in [10], this, along with extra conditions fulfilled by a globally hyperbolic Lorentzian manifold implies that $\tilde{u}$ vanishes in $I_{-}^{\Omega}(S)$, which is a globally hyperbolic manifold for its own right. Let $u_{+}:=\hat{u}-\tilde{u}$; then all this means that $u \equiv \hat{u}$ up to infinite order on $S$. It sure is a smooth section, and obeys $P u_{+}=P \hat{u}-P \tilde{u}=v+f-v=v$ on $J_{+}^{\mathrm{M}}(S \cap \Omega)$, besides $\left.u_{+}\right|_{S}=\left.\hat{u}\right|_{S}=u_{0}$ and $\left.\nabla_{\mathfrak{n}} u_{+}\right|_{S}=\left.\nabla_{\mathfrak{n}} \hat{u}\right|_{S}=u_{1}$. Finally, we could construct $u_{-}$on $J_{-}^{\mathrm{M}}(S)$ and define $u(t, x)$ as $u_{+}(t, x)$ for $t \geq 0$ and $u_{-}(t, x)$ for $t \leq 0$, the continuity at $t=0$ following from $\hat{u}$ and $v$. Then $P u=f$ on $\mathrm{M}$ with desired initial conditions and supp $u$ lays in $J^{\mathrm{M}}(K)$.

After the statement of the trivial global Cauchy problem and the local non-trivial one, the global Cauchy problem may be formulated after the technical results above.

Lemma 23. For each compact subset $K$ of $M$ there is a $\delta>0$ such that for each $t \in \mathbb{R}$ and for each pair $u_{0}, u_{1}$ with support in $K$, there exists $u$ obeying $P u=0$ defined in the foliation $(t-\delta, t+\delta) \times S$ with boundary conditions $u_{0}, u_{1}$ in $S_{t}$. Furthermore, the support of $u$ is within $J^{M}\left(K \cap S_{t}\right)$.

We shall not prove this lemma, whose demonstration is quite technical. We refer to lemma 3.2 .10 of $[10]$.

Theorem 12. On the existence and uniqueness of solutions of the global Cauchy problem For each $f \in \mathscr{D}(\mathrm{M}, \mathrm{E})$ and for each pair of initial conditions $u_{0}, u_{1} \in$ $\mathscr{D}(S, \mathrm{E})$ there is a unique $u \in C^{\infty}(\mathrm{M}, \mathrm{E})$ such that $P u=f,\left.u\right|_{S}=u_{0}$ and $\left.\nabla_{\mathfrak{n}} u\right|_{S}=u_{1}$. Furthermore, supp $u=J^{M}(K)$, where $K$ is the set defined in lemma 22.

Proof. Uniqueness of solution follows from the trivial Cauchy problem presented in lemma 20, so we are only left with showing existence.

Once again, consider $\mathrm{M}=\mathbb{R} \times S$ and $(0, S) \equiv S$. Let $K=\operatorname{supp} u_{0} \cap \operatorname{supp} u_{1} \cap \operatorname{supp} f$ and assume there is $\Omega \subset \mathrm{M}$ with the usual properties such that $K \subset \Omega$; this hypothesis will turn out not to imply any loss of generality since we shall work with a partition of unity $\left\{\rho_{i}\right\}_{i=1, \cdots, n}$ to write $u_{j}=\sum_{i} \rho_{i} u_{j}, j=0,1$. Indeed, we shall furthermore suppose a $\varepsilon>0$ such that $((-\varepsilon, \varepsilon) \times S) \cap J^{M}(K) \subset \Omega$. Let $u$ be the solution of the local Cauchy problem in $\Omega$; whithin $(-\varepsilon, \varepsilon) \times S$, we may extend $u$ smoothly by 0 since supp $u \subset J^{M}(K)$. Let $\tau$ be the supremum of the set of $t \in \mathbb{R}$ for which $u$ may be smoothly extended to a solution in $(-\varepsilon, t) \times S$ with support in the causal development of $K$, and we shall prove $\tau=\infty$. We remark that uniqueness implies two extensions should coincide in their common domain and that in $[\varepsilon, \infty) \times S$ the equation to be solved is simply $P u=0$ since support of $f$ lays within $K$.

Assume $\tau<\infty$. We affirm that $K^{\prime}:=\{[-\varepsilon, \tau] \times S\} \cap J^{M}(K)$ is compact, and hence pick its $\delta>0$ satisfying the lemma above. Now, fix a certain $t<\tau$ such that $\tau-t<\delta$ and with $K \subset(-\varepsilon, t) \times S$. Let $v$ solve $P v=0$ on $(t-\delta, t+\delta) \times S$ with boundary conditions $u_{j}=v_{j}$. Let $\eta>0$ be such that $f$ vanishes on $(t-\eta, t+\delta) \times S$. As $u$ and $v$ 
coincide in $(t-\eta, t) \times S, v$ is a smooth extension of $u$ to $(t-\eta, t+\delta) \times S$; this, together with the fact that the support of $v$ is still contained in $J^{M}(K)$, violates the maximality of $\tau$. We conclude $\tau=\infty$. An analogous computation considering the negative part of the real line entails the theorem. The assertion about the support of $v$ is proved as follows:

$$
\begin{aligned}
\left.\operatorname{supp} v\right|_{[t, t+\delta) \times S} \subset J_{+}^{M}\left(\operatorname{supp} v_{0} \cup \operatorname{supp} v_{1}\right) \subset J_{+}^{M}\left(K^{\prime} \cap S_{t}\right) \subset J_{+}^{M}\left(J_{+}^{M}(K)\right) \\
=J_{+}^{M}(K)
\end{aligned}
$$

where $v_{j}$ is the restriction to the boundary condition $u_{j}$ to $S_{t}$.

In conclusion, if $\left\{\rho_{i}\right\}_{i=1, \cdots, m}$ is the partition of unity used, the globalization is achieved by writing $u_{j}=\sum_{i} p_{i} U_{j}, f=\sum_{i} \rho_{i} f$.

Lemma 24. The association $\left(u_{0}, u_{1}, f\right) \longmapsto u$ is linear and continuous.

Proof. See [14], section V.6 and [10], theorem 3.2.12.

Theorem 13. On the existence of global fundamental solutions. For each $x \in \mathrm{M}$ there is a unique pair of fundamental solutions $F_{ \pm}(x)$ for $P$ at $x$ satisfying supp $F_{ \pm}(x) \subset$ $J^{M}(x)$ and such that for each section $\varphi \in \mathscr{D}\left(\mathrm{M}, \mathrm{E}^{*}\right)$ the map $x \longmapsto F_{ \pm}(x)(\varphi)$ defines a smooth section of $\mathrm{E}^{*}$ solving $P^{*}\left(F_{ \pm}(x)(\varphi)\right)=\varphi(x)$.

Proof. Consider the usual foliation of M. Let $\varphi \in \mathscr{D}(\mathrm{M}, \mathrm{E})$, and let $t \in \mathbb{R}$ be chosen in order to satisfy supp $\varphi \subset I_{-}^{\mathrm{M}}\left(S_{t}\right)$. Let $\chi \in C^{\infty}(\mathrm{M}, \mathrm{E})$ obey $P^{*} \chi=\varphi$ with conditions $\left.\chi\right|_{S_{t}}=\left(\left.\nabla_{\mathfrak{n}} \chi\right|_{S_{t}}\right)=0$ - please notice that $\chi$ does depend on the choice of $\varphi$, but, for a moment, assume that it does not depend on the choice of $t$, and we shall prove it ahead. As stated above, the map $\varphi \longmapsto \chi$ is continuous; as $\chi$ is such that $P^{*} \chi=\varphi=u^{*}$ for some $u \in \mathscr{D}(\mathrm{M}, \mathrm{E})$ with $P \chi^{*}=u$ and since both $*: C^{\infty}(\mathrm{M}, \mathrm{E}) \longrightarrow C^{\infty}\left(\mathrm{M}, \mathrm{E}^{*}\right), v \longmapsto v^{*}$ and the evaluation map are continuous, so is the dual evaluation map $\mathscr{D}\left(\mathrm{M}, \mathrm{E}^{*}\right) \longrightarrow \mathrm{E}_{x}^{*}$ $\varphi \longmapsto \chi(x)$. Therefore,

$$
F_{+}(x)(\varphi):=\chi(x)
$$

defines a distribution, which we have to prove is a fundamental solution. Representing explicitly the dependence of $\chi$ on $\varphi$, from $P^{*} \chi_{P^{*} \varphi}=P^{*} \varphi$ we have $P^{*}\left(\chi_{P^{*} \varphi}-\varphi\right)=0$; that, along with the boundary conditions of the later equation being null on $S_{t}$ and the trivial Cauchy solution assures $\chi_{P^{*} \varphi}-\varphi=0$. Thereafter,

$$
\left[P F_{+}(x)\right](\varphi)=F_{+}\left(P^{*} \varphi\right)=\chi_{P^{*} \varphi}(x)=\varphi(x)=\delta_{x}(\varphi)
$$

Thus it is a fundamental solution.

We return to the assertion that $\chi_{\varphi}$ does not depend on the choice of $t$, as long as the condition on the support of $\varphi$ be maintained. Pick $\tau, t^{\prime}, t^{\prime \prime}, \tau<t<t^{\prime}$ such that supp $\varphi \subset I_{-}^{\mathrm{M}}\left(S_{\tau}\right) \subset I_{-}^{\mathrm{M}}\left(S_{t}\right) \subset I_{-}^{\mathrm{M}}\left(S_{t^{\prime}}\right)$. Consider the (globally hyperbolic) open subspace $\mathrm{M}^{\prime}:=\bigcup_{\tau<i} S_{i}$; if $\chi$ is the solution for $t$, let $\chi^{\prime}$ be the one for $t^{\prime}$. Then, $P^{*} \chi^{\prime}=0$ on $\mathrm{M}^{\prime}$ and 
the boundary conditions for $\chi$ on $S_{t}$ are zero, which implies $\chi^{\prime}=0$ on $\mathrm{M}^{\prime}$. Particularly, $P^{*} \chi^{\prime}$ has null boundary conditions on $S_{t}$ also. We conclude $\chi-\chi^{\prime}$ has vanishing Cauchy data in $S_{t}$; by definition, $P^{*}\left(\chi-\chi^{\prime}\right)=0$ on the whole M, so $\chi-\chi^{\prime} \equiv 0$.

Uniqueness now follows from corollary 3.1.2 of [10], which assures the existence of at most one global fundamental solution for any globally hyperbolic operator acting on the sections of a vector bundle $\mathrm{E}$ whose base space $\mathrm{M}$ is a Lorentzian manifold without causal closed curves, where relation $\leq$ is closed and where the time separation function is continuous ${ }^{4}$. We affirm this is the case of globally hyperbolic manifolds.

It follows from the previous assertions that supp $F_{+}(x) \subset J^{\mathrm{M}}(K)$.

\subsection{Green's operator}

The use of Green's operators provide a way to define an inverse operator for the normally hyperbolic operator $P$. Precisely, given $P$, operators $G_{ \pm}: \mathscr{D}(\mathrm{M}, \mathrm{E}) \longrightarrow C^{\infty}(\mathrm{M}, \mathrm{E})$ satisfying

(i) $P \circ G_{ \pm}=\operatorname{id}_{\mathscr{D}(\mathrm{M}, \mathrm{E})}$;

(ii) $\left.G_{ \pm} \circ P\right|_{\mathscr{D}(\mathrm{M}, \mathrm{E})}=\mathrm{id}_{\mathscr{D}(\mathrm{M}, \mathrm{E})}$;

(iii) $\operatorname{supp} G_{ \pm} \varphi \subset J_{ \pm}^{M}(\operatorname{supp} \varphi)$ for all $\varphi \in \mathscr{D}(\mathrm{M}, \mathrm{E})$

are called Green's operators. Their existence is guaranteed in the context of our interest by the following.

Lemma 25. Let $\varphi \in \mathscr{D}\left(\mathrm{M}, \mathrm{E}^{*}\right)$ and let $F_{ \pm}(\varphi)$ be fundamental solutions for $P^{*}$, smooth w.r.t. $x \in \mathrm{M}$, obeying $P F_{ \pm}(x)(\varphi)=\varphi(x)$. Under these conditions, the operators defined by

$$
\left(G_{ \pm} \varphi\right)(x):=F_{\mp}(x)(\varphi)
$$

are Green's operators for P. Furthermore, given Green's operators $G_{ \pm}$for $P, F_{ \pm}(x)(\varphi):=$ $\left(G_{ \pm} \varphi\right)(x)$ defines a fundamental solution.

Corollary. If $M$ is a globally hyperbolic Lorentzian manifold and $P$ is a normally hyperbolic operator acting on sections of $\mathrm{E} \longrightarrow \mathrm{M}$, then there is a unique pair of an advanced and a retarded Green's operator $G_{ \pm}: \mathscr{D}(\mathrm{M}, \mathrm{E}) \longrightarrow C^{\infty}(\mathrm{M}, \mathrm{E})$ for $P$.

Proof. (Of lemma 25) We prove $G_{ \pm}$as defined in lemma 25 obeys conditions (i)-(iii) of the definition above. First,

\footnotetext{
${ }^{4}$ The time separation function $\mathrm{M} \times \mathrm{M} \longrightarrow \mathbb{R} \cup\{\infty\}$ represents the maximum length that a future directed causal curve connecting two point may have. For a more precise definition, see [10], definition 1.3.14.
} 


$$
P\left(G_{ \pm} \varphi\right)(x)=P F_{\mp}(x)(\varphi)=\varphi(x) \quad \forall x \in \mathrm{M}, \forall \varphi \in \mathscr{D}\left(\mathrm{M}, \mathrm{E}^{*}\right)
$$

shows assertion (i). To prove assertion (ii), notice that

$$
\left(G_{ \pm} P \varphi\right)(x)=F_{\mp}(x)(P \varphi)=P^{*} F_{\mp}(x)(\varphi)=\varphi(x) \quad \forall x \in \mathrm{M}, \forall \varphi \in \mathscr{D}\left(\mathrm{M}, \mathrm{E}^{*}\right) .
$$

Finally, let $x \in \operatorname{supp} G_{ \pm} \varphi$. Since supp $F_{\mp}(x) \subset J_{\mp}^{M}(x)$, then the support of $\varphi$ must be partially within $J_{\mp}^{M}(x)$, which is equivalent to $x \in J_{\mp}^{M}(\operatorname{supp} \varphi)$.

As for the corollary, it follows directly from the lemma and uniqueness of fundamental solutions.

An interesting property of Green's operator $G_{ \pm}$is that if $G_{ \pm}^{*}$ is the operator relative to $P^{*}$, then $G_{ \pm}^{*}$ is the formal adjoint of $G_{ \pm}$. Let $\varphi \in \mathscr{D}\left(\mathrm{M}, \mathrm{E}^{*}\right)$ and $u \in \mathscr{D}(\mathrm{M}, \mathrm{E})$; then,

$$
\begin{aligned}
\int_{M}\left(G_{ \pm}^{*} \varphi\right) \cdot u d V & =\int\left(G_{ \pm}^{*} \varphi\right) P G_{\mp} u d V=\int\left(P^{*} G_{ \pm}^{*} \varphi\right) G_{\mp} u d V \\
& =\int \varphi\left(G_{\mp} u\right) d V .
\end{aligned}
$$

In the above, an important detail is the introduction of $P G_{\mp}$ instead of $P G_{ \pm}$, i.e. $\mp$ instead of \pm , since $\operatorname{supp} G_{ \pm} \varphi \cap \operatorname{supp} G_{\mp} u \subset J_{ \pm}^{\mathrm{M}}(\operatorname{supp} \varphi) \cap J_{\mp}^{\mathrm{M}}(\operatorname{supp} u)$ - which is compact in a globally compact hyperbolic manifold.

An immediate use of this information regards an important analytic property of Green's operators. We denote $C_{S C}^{\infty}(\mathrm{M}, \mathrm{E})$ the space of spacelike compact supported sections - i.e., $\varphi \in C^{\infty}(\mathrm{M}, \mathrm{E})$ is sad to be spacelike compact if there exists $K \subset \mathrm{M}$ compact such that supp $\varphi \subset K$; notice $\varphi$ itself is not required to have compact support. The term "spacelike" stands for the fact that for each Cauchy surface in M supp $\left.\varphi\right|_{S} \subset$ $J^{\mathrm{M}}(K) \cap S$, which in its turn is compact - see [10], corollary A.5.4. Now, the map $G_{ \pm}: \mathscr{D}(\mathrm{M}, \mathrm{E}) \longrightarrow C_{S C}^{\infty}(\mathrm{M}, \mathrm{E})$ are sequentially continuous in the sense of sequentially continuous for distributions on manifolds already presented.

As a last remark for this chapter, we should say that part of what was done here may be extended to non-globally hyperbolic manifolds, although something is lost for example, existence of Green's operator may not be guaranteed any longer once one abandon global hyperbolic spaces. As usual, we refer to [10]. 


\section{Chapter 4}

\section{Functorial Quantization}

\subsection{Introduction}

Everything that was developed in the previous chapter has a clear physical motivation, since the Schrödinger, Klein-Gordon and Dirac equations, among others, are particular cases of the general problem we analysed. However, we have only discussed classical equations until now, in the sense that no quantization argument was presented yet. A typical way to introduce quantization in a theory, e.g., the free scalar field theory described by the Klein-Gordon equation $\left(\square+m^{2}\right) \varphi=0$, is through the imposition of canonical commutation relations. This quantization process, often called canonical quantization, is presented, for example, in [20] and [21]. We here attempt at another quantization method, one which applies to general globally hyperbolic spaces.

We shall not deal with interacting models: our main interest will remain dealing with free scalar fields, the simplest example possible, though still endowed with significant interest and motivation. Moving further to other situations, even the already solved ones, would considerably extend this work.

We present a very limited discussion about physical systems, observables and states; for a further treatment of these topics, we refer to [22] $]^{1}$, to [23] and to [15]. Following [23], our discussion shall not entails any consideration on the role of the observer.

By a physical system, we understand the set of all elements of Nature which may be observed, both directly or indirectly, and its observable interactions. Each component of a system is then called an observable, a social construction of those who perform an experiment, and which is supposed to reflect the existence of an element of the Universe independent of the observer. Thereafter, every assertion about Nature should be understood as an assertion about the model, the description of the observation. The conditions of the experimental apparatus and of the observables in a given moment is a state, and the act of associating to some observable in a given state a (real) number is what we understand as a measurement. We may then think of a state as a real-valued linear functional over the system $S$, a function associating a number to each observable. On the other hand, we may identify the observables with real-valued functionals over

\footnotetext{
${ }^{1}$ lecture notes currently available only under request to the author
} 
the set of states. The migration from this abstract presentation to a solid formalism is found in the referred texts [22], [23] and [15].

That said, the quantization process presented in this chapter consists on an association from globally hyperbolic spaces, endowed with wave operators, to the observables. The quantum character of the theory lays on the algebraic structure of the set of observables: we shall request it to be a $C^{*}$-algebra, though weaker assumptions could be made; we shall define a $C^{*}$-algebra ahead. Furthermore, locality condition implies the observables ought to be described not by a single operator algebra, but by a net of local algebras.

\subsection{Categories}

The present analysis of categories is based on [24]. Although these objects appeared in local quantum physics much earlier, Brunetti, Fredenhagen and Verch presented in [2] a new formalism of quantum field theories in which categories are used to develop a naturally covariant theory from the functorial processes involved in quantization, and so this is why we start this chapter introducing briefly this concept.

A metagraph consists of objects $a, b, c, \ldots$ and arrays, or morphisms $f, g, h, \ldots$ connected by the following associations: ${ }^{2}$

- Domain: for each array $f$, we associate an object $a \equiv \operatorname{Dom} f$ called the domain of $f$;

- Codomain: for each array $f$, we associate an object $b \equiv \operatorname{Cdom} f$ called the codomain of $f$.

For a given array $f$ of a metagraph, the associations of objects presented above may be represented by a proper array by the diagram

$$
f: a \longrightarrow b \text {. }
$$

A metacategory thereafter is a metagraph with the two extra following associations:

- Identity: for each given object $a$, the identity associates an array $\mathbb{1}_{a}$ such that $\mathbb{1}_{a}: a \longrightarrow a$;

- Composition: for each pair $f, g$ of arrays such that $\operatorname{Cdom} g=\operatorname{Dom} f$, the composition associates an array $f \circ g$ such that $f \circ g$ : Dom $g \longrightarrow$ Cdom $f$; we call such $f \circ g$ the composition of $f$ and $g$.

Furthermore, the associations above ought to fulfil the following axioms in order for a metagraph to be a metacategory:

\footnotetext{
${ }^{2}$ Each concept introduced in this first paragraph is absolutely fundamental and therefore has no definition rather what was given within the text. For a "connection" we do not refer to the mathematical concept, but to a smeared and rough ideas of association between elements of a theory.
} 
- Associativity: given the arrays $f, g, h$ satisfying

$$
a \stackrel{f}{\longrightarrow} b \stackrel{g}{\longrightarrow} c \stackrel{h}{\longrightarrow} d,
$$

then $(f \circ g) \circ h=f \circ(g \circ h) \equiv f \circ g \circ h$;

- Unity: For each array $f$ with $\operatorname{Dom} f=a$ there is an array $\mathbb{1}_{a}$ such that the composition $f \circ \mathbb{1}_{a}$ is well defined and equals to $f$. Besides, for each array $g$, Cdom $g=b$, there is an array $\mathbb{1}_{b}$ such that $\mathbb{1}_{b} \circ g$ is not only well defined but also equals to $g$. We call $\mathbb{1}_{a}$ a left-identity and right-identity.

The passage to set theory now turns a metacategory into a category: a graph is a metagraph formed by a set $O$ of objects and a set $S$ of arrays, between which we define the functions

$$
\begin{array}{r}
S \stackrel{\text { Dom }}{\longrightarrow} O \\
S \stackrel{\text { Cdom }}{\longrightarrow} O .
\end{array}
$$

We define in a graph the set $S \times_{O} S:=\{(f, g): f, g \in S$ and $\operatorname{Dom} f=\operatorname{Cdom} g\}$ of composable pairs. Then, a category $\mathfrak{C}$ is a graph with the two additional functions

$$
\begin{aligned}
& O \stackrel{i d}{\longrightarrow} S \\
& a \mapsto i d_{a} \equiv \mathbb{1}_{a}
\end{aligned}
$$

and

$$
\begin{aligned}
& S \times_{O} S \stackrel{\circ}{\longrightarrow} S \\
& (f, g) \mapsto f \circ g
\end{aligned}
$$

respectively named identity and composition, and fulfilling

- $\operatorname{Dom} \mathbb{1}_{a}=\operatorname{Cdom} \mathbb{1}_{a}=a$ for each object $a \in O$;

- Whenever the composition is well defined $\operatorname{Dom} f \circ g=\operatorname{Dom} g, \operatorname{Cdom} f \circ g=$ $\operatorname{Cdom} f$,

the latter one implying associativity.

The last element of the theory of categories we shall define is a functor, which is a morphism between categories. I. e., given the categories $\mathfrak{B}$ and $\mathfrak{C}$, a functor is an array $T: \mathfrak{B} \longrightarrow \mathfrak{C}$ which consists of the object functions $\mathfrak{B} \longrightarrow \mathfrak{C}, b \mapsto T b$ and on the array function $\mathfrak{B} \longrightarrow \mathfrak{C}, f \mapsto T f$, the first mapping objects into objects and the second mapping arrays into arrays, supposed to satisfy

$$
T\left(\mathbb{1}_{b}\right)=\mathbb{1}_{T b} \quad \text { and } \quad T(f \circ g)=T f \circ T g
$$

whenever the composition is well defined.

The composition of functors is now defined in terms of the composition of the functions defining them. 


\section{3 $C^{*}$-Algebras}

As a $\mathbb{K}$-algebra, we understand a vector space $V$ over the field $\mathbb{K}$ with an operation $\cdot: V \times V \longrightarrow V$, named product or multiplication, which commutes with the two vector spaces operations. Precisely, the product · has to satisfy

$$
\begin{aligned}
& u \cdot(\alpha v+w)=\alpha(u \cdot v)+u \cdot w \\
& (\alpha u+v) \cdot w=\alpha(u \cdot w)+v \cdot w
\end{aligned}
$$

for all $u, v, w \in V$ and for all $\alpha \in \mathbb{K}$. As previously observerd, we shall not be very orthodox with respect to the notation for the operations in an algebra, and - may be used for both the product by an scalar, for the algebra product, and for the natural pairing between fibres in the bundles $\mathrm{E}^{*}$ and $\mathrm{E}$, as in the last chapter.

An algebra $\mathfrak{A}$ is called unital if it contains an element $\mathbb{1} \in \mathfrak{A}$ named identity such that $\mathbb{1} \cdot a=a \cdot \mathbb{1}=a$ for all $a \in \mathfrak{A}$. If there exists an identity, then it can be proved to be unique. The algebra is said to be normed if it is normed as a vector space and submultiplicative, i.e., $\|A B\| \leq\|A\| .\|B\|$ for all $A, B \in \mathfrak{A}$. If the vector space is a Banach space w.r.t. this norm, the algebra is then called a Banach algebra if, in addition, it is unital and $\|\mathbb{1}\|=1$. This last condition excludes the trivial algebra $\mathfrak{A}=\{0\}$.

A K-anti-linear map $*: \mathfrak{A} \longrightarrow \mathfrak{A}, a \longmapsto a^{*}$ between (not necessarily normed) algebras is called an involution if, for all $a, b \in \mathfrak{A}$

$$
\begin{gathered}
a^{* *}=a \\
(a b)^{*}=b^{*} a^{*} .
\end{gathered}
$$

An algebra $\mathfrak{A}$ equipped with an involution $*$ is called a $*$-algebra. Finally, a $\mathbf{C}^{*}$-algebra is a $*$-algebra whose involution is an isometry, - i.e., such that $\left\|a^{*}\right\|=\|a\|$ for all $a \in \mathfrak{A}$, and which obeys the $C^{*}$-condition

$$
\left\|a^{*} a\right\|=\|a\|^{2} \quad \forall a \in \mathfrak{A} .
$$

An element $a$ of $\mathfrak{A}$ is called self-adjoint if it is invariant under $*$, i.e., if $a^{*}=a$. In particular, if $\mathbb{1}$ is an element of the algebra, it is self-adjoint, since, for each $a \in \mathfrak{A}$,

$$
\mathbb{1}^{*} a=\mathbb{1}^{*} a^{* *}=\left(a^{*} \mathbb{1}\right)^{*}=a^{* *}=a,
$$

and similarly for $a \mathbb{1}^{*}=a$. The uniqueness of the unity then implies its self-adjointness.

We comment that usually a $C^{*}$-algebra is not required, in principle, to contain a unity. Furthermore, we clarify that the conditions above are not completely independent; for instance, the isometry of the involution may follow from the $C^{*}$ property $\left\|a^{*} a\right\|=\|a\|^{2}$, from the sub-multiplicativity of the algebraic product and from the involution condition 
$a^{* *}=a$. As for the $C^{*}$ condition, its motivation is that, when dealing with states for physical theories, positivity implies norm continuity. We notify this statement may be found proved in [25], theorem 4.3.2.

A $\mathbf{C}^{*}$-subalgebra of a given $C^{*}$-algebra is a subspace $\mathfrak{A}^{\prime} \subset \mathfrak{A}$ invariant under $*$, i.e., for each $a \in \mathfrak{A}^{\prime}, a^{*} \in \mathfrak{A}^{\prime}$. A $C^{*}$-subalgebra is then a $C^{*}$-algebra in its own right.

Lemma 26. For $\mathfrak{A}$ being a $C^{*}$-algebra, denote by $\mathfrak{A}^{-1}$ the set of invertible elements of $\mathfrak{A}$ - i.e., $\mathfrak{A}^{-1}:=\left\{a \in \mathfrak{A}: \exists a^{-1} \in \mathfrak{A}\right.$ s.t. $\left.a^{-1} a=a a^{-1}=\mathbb{1}\right\}$. Then, the operations of vector addition, product by scalar, algebraic product, the involution and $\mathfrak{A} \longrightarrow \mathfrak{A}^{-1}, a \mapsto a^{-1}$ are all continuous w.r.t. the norm.

Proof. The proof of this statement may be found in any introductory book on the subject; we refer to [25] and [15].

An algebra homomorphism $\mathfrak{A} \longrightarrow \mathfrak{B}$ between $*$-algebras is called a $*$-morphism if commutes with $*$ - i.e., $\pi$ is a $*$-morphism iff $\pi\left(a^{*}\right)=\pi(a)^{*}$ for all $a \in \mathfrak{A}$. In case $\pi$ is also an automorphism, we call it a $*$-automorphism.

Example: Let $\mathcal{H}$ be a complex Hilbert space, with its inner product denoted by $\langle\cdot, \cdot\rangle$. The set of bounded linear operators over $\mathcal{H}$ defines a $C^{*}$-algebra, with unit $\mathbb{1}=i d: \mathcal{H} \longrightarrow \mathcal{H}$, in terms of the operator norm

$$
\|a\|_{\infty}:=\sup _{x \in \mathcal{H}}\{\|a x\|:\|x\|=1\}
$$

and with the involution given by the adjoint map $a \mapsto a^{*}$, where $a^{*}$ is the unique operator such that $\langle x, a y\rangle=\left\langle a^{*} x, y\right\rangle$ for all $x, y \in \mathcal{H}$. The only non-trivial part of the definition which has to be shown is the $C^{*}$-condition:

$$
\begin{aligned}
\|a\|^{2} & =\left(\sup _{x}\|a x\|\right)^{2}=\sup _{x}\|a x\|^{2}=\sup _{x}\langle a x, a x\rangle=\sup _{x}\left\langle x, a^{*} a x\right\rangle \\
& \leq \sup _{x}\|x\|\left\|a^{*} a x\right\|=\left\|a^{*} a\right\| \leq\left\|a^{*}\right\|\|a\|=\|a\|^{2} .
\end{aligned}
$$

The theory of $C^{*}$-algebras is much deeper than what we presented and extremely interesting in terms of its physical significance. For example, the $C^{*}$-algebra of operators over a Hilbert space is intimately related to axioms of quantum physics, though we shall not explore this connection with foundations of Physics any further than the strictly necessary. We shall have to refer to [25] for the algebraic basis; with regard to the interest Physics has on it, we suggest Professor Walter Pedra's lecture notes [22] $C^{*}$-algebras and Mathematical Foundation on Quantum Mechanics and Statistical Mechanics. A more complete list of references, including [23], may be found there.

Joining the present section to the previous one, we may define the category $\mathfrak{C}^{*}$, whose objects are $C^{*}$-algebras and whose arrows are $*$-monomorphisms between them. 


\subsection{Weyl Systems}

The relation between operator algebras and the free fields will be firmly established from the algebra of canonical commutation relations, because we shall only deal with free scalar fields. If we were dealing with fermions, the canonical anti-commutation relations would have to be considered. Weyl systems are nothing but a formalization of these commutation relations in terms of exponentials.

We define a symplectic vector space as vector space $V$ equipped with an antisymmetric non-degenerate bilinear map $\omega: V \times V \longrightarrow \mathbb{R}$ - i.e., an antisymmetric bilinear $\omega$ such that $\omega(\varphi, \psi)=0$ for all $\varphi \Leftrightarrow \psi=0$. Then, a Weyl system for $V \equiv(V, \omega)$ is a $C^{*}$-algebra $\mathfrak{A}$ with a map $W: V \longrightarrow \mathfrak{A}$ obeying

(i) $W(0)=\mathbb{1}$;

(ii) $W(-\varphi)=W(\varphi)^{*}$;

(iii) $W(\varphi) \cdot W(\psi)=e^{-i \omega(\varphi, \psi) / 2} W(\varphi+\psi)$.

We may therefore regard the map $W$ as a representation of the algebra $\mathfrak{A}$ up to the term $e^{-i \omega(\cdot, \cdot) 3}$. It has the following properties.

Lemma 27. If $(\mathfrak{A}, W)$ is a Weyl system over the symplectic vector space $V$, then

(i) for all $\varphi \in V, W(\varphi)$ is unitary;

(ii) the family $\{W(\varphi)\}_{\varphi \in V}$ is linearly independent;

(iii) for each pair $\varphi, \psi \in V$ with $\varphi \neq \psi,\|W(\varphi)-W(\psi)\|=2$;

(iv) the linear span $[W(V)] \equiv[\{W(\varphi): \varphi \in V\}]$ is closed under $*$ and under the algebra product;

(v) $[W(V)]$ is unique up to an $*$-isomorphism.

Proof. Item (i) is quite trivial: $W(\varphi)^{*} W(\varphi)=W(-\varphi) W(\varphi)=e^{-i \omega(0,0)} W(0)=e^{0} \mathbb{1}$, and similarly for $W(\varphi) W(\varphi)^{*}$. To prove item (ii), consider the linear combination

$$
\sum_{j=1}^{n} \alpha_{j} W\left(\varphi_{j}\right)=0
$$

with $\varphi_{i} \neq \varphi_{j}$ if $i \neq j$. For $n=1$, it is only possible if $\alpha=0$ : suppose there was some $\psi$ with $W(\psi)=0$; then, for all $\varphi \in V, W(\psi) W(\varphi)=e^{i \omega(\psi, \varphi)} W(\psi+\varphi)=0$, which is only possible if $W(\psi+\varphi)=0$ for all $\varphi$. Under these conditions, either $W$ is identically equal to some element of $\mathfrak{A}$, which would have to be 0 in order for $W(\psi)$ equals 0 , and then $W$ would not define a Weyl system, or $\psi=0$, which contradicts the condition $W(0)=\mathbb{1}$. We proceed by induction on $n$ and suppose $\alpha_{n} \neq 0$ to write

\footnotetext{
${ }^{3}$ If $\mathcal{H}$ is a Hilbert space, a map $\pi: \mathfrak{A} \longrightarrow \mathscr{L}(\mathcal{H})$ is called a representation of the algebra $\mathfrak{A}$ if it is a $*$-morphism.
} 


$$
\begin{gathered}
W\left(\varphi_{n}\right)=\sum_{j=1}^{n-1} \underbrace{\frac{-\alpha_{j}}{\alpha_{n}}}_{=: \beta_{j}} W\left(\varphi_{j}\right) \Longrightarrow \\
\mathbb{1}=W\left(\varphi_{n}\right)^{*} W\left(\varphi_{n}\right)=\sum_{j=1}^{n-1} \beta_{j} W\left(-\varphi_{n}\right) W\left(\varphi_{j}\right) \\
=\sum_{j=1}^{n-1} \beta_{j} e^{-i \omega\left(\varphi_{n}, \varphi_{j}\right)} W\left(\varphi_{j}-\varphi_{n}\right) \\
=\sum_{j=1}^{n-1} \varepsilon_{j} W\left(\varphi_{j}-\varphi_{n}\right)
\end{gathered}
$$

where the term $\varepsilon_{j}$ absorbed the exponential. It now follows that for each $\psi \in V$

$$
\begin{aligned}
& \mathbb{1}=W(\psi) W(-\psi)=W(\psi) \mathbb{1} W(-\psi) \\
& =\sum_{j=1}^{n-1} \varepsilon_{j} W(\psi) W\left(\varphi_{j}-\varphi_{n}\right) W(-\psi)=\sum_{j=1}^{n-1} \varepsilon_{j} e^{-i \omega\left(\psi, \varphi_{j}-\varphi_{n}\right) / 2} W\left(\varphi_{j}-\varphi_{n}+\psi\right) W(-\psi) \\
& =\sum_{j=1}^{n-1} \varepsilon_{j} e^{-i \omega\left(\psi, \varphi_{j}-\varphi_{n}\right) / 2} e^{-i \omega\left(\varphi_{j}-\varphi_{n}+\psi,-\psi\right) / 2} W\left(\varphi_{j}-\varphi_{n}\right) \\
& =\sum_{j=1}^{n-1} \varepsilon_{j} e^{-i \omega\left(\psi, \varphi_{j}-\varphi_{n}\right) / 2} e^{-i \omega\left(\varphi_{j}-\varphi_{n},-\psi\right) / 2} e^{-i \omega\left(\psi,-\psi^{\prime}\right)} W\left(\varphi_{j}^{0}-\varphi_{n}\right) \\
& =\sum_{j=1}^{n-1} \varepsilon_{j} e^{-i \omega\left(\psi, \varphi_{j}-\varphi_{n}\right)} W\left(\varphi_{j}-\varphi_{n}\right)=\sum_{j=1}^{n-1} \varepsilon_{j} W\left(\varphi_{j}-\varphi_{n}\right) .
\end{aligned}
$$

By induction on $n$, the last equality implies $\omega\left(\psi, \varphi_{j}-\varphi_{n}\right)=0$ for all $\psi$, so $\varphi_{j}=\varphi_{n}$ for all $j=1, \ldots, n-1$, a contradiction. The alternative is that $\varepsilon_{j}=0$ for all $j$, hence $\alpha_{j}=0$ for all $j$, another contradiction.

The property announced in item (iii) will not be proved here, we refer to [15]. Item (iv) follows immediately from the definition, and for item (v), suppose an alternative Weyl system $W^{\prime}(V)$ related to $V$; the map $\pi:[W(V)] \longrightarrow\left[W^{\prime}(V)\right]$ given by $\pi(W(\varphi)):=$ $W^{\prime}(\varphi)$ defines a bijection between the basis $\mathcal{B}:=\{W(\varphi): \varphi \in V\}$ and $\mathcal{B}^{\prime}:=\left\{W^{\prime}(\varphi):\right.$ $\varphi \in V\}$ and therefore is a isomorphism. That it is also a $*$-morphism follows from $\pi\left(W(\varphi)^{*}\right)=\pi(W(-\varphi))=W^{\prime}(-\varphi)=W^{\prime}(\varphi)^{*}=\pi(W(\varphi))^{*}$.

We give an example of a Weyl system, therefore proving its existence. Let $V$ be a symplectic vector space without further assumptions, and let $\mathcal{H}=\mathscr{L}^{2}(V, \mathbb{C})$ be the set of square-integrable functions $f: V \longrightarrow \mathbb{C}$ vanishing in almost all $V$, i.e., $f(x)=0$ except for a finite set of elements $x \in V$, so that the integration is performed with respect to the counting measure. On $\mathcal{H}$, we define the inner product 


$$
\langle f, g\rangle:=\sum_{x \in V} \overline{f(x)} g(x)
$$

which is well defined as a finite sum and induces a norm $\|f\|_{\mathscr{L}^{2}}^{2}:=\sum_{x \in V}|f(x)|^{2}$, therefore turning $\mathcal{H}$ into a Hilbert space. Let now $\mathfrak{A}=\mathscr{B}(\mathcal{H})$ be the $C^{*}$-algebra of bounded linear operator $\mathcal{H} \longrightarrow \mathcal{H}$, and we construct the map $W: V \longrightarrow \mathscr{B}(\mathcal{H})$ to be

$$
\begin{aligned}
& x \longmapsto W(x): \mathcal{H} \longrightarrow \mathcal{H} \\
& (W(x) f)(y):=e^{-i \omega(x, y) / 2} f(x+y) ;
\end{aligned}
$$

hence, $W$ is a bounded linear map which satisfies the required properties for $(\mathscr{B}(\mathcal{H}), H)$ to be a Weyl system over $V$. The proof may be found in [10]. We denote by $\mathbf{C C R}(\mathbf{V})$ the $C^{*}$-subalgebra of $\mathscr{B}(\mathcal{H})$ the generated by $[W(x): x \in V]$, which together with $W$ : $V \longrightarrow \mathscr{B}(\mathcal{H})$ is a Weyl system: in general, a Weyl system of a given symplectic vector $V$ space is called a CCR-representation of $V$. If the algebra $\mathfrak{A}$ is a $C^{*}$-algebra generated by $[W(V)]$, it is called $\mathfrak{A}$ the $\mathbf{C C R}$-algebra of $V$. The assertion about the uniqueness of the space $[W(V)]$ up to an $*$-isomorphism induces then a similar result to CCRrepresentations,

Theorem 14. Let $(\mathfrak{A}, W)$ and $(\mathfrak{B}, X)$ be two distinct CCR-representations for a common symplectic $V$. Then, there is a $*$-isomorphism $\pi: \mathfrak{A} \longrightarrow \mathfrak{B}$ such that the following diagram commutes.

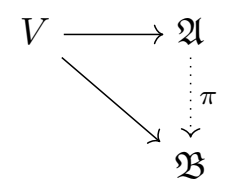

We need some further development in order to prove this theorem. On a subalgebra generated by a set like $[W(x: x \in V]$, the norm

$$
\left\|\sum_{x \in V} \alpha(x) W(\varphi)\right\|_{1}:=\sum_{x \in V}|\alpha(x)|, \quad \alpha(x) \in \mathbb{C} \forall x \in V
$$

is also well defined as a finite sum, since it is in the (finitely) generated subalgebra $[W(x)]$. It clearly does not satisfy the $C^{*}$ condition,

$$
\begin{gathered}
\left\|\left(\sum_{x \in V} \alpha(x) W(x)\right)^{*}\left(\sum_{x \in V} \alpha(x) W(x)\right)\right\|_{1}=\left\|\sum_{x \in V} \overline{\alpha(x)} \alpha(x) W(x)^{*} W(x)\right\|_{1} \\
=\sum_{x \in V}|\alpha(x)|^{2} \neq\left\|\sum_{x \in V} \alpha(x) W(x)\right\|_{1}^{2} .
\end{gathered}
$$


However, for each $C^{*}$-norm $\|\cdot\|$ considered on $[W(V)]$, due to the unitarity of $W(x)$ for all $x \in[W(V)]$ and to the triangle inequality, as may be seen in the calculation just presented, $\|\cdot\| \leq\|\cdot\|_{1}$, what implies that in the expression for the norm

$$
\|A\|_{\max }:=\sup \left\{\|A\|_{0}:\|\cdot\|_{0} \text { is a } C^{*} \text {-norm in }[W(V)]\right\},
$$

the supremum is finite - it is also not taken over an empty set, since $[W(V)]$ naturally inherits a $C^{*}$-norm from $\mathfrak{A}$. We affirm that $\|\cdot\|_{\max }$ is a $C^{*}$-norm - the proof is actually quite simple.

It is now possible to prove the uniqueness of a CCR-representation of a symplectic vector space up to an isomorphism. We extend the previous assertion to $[W(V)] \longrightarrow \mathfrak{A}$ and $\left[W^{\prime}(V)\right] \longrightarrow \mathfrak{B}: \pi:[W(V)] \longrightarrow\left[W^{\prime}(V)\right]$ extends to a $*$-morphism $\overline{[W(V)]} \longrightarrow \mathfrak{B}$, where the overline means the completion with respect to the norm $\|\cdot\|_{\max }$, because $\|\pi(A)\|_{\mathfrak{B}} \leq\|A\|_{\max }$. In [10], lemma 4.2 .7 we find a proof that $\pi$ is injective.

\subsection{Quantization Functor}

In this section we present a quantization process based on categories and functors. For quantization we shall mean the association of an operator $C^{*}$-algebra to our theory describing the observables, and for instance we shall not make any further assumption on the states whatsoever. However, locality is not ab initio present within the operator algebra - and probably could not be. In order to construct a relativistic mathematical basis for physical theories, the Principle of Relativity will be encoded in the nets of quasilocal $C^{*}$-algebras, where the locality condition then arises naturally. All this, plus the accordance with Haag-Kastler axioms will be properly developed ahead in some depth.

Our main strategy is the construction of a functor connecting the category of wave equation theories to $\mathfrak{C}^{*}$, but this will involve some steps.

We construct the category $\mathfrak{H} \mathfrak{y p}$, whose objects are triplets $(\mathrm{M}, \mathrm{E}, P), \mathrm{E} \longrightarrow \mathrm{M}$ a real vector bundle over a globally hyperbolic time-oriented Lorentzian manifold with a inner product and $P$ a formally selfadjoint normally hyperbolic operator, all this meaning the following. Assume the bundle E, now a real one, is equipped with a inner product defined in each fibre which depends smoothly on the base point - i.e., for each $x \in \mathrm{M}$, the finite dimensional real vector space $\mathrm{E}_{x}$ has a inner product $\langle\cdot, \cdot\rangle_{x}$ defined, in such a way that for each pair $f, g \in \mathrm{E}$ the function $x \longmapsto\langle f, g\rangle_{x} \in \mathbb{R}$ is continuous. If, for each pair of sections $\psi, \varphi \in \mathscr{D}(\mathrm{M}, \mathrm{E})$, the normally hyperbolic operator satisfies

$$
\int_{\mathrm{M}}\langle\psi, P \varphi\rangle d V=\int_{\mathrm{M}}\langle P \psi, \varphi\rangle d V
$$

being this expression well defined as

$$
\int_{\mathrm{M}}\langle\psi, P \varphi\rangle d V \equiv \int_{\mathrm{M}}\langle\psi(x), P \varphi(x)\rangle d V(x)
$$


then we regard it as formally self-adjoint, in a similar way as what was defined previously for differential operators acting on distributions. We give a unique example of such a structure, related to the free scalar field, extracted from [10], where other examples may be found.

Example: The free scalar field: if $\nabla$ denotes the connection on $M$, we assume that it is related to the inner product in the vector bundle as

$$
\partial_{X}\langle\psi, \varphi\rangle=\left\langle\nabla_{X} \psi, \varphi\right\rangle+\left\langle\psi, \nabla_{X} \varphi\right\rangle
$$

Consider the isomorphism $\mathrm{E} \longrightarrow \mathrm{E}^{*}$ given by $\varphi \longmapsto\langle\varphi, \cdot\rangle$. Thus, it is not hard to prove that

$$
\nabla_{X}\langle\varphi, \cdot\rangle=\left\langle\nabla_{X} \varphi\right\rangle
$$

With some more extra work, one may show that

$$
\langle\varphi, \square \psi\rangle=\sum_{j=1}^{n} \varepsilon_{j}\left\langle\nabla_{e_{j}} \varphi, \nabla_{e_{j}} \psi\right\rangle-\operatorname{div} V
$$

where $V$ is a vector field whose support lays in the support of both sections $\psi$ and $\varphi$. It then follows that

$$
\langle\varphi, \square \psi\rangle-\langle\square \varphi, \psi\rangle=\operatorname{div}\left(V^{\prime}-V\right)
$$

Suppose both sections have compact support; then we conclude that

$$
\int_{\mathrm{M}}\langle\varphi, \square \psi\rangle-\langle\square \varphi, \psi\rangle d V=\int_{\mathrm{M}} \operatorname{div}\left(V^{\prime}-V\right) d V=0
$$

The category $\mathfrak{H} \mathfrak{y p}$ contains at least one class of objects, those which fit in the example above; its morphisms, on the other hand, connecting $\left(\mathrm{M}_{1}, \mathrm{E}_{1}, P_{1}\right) \longrightarrow\left(\mathrm{M}_{2}, \mathrm{E}_{2}, P_{2}\right)$ are given by pairs of mappings $(f, F), f: \mathrm{M}_{1} \longrightarrow \mathrm{M}_{2}$ an isometric embedding such that $f\left(\mathrm{M}_{1}\right)$ is a causally compatible subset of $\mathrm{M}_{2}$; and $F: \mathrm{E}_{1} \longrightarrow \mathrm{E}_{2}$ a homomorphism constituting an isometry in each fiber. We therefore request that the diagrams

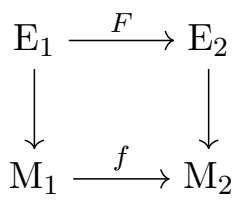

and 


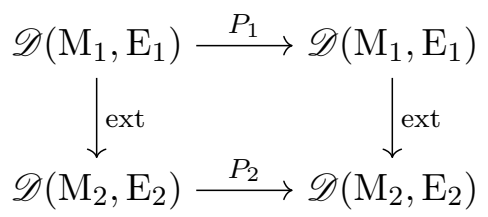

to be both commutative - in the second one, ext means the extension $\mathscr{D}\left(f\left(\mathrm{M}_{1}\right), \mathrm{E}_{2}\right) \hookrightarrow$ $\mathscr{D}\left(\mathrm{M}_{2}, \mathrm{E}_{2}\right)$ given by $\operatorname{ext}(\varphi):=F \circ \varphi \circ f^{-1}$, which involves the commutativity of the former diagram. The second condition may be regarded as the invariance of normally hyperbolic operator.

Let $\mathfrak{S} \mathfrak{y m}$ be the category of symplectic vector space, whose morphisms are symplectomorphisms, maps $f:\left(V_{1}, \omega_{1}\right) \longrightarrow\left(V_{2}, \omega_{2}\right)$ such that the pull-backs preserve the symplectic map, i.e., $f^{*} \omega_{2}=\omega_{1}$ : for all $x \in V_{1},\left(f^{*} \omega_{2}\right)(x)=\left(\omega_{2} \circ f\right)(x)=\omega_{2}(f(x))=\omega_{1}(x)$. For each given object (M.E, $P$ ) in $\mathfrak{H y p}$, consider the unique pair of Green's operator associated - formally, we may extend each object to $(\mathrm{M}, \mathrm{E}, P) \longmapsto\left(\mathrm{M}, \mathrm{E}, P, G_{+}, G_{-}\right)$, in such a way that the second diagram above becomes

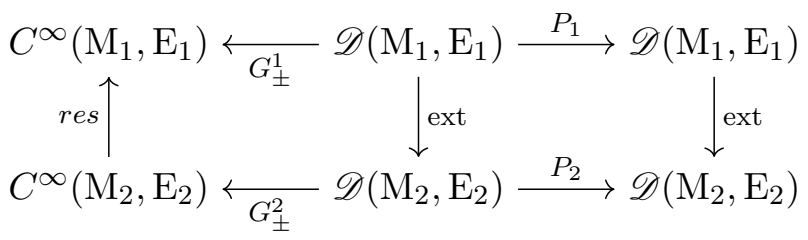

where res stands for the restriction $F^{-1} \circ \psi \circ f$. In this extension on the category, we also request the morphisms $(f, F)$ allow the commutativity of this third diagram, but this is a direct consequence of the commutativity of the first one, so we will not worry about the morphisms for this extension covering the objects. It is now possible to construct a functor from $\mathfrak{H y p}$ to $\mathfrak{S y m}$ connecting objects $\left(\mathrm{M}, \mathrm{E}, P, G_{ \pm}\right)$to symplectic vector spaces defined over the vector space $\mathscr{D}(\mathrm{M}, \mathrm{E}) / \operatorname{ker}(G)$ with a symplectic map induced by

$$
\omega(\varphi, \psi):=\int_{\mathrm{M}}\langle G \varphi, \psi\rangle d V
$$

If we consider $\omega$, as defined above, as a map $\mathscr{D}(\mathrm{M}, \mathrm{E}) \times \mathscr{D}(\mathrm{M}, \mathrm{E}) \longrightarrow \mathbb{R}$, the map will be degenerated - in fact, from the definition of Green's operator we have that $P \mathscr{D}(\mathrm{M}, \mathrm{E}):=\{P \varphi: \varphi \in \mathscr{D}(\mathrm{M}, \mathrm{E})\} \subset \operatorname{ker}(G)$, since $G(P \varphi)=\left(G_{+}-G_{-}\right)(P \varphi)=0-$ in considering globally hyperbolic manifolds, however, it is possible to prove that $\operatorname{ker}(G)$ equals the set $P \mathscr{D}(\mathrm{M}, \mathrm{E})$, see [10] for this. Anyway, we simply remove the degenerescence of $\omega$ by considering the quotient $\mathscr{D}(\mathrm{M}, \mathrm{E}) / \operatorname{ker}(G)$ and regarding the induced form

$$
\omega([\varphi],[\psi]):=\omega(\varphi, \psi)
$$

for any representatives $\varphi \in[\varphi], \psi \in[\psi]$, as for if $\varphi^{\prime}, \psi^{\prime}$ are another pair of representatives, $\left(\varphi-\varphi^{\prime}\right),\left(\psi-\psi^{\prime}\right) \in \operatorname{ker}(G)$ then $\omega(\varphi, \psi)-\omega\left(\varphi^{\prime}, \psi^{\prime}\right)=\omega\left(\varphi-\varphi^{\prime}, \psi-\psi^{\prime}\right)=0$. Returning to our main point, the functor 


$$
\mathfrak{H} \mathfrak{y p} \rightrightarrows \mathfrak{S} \mathfrak{y} \mathfrak{m}
$$

$$
\begin{aligned}
\left(\mathrm{M}, \mathrm{E}, P, G_{ \pm}\right) & \longmapsto \mathscr{D}(\mathrm{M}, \mathrm{E}) / \operatorname{ker}(G) \\
(f, F) & \longmapsto e x t^{*} \omega
\end{aligned}
$$

is constructed as follows.

Lemma 28. ext: $\mathscr{D}\left(\mathrm{M}_{1}, \mathrm{E}_{1}\right) \longrightarrow \mathscr{D}\left(\mathrm{M}_{2}, \mathrm{E}_{2}\right)$ maps ker $\left(G_{1}\right)$ into ker $\left(G_{2}\right)$ and induces a symplectomorphism between the quotient spaces.

Proof. Let $\varphi \in \operatorname{ker} G_{1}$ and let $\psi \in \mathscr{D}\left(\mathrm{M}_{1}, \mathrm{E}_{1}\right)$ such that $P_{1} \psi=\varphi$. Then, $\operatorname{ext}(\varphi) \in$ $\mathscr{D}\left(\mathrm{M}_{2}, \mathrm{E}_{2}\right)$ and, from the commutativity of the diagrams in $\mathfrak{H} \mathfrak{y p}, G_{2}(\operatorname{ext}(\varphi))=G_{2}\left(\operatorname{ext}\left(P_{1} \psi\right)\right)=$ $G_{2}\left(P_{2} \operatorname{ext}(\varphi)\right)=0$. The induced symplectomorphism is given by the pullback since

$$
\begin{aligned}
\omega_{2}(\operatorname{ext}(\varphi), \operatorname{ext}(\psi)) & =\int_{\mathrm{M}_{2}}\left\langle G_{2} \operatorname{ext}(\varphi), \operatorname{ext}(\psi)\right\rangle d V_{2} \\
& =\int_{\mathrm{M}_{1}}\left\langle\operatorname{res} G_{2} \operatorname{ext}(\varphi), \psi\right\rangle d V_{1} \\
& =\int_{\mathrm{M}_{1}}\left\langle G_{1} \varphi, \psi\right\rangle d V_{1} \\
& =\omega_{1}(\varphi, \psi) .
\end{aligned}
$$

Therefore, the map between morphisms in the above functor is well defined. We shall denote this functor by $\mathfrak{S y m}: \mathfrak{H} \mathfrak{y} \mathfrak{p} \rightrightarrows \mathfrak{S y m}$.

Moving forward with the quantization process, it is necessary a functor connecting $\mathfrak{S y m}$ to $\mathfrak{C}^{*}$, but this is quite easy: first, we shall denote it by $\mathfrak{C} \mathfrak{C}: \mathfrak{S} \mathfrak{n} m \rightrightarrows \mathfrak{C}^{*}$; let $S:\left(V_{1}, \omega_{1}\right) \longrightarrow\left(V_{2}, \omega_{2}\right)$ be a symplectomorphism in the category of symplectic vector spaces, and by theorem 14 we conclude the existence of a unique injective $*$-morphism $C C R(S): C C R\left(V_{1}\right) \longrightarrow C C R\left(V_{2}\right)$ mapping $C^{*}$-algebras given by the Weyl systems on $V_{1}$ and $V_{2}$, such that the diagram below commutes,

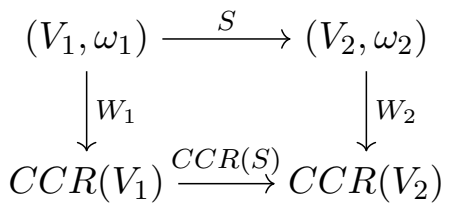

Since $C C R\left(\operatorname{id}_{V}\right)=\operatorname{id}_{C C R(V}$ and $C C R\left(S \circ S^{\prime}\right)=C C R(S) \circ C C R\left(S^{\prime}\right)$, we have the functor $\mathfrak{C} \mathfrak{R}$ mapping $(V, \omega) \longmapsto C C R(V)$ and with the map between $*$-morphisms given by $S \longmapsto C C R(S)$. We represent this net of categories and functors describing quantization with the following diagram. 


$$
\mathfrak{H} \mathfrak{H p} \stackrel{S y m}{\rightrightarrows} \mathfrak{S} \mathfrak{y m} \stackrel{C C R}{\rightrightarrows} \mathfrak{C}^{*}
$$

All this would be enough if we were not interested in a relativistic theory: there is no locality condition within the algebras of observables yet. This is introduced via HaagKastler axioms as presented in [10] and [18]. Without a very deep discussion about the meaning of those axioms, we may understand the introduction of locality in a physical theory as a restriction to the information influencing an experimental arrangement. If one is performing a measurement of a certain observable over some apparatus in a given well defined state (let it be a pure state, for instance), this measurement takes a time interval which is restricted by Heisenberg's Uncertainty Principle. The value $\delta t$ of this time interval determines a limited region in space which may influence or may be influenced by this experiment, all the rest of the Universe being causally disconnected to this measuring process. It is then natural to conceive these physically interesting regions of spacetime with the properties and characteristics we explored so far. Furthermore, it is also natural to expect coherence between causally connected regions: if we consider our experiment is causally determined by some region $O$ of the Universe and if there is some other region $O^{\prime}$ causally connected to $O$, then we would expect our experiment to be either determined or influenced by $O^{\prime}$. In a concrete example, suppose $O \subset O^{\prime}$, what implies that considering the effect of the information laying within $O^{\prime}$ should not imply any loss whatsoever in the experiment. On the other hand, we should also expect complete independence of any kind of influence between experiments performed in causally disconnected regions. This, in accordance to the basic principles of quantum mechanics, traduces into the possibility of the simultaneous measurement of any observable within the disconnected regions. The last motivation we may mention to the set of Haag-Kastler axioms is the following: we affirm it is enough that two regions have a common Cauchy surface for the measurement process be equivalent. This is not a deterministic condition, since we are only imposing the equality of the algebras of observables, and no statement about expected values is made. For this, a discussion about states would be necessary, but this is beyond the scope of this work.

Thereafter, without further discussions we present a version of the mentioned axioms. We recall that these axioms presented here only apply for free theories.

\section{Haag-Kastler Axioms:}

Axiom 1: On the existence of a local net of algebras of observables: for each bounded open region $O$ of $\mathrm{M}$, there exists a $C^{*}$-algebra $\mathfrak{A}(O)$ such that if $O_{1}, O_{2} \subset \mathrm{M}$ and $O_{1} \subset O_{2}$, then $\mathfrak{A}\left(O_{1}\right) \subset \mathfrak{A}\left(O_{2}\right)$.

Axiom 2: On a global algebra of observables: $\mathfrak{A}(\mathrm{M})=\bigvee \mathfrak{A}(O)$, i.e., it is the $C^{*}$-algebra generated by $\{\mathfrak{A}(O)\}_{\emptyset \neq O \neq \mathrm{M}}$, and it is simple, i.e., all unit preserving $*$-morphism is injective.

Axiom 3: On the causal coherence and independence between the nets: if $J\left(\overline{O_{1}}\right) \cap$ $\overline{O_{2}}=\emptyset,\left[\mathfrak{A}\left(O_{1}\right), \mathfrak{A}\left(O_{2}\right)\right]=\{0\}$, i.e., the algebras commute. Besides, if $O_{1}$ and $O_{2}$ are non-empty, if the Cauchy development $D$ of $O_{2}$ is compact and if $O_{1} \subset D$, then $\mathfrak{A}\left(O_{1}\right) \subset \mathfrak{A}\left(O_{2}\right)$. 
Axiom 4: The algebras $\mathfrak{A}(O)$ are required to have a common unit $\mathbb{1}$.

Axiom 5: The time-slice axiom: if $O_{1}$ and $O_{2}$ are non-empty and admit a common Cauchy surface, then $\mathfrak{A}\left(O_{1}\right)=\mathfrak{A}\left(O_{2}\right)$.

We emphasize the compacity of $D$ in axiom 3 because it may not be even if $\mathrm{O}_{2}$ is - needles to say we are still and always dealing with a globally hyperbolic Universe M. An example, actually quite simple one, may be found on [10], remark 4.5.2, and consists of the removal of the top and the bottom of $D$. One also usually sees the request of permittivity of the algebra $\mathfrak{A}(\mathrm{M})$ instead of simplicity, as in [18]; for now, we only affirm this condition is fulfilled in the present case, but we shall return to this topic ahead.

In order to move onwards with the quantization functor, we must create a new category of nets of $C^{*}$-algebras satisfying the axioms just presented. We begin with the following. Let $I$ be a non-empty set, which we shall later regard as an indexing set. We say $I$ is partially ordered with orthogonality relation if it is given a partial order relation $\leq$ and a symmetric relation $\perp$ such that

(i) for each $x \in I$, there is a $y \in I$ such that $x \leq y$;

(ii) for all $x \in I$, there is a $z \in I$ such that $x \perp z$;

(iii) $x \leq y$ and $y \perp z \Rightarrow x \leq z$;

(iv) $x \perp y$ and $x \perp z \Rightarrow$ there is $w \in I$ such that $y \leq w, z \leq w$ and $x \perp w$.

(For example, consider the subset of $\mathbb{R}^{2}$ given by $I:=\mathbb{R}_{+} \times\left\{(x, x) \in \mathbb{R}_{+} \times \mathbb{R}_{+}\right\}$). Next, we define a quasi-local $C^{*}$-algebra as a pair $\left(\mathfrak{A},\left\{\mathfrak{A}_{x \in I}\right\}\right)$ of a $C^{*}$-algebra $\mathfrak{A}$ and a family $\left\{\mathfrak{A}_{x}\right\}_{x \in I}$ where $I$ is partially ordered with a orthogonality relation, obeying

(i) $x \leq y \Rightarrow \mathfrak{A}_{x} \subset \mathfrak{A}_{y}$;

(ii) $\mathfrak{A}=\overline{\bigcup \mathfrak{A}_{x}}$ - the completion with respect to the norm topology;

(iii) there is a common $\mathbb{1} \in \mathfrak{A}_{x}$;

(iv) $x \perp y \Rightarrow\left[\mathfrak{A}_{x}, \mathfrak{A}_{y}\right]=\{0\}$.

One may already see where we are trying to get: we shall label the algebras with the open sets of M, and define the orthogonality relation as a causal independence, i.e., we define

$$
O \perp O^{\prime} \Leftrightarrow J(\bar{O}) \cap \overline{O^{\prime}}=\emptyset .
$$

In fact, we have the following result.

Lemma 29. The collection of relatively compact, causally compatible and globally hyperbolic open subsets of $\mathrm{M}$ with $\{\emptyset, \mathrm{M}\}$ is a partially ordered set with orthogonality relation, where the partial order is given by $\subset$ and the orthogonality by (4.7). 
Proof. For each subset $O$ of $\mathrm{M}$ satisfying the conditions of this lemma, we may take $\mathrm{M}$ to show item (i) on the definition. Trivially, item (ii) is fulfilled by $z=\emptyset$. If $O \subset O^{\prime}$ and $O^{\prime} \perp O^{\prime \prime}$, then item (iii) follows since $J(O) \subset J\left(O^{\prime}\right)$, thus $J(O) \cap O^{\prime \prime}=\emptyset$. For property (iv), consider $O, O^{\prime}$ and $O^{\prime \prime}$, all of them satisfying the necessary conditions and all of them different of $\mathrm{M}$ - in this case the result is trivial. Consider $O \perp O^{\prime}$ and $O \perp O^{\prime \prime}$ and let $N:=\overline{O^{\prime}} \cup \overline{O^{\prime \prime}}$, and $N$ obviously satisfies $O \perp N$ and $O^{\prime}, O^{\prime \prime} \subset N$. The global hyperbolicity of $N$, however, is not a direct consequence of its definition, and we use lemma A.5.13 of [10], which says that for a given relatively compact subset $K$ of a globally hyperbolic manifold there is $K \subset K^{\prime}$ globally hyperbolic in order to claim a $N^{\prime} \subset \mathrm{M} \backslash J(\bar{O})$ satisfying the conditions of the present lemma and causally compatible w.r.t. $\mathrm{M} \backslash J(\bar{O})$. That $N^{\prime}$ is causally compatible in $\mathrm{M}$ follows from $N^{\prime} \subset \mathrm{M} \backslash J(\bar{O})$, since the latter set is causally compatible with respect to $\mathrm{M}$.

Finally, we define a morphism between quasi-local $C^{*}$-algebras $\left(\mathfrak{A}, \mathfrak{A}_{x \in I}\right)$ and $\left(\mathfrak{B}, \mathfrak{B}_{x \in J}\right)$ as a pair of maps $(\varphi, \Phi), \phi: I \longrightarrow J$ a orthogonality preserving monotonic map and $\Phi: \mathfrak{A} \longrightarrow \mathfrak{B}$ is a $*$-morphism such that $\Phi\left(\mathfrak{A}_{x}\right) \subset \mathfrak{B}_{\varphi(x)}$ for each $x \in I$. The construction of a category $\mathfrak{L o c C}^{*}$ of quasi-local $C^{*}$-algebras is now complete; the functor connecting $\mathfrak{H} \mathfrak{y p}$ to $\mathfrak{L o c h}^{*}$, for its turn, will be defined in the next step.

Consider the inclusion $O \hookrightarrow O^{\prime}$ of open subsets on $\mathrm{M}$; since the morphisms in $\mathfrak{H} \mathfrak{y p}$ are pair of isometries, this inclusion induces a morphism $i_{O, O^{\prime}}$ in this category simply by regarding the bundle map as $\left.\left.\mathrm{E}\right|_{O} \hookrightarrow \mathrm{E}\right|_{O^{\prime}}$; let $\alpha_{O, O^{\prime}}$ be the induced unit preserving injective ${ }^{*}$-morphism in $\mathfrak{C}^{*}$ from $i_{O, O^{\prime}}, \alpha_{O, O^{\prime}}:=(C C R \circ S y m)\left(i_{O, O^{\prime}}\right)$. We then consider each algebra $\mathfrak{A}_{O}$ of the net as

$$
\mathfrak{A}_{O}=\left(\alpha_{\mathrm{M}, O} \circ C C R \circ \operatorname{Sym}\right)\left(O,\left.\mathrm{E}\right|_{O}, P, G_{ \pm}\right),
$$

with the collection of open sets $O$ as in lemma 29, and the global algebra $\mathfrak{A}_{\mathrm{M}}$ as the $C^{*}$-subalgebra of $C C R\left(V_{\mathrm{M}}\right)$ generated by the collection $\left\{\mathfrak{A}_{O}\right\}_{O}$,

$$
\mathfrak{A}_{\mathrm{M}}:=\overline{\bigcup_{O \subset \mathrm{M}} \mathfrak{A}_{O}}
$$

while $\mathfrak{A}_{\emptyset}:=\mathbb{C} . \mathbb{1}$.

Lemma 30. As defined above, $\left(\mathrm{M}, \mathrm{E}, P, G_{ \pm}\right) \longmapsto\left(\mathfrak{A}_{\mathrm{M}},\left\{\mathfrak{A}_{O}\right\}_{O \in I}\right)$ defines a quasi-local $C^{*}$-algebra. Let $\left(\mathrm{M}_{1}, \mathrm{E}_{1}, P_{1}, G_{ \pm}^{1}\right)$ and $\left(\mathrm{M}_{2}, \mathrm{E}_{2}, P_{2}, G_{ \pm}^{2}\right)$, and let $\left(\mathfrak{A}_{\mathrm{M}},\left\{\mathfrak{A}_{O}\right\}_{O \in I}\right)$ and $\left(\mathfrak{B}_{\mathrm{M}},\left\{\mathfrak{B}_{O}\right\}_{O \in J}\right)$ be the quasi-local algebras respectively related to them. Furthermore, let $(f, F)$ be a morphism in $\mathfrak{H} \mathfrak{y}$ connecting $\left(\mathrm{M}_{1}, \mathrm{E}_{1}, P_{1}, G_{ \pm}^{1}\right)$ to $\left(\mathrm{M}_{2}, \mathrm{E}_{2}, P_{2}, G_{ \pm}^{2}\right)$, and let $(\varphi, \Phi)$ be given by

$$
\begin{gathered}
\varphi: I \longrightarrow J, \quad\left\{\begin{array}{l}
\varphi\left(\mathrm{M}_{1}\right):=\mathrm{M}_{2}, \\
\varphi(O):=f(O) \quad \forall O \neq \mathrm{M}_{1}
\end{array}\right. \\
\Phi: C C R\left(V_{\mathrm{M}_{1}}\right) \longrightarrow C C R\left(V_{\mathrm{M}_{2}}\right), \\
\Phi:=(C C R \circ \text { Sym })(f, F) .
\end{gathered}
$$


Then $(\varphi, \Phi)$ is a morphism in $\mathfrak{L o c h}^{*}$, and thus we have a functor from $\mathfrak{H y p}$ to $\mathfrak{L o c h}^{*}$, which we shall denote by Loc.

Proof. We already know the indexing set is partially ordered with orthogonality relation. Condition (ii), namely that $\mathfrak{A}_{\mathrm{M}}=\bigvee \mathfrak{A}_{O}$ is guaranteed by construction. Let $0_{O} \in$ $\operatorname{Sym}\left(O,\left.\mathrm{E}\right|_{O}, P, G_{ \pm}\right) \equiv V_{O}$, and thus $W\left(0_{O}\right)=\mathbb{1}_{C C R\left(V_{O}\right)}$; consider in the same way $\mathbb{1}_{\mathrm{M}}$, and, therefore, $\mathbb{1}_{O}=\mathbb{1}_{\mathrm{M}}$ by construction - i.e., since we are considering 0 as the null section, according to the definition of the symplectic vector space as $\mathscr{D}(\mathrm{M}, \mathrm{E}) / \operatorname{ker}(G)$. Let $O \subset O^{\prime}$; from the definition of $\alpha_{O^{\prime}, O}$ in terms of the inclusion $i_{O^{\prime}, O}$, we have the diagram

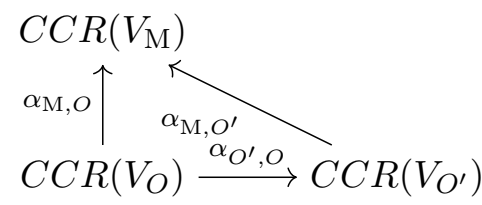

commuting; since $\alpha$ is injective, $\mathfrak{A}_{O} \subset \mathfrak{A}_{O^{\prime}}$. To prove the commutativity of the algebras, it is enough proving the commutativity of the generators $W(V)$ : suppose now $O \perp O^{\prime}$, i.e. $J(\bar{O}) \cap \overline{O^{\prime}}$, and let $\varphi \in \mathscr{D}(O, \mathrm{E})$ and $\psi \in \mathscr{D}\left(O^{\prime}, \mathrm{E}\right)$; since supp $G \varphi \subset J(O)$, the causal independence translates into supp $G \varphi \cap \operatorname{supp} \psi=\emptyset$, and hence $\int\langle G \varphi, \psi\rangle d V=0$. Let $\varphi$ and $\psi$ denote the equivalence classes of the sections trivially extended to the whole M, and thus we have $\omega(\varphi, \psi)=0$. According to the relations of a Weyl system, this implies $W(\varphi) W(\psi)=W(\varphi+\psi)=W(\psi) W(\varphi)$. This cncludes the first part of the lemma.

Consider the pair of maps $(\varphi, \Phi)$ as presented. Let $O \perp O^{\prime}$, and since $f$ is an embedding, $\varphi$ is monotonic, $\varphi(O) \perp \varphi\left(O^{\prime}\right)$ since the orthogonality is maintained by $f$. To see this, suppose the contrary; then, there would be a subset $U \subset O^{\prime}$ such that $J(\overline{f(O)}) \cap \overline{f(U)} \neq \emptyset$, and, using the hypothesis that $f\left(\mathrm{M}_{1}\right) \subset \mathrm{M}_{2}$ is causally complete, there would be a causal curve connecting $\overline{f(O)}$ to $\overline{f(U)}$. Consider the pre-image of this curve, which, since $f$ is an injective isometry, is also a causal curve which would connect $J(\bar{O})$ to $\bar{U}$, a contradiction.

Consider now the diagram

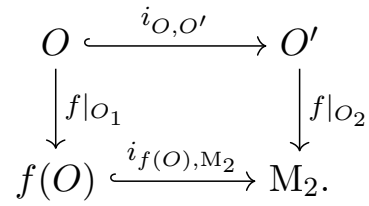

It implies

$$
\begin{aligned}
\Phi(\mathfrak{A}(O)) & =(C C R \circ \operatorname{Sym})(f, F)\left(\alpha_{\mathrm{M}, O} \circ C C R \circ \operatorname{Sym}\left(O,\left.\mathrm{E}\right|_{O}, P, G_{ \pm}\right)\right) \\
& =C C R \circ \operatorname{Sym}(f, F) \circ C C R \circ \operatorname{Sym}\left(i_{\mathrm{M}_{1}, O}\right) \circ C C R \circ \operatorname{Sym}\left(O,\left.\mathrm{E}\right|_{O}, P, G_{ \pm}\right) \\
& =C C R \circ \operatorname{Sym}\left(i_{\mathrm{M}_{2}, f(O)}\right) \circ C C R \circ \operatorname{Sym}\left(\left.f\right|_{O},\left.F\right|_{\left.\mathrm{E}\right|_{O}}\right) \circ \operatorname{Sym}\left(O,\left.\mathrm{E}\right|_{O}, P, G_{ \pm}\right)
\end{aligned}
$$




$$
\begin{aligned}
& \subset \alpha_{\mathrm{M}_{2}, f(O)} \circ C C R \circ \operatorname{Sym}\left(f(O),\left.\mathrm{E}\right|_{f(O)}, P, G_{ \pm}\right) \\
& =\mathfrak{B}_{f\left(O_{1}\right)}
\end{aligned}
$$

which also applies for $\mathrm{M}_{1}$ in the form of $\Phi\left(\mathfrak{A}\left(\mathrm{M}_{1}\right)\right) \subset \mathfrak{B}_{\mathrm{M}_{2}}$.

Now it only remains to prove that this net of observables obtained through this functorial formalism satisfy the Haag-Kastler axioms presented above, which are to be understood as the main fundamental axioms of a local quantum theory.

Theorem 15. Each net of observables in $\mathfrak{L o c}^{*}$ satisfies the Haag-Kastler axioms.

Proof. Let $O, O^{\prime} \subset \mathrm{M}$ with $O \subset O^{\prime}$. That $\mathfrak{A}(O) \subset \mathfrak{A}\left(O^{\prime}\right)$ is clear from the commutativity of the diagram (4.10) for $\alpha$

$$
\begin{aligned}
\mathfrak{A}(O)= & \left(\alpha_{\mathrm{M}, O} \circ C C R \circ S y m\right)\left(O,\left.\mathrm{E}\right|_{O}, P, G_{ \pm}\right) \\
= & \left(\left[(C C R \circ S y m)\left(i_{O, \mathrm{M}}\right)\right] \circ C C R \circ S y m\right)\left(O,\left.\mathrm{E}\right|_{O}, P, G_{ \pm}\right) \\
\subset & \left(\left[(C C R \circ S y m)\left(i_{O^{\prime}, O}\right)\right] \circ\left[(C C R \circ S y m)\left(i_{O^{\prime}, \mathrm{M}}\right)\right] \circ C C R \circ S y m\right) \\
& \quad\left(\left(O,\left.\mathrm{E}\right|_{O}, P, G_{ \pm}\right) \hookrightarrow\left(O^{\prime},\left.\mathrm{E}\right|_{O^{\prime}}, P, G_{ \pm}\right)\right)
\end{aligned}
$$$$
\subset \mathfrak{A}\left(O^{\prime}\right)
$$

what can also be represented in the diagram

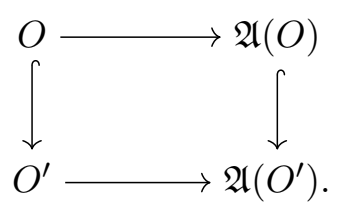

That $\mathfrak{A}_{\mathrm{M}}=\bigvee \mathfrak{A}_{O}$ follows immediately from the definition of quasi-local algebras. The simplicity of the quasi-local algebras follows from the fact that CCR-algebras of symplectic vector spaces are simple ${ }^{4}$. The commutativity was already proved, so it only remains to prove the last part of axiom 3 - i.e., that $\mathfrak{A}(O) \subset \mathfrak{A}\left(O^{\prime}\right)$ if $O$ is a subset of the relatively compact Cauchy development of $O^{\prime}$, and the time-slice condition.

Proving that the net of quasi-local algebras satisfy the Time-slice condition if more difficult and requires a technical statement, presented in the lemma below.

\footnotetext{
${ }^{4}$ In [18] the simplicity condition is replaced by a primitivity condition: an algebra is sad primitive if it has a faithful irreducible representation into a given Hilbert space. A comment about simplicity implying primitivity in the present case may be found in [10], with a reference to a detailed explanation
} 
Lemma 31. Let $\left(\mathrm{M}, \mathrm{E}, P, G_{ \pm}\right) \in \mathfrak{H} \mathfrak{y}$ and let $O \subset \mathrm{M}$ be a causally compatible and globally hyperbolic open subset of M. Let, in addition, $S$ be a Cauchy surface of both $O$ and $\mathrm{M}$. Then, each section $\varphi \in \mathscr{D}(\mathrm{M}, \mathrm{E})$ may be written as

$$
\varphi=\phi+P \psi
$$

with $\phi, \psi \in \mathscr{D}(\mathrm{M}, \mathrm{E})$ and supp $\phi \in O$.

Proof. See [10], lemmas 4.5.4 and 4.5.6.

Now, the Time-slice axiom is a corollary of the lemma above: consider $O \subset O^{\prime}$ as we should, i.e., causally compatible, open and globally hyperbolic with a common Cauchy surface. Let $[\varphi] \in \mathscr{D}\left(O^{\prime}, \mathrm{E}\right) / \operatorname{ker} G^{\prime}$, and, according to the previous statement, there are $\phi \in \mathscr{D}(O, \mathrm{E})$ and $\psi \in \mathscr{D}\left(O^{\prime}, \mathrm{E}\right)$ such that $\varphi=e x t \phi+P \psi$. As $P \psi \in \operatorname{ker} G^{\prime}$, we conclude that $[\varphi]=[\operatorname{ext} \phi]$, which is exactly the same of saying that $[\varphi]$ is the image of a symplectic map $[\psi] \longmapsto[e x t \psi]$ induced by the inclusion $O \hookrightarrow O^{\prime}$. Since this map is surjective, it defines an isomorphism between symplectic spaces, and thus an isomorphism between $C^{*}$-algebras, and thus we conclude $\mathfrak{A}(O)=\mathfrak{A}\left(O^{\prime}\right)$ up to an isomorphism.

There is now only axiom 3 to be completed: let $O, O^{\prime} \in I$ with $O \subset D\left(O^{\prime}\right)$, the latter is relatively compact. Let $S$ be a Cauchy surface in $O^{\prime}$. Since $O^{\prime}$ is causally compatible in $\mathrm{M}, S$ is acausal and, therefore, the Cauchy development of $S, D(S)$, is causally compatible and globally hyperbolic. On the other hand, by definition, $D(S)=D\left(O^{\prime}\right)$, and thus we showed $D\left(O^{\prime}\right) \subset I$. By the Time-slice axiom, $\mathfrak{A}\left(O^{\prime}\right)=\mathfrak{A}\left(D\left(O^{\prime}\right)\right)$, and by the first axiom we conclude $\mathfrak{A}(O) \subset \mathfrak{A}\left(D\left(O^{\prime}\right)\right)=\mathfrak{A}\left(O^{\prime}\right)$. This completes this proof.

The following diagrams summarizes the concepts of this section up to now.
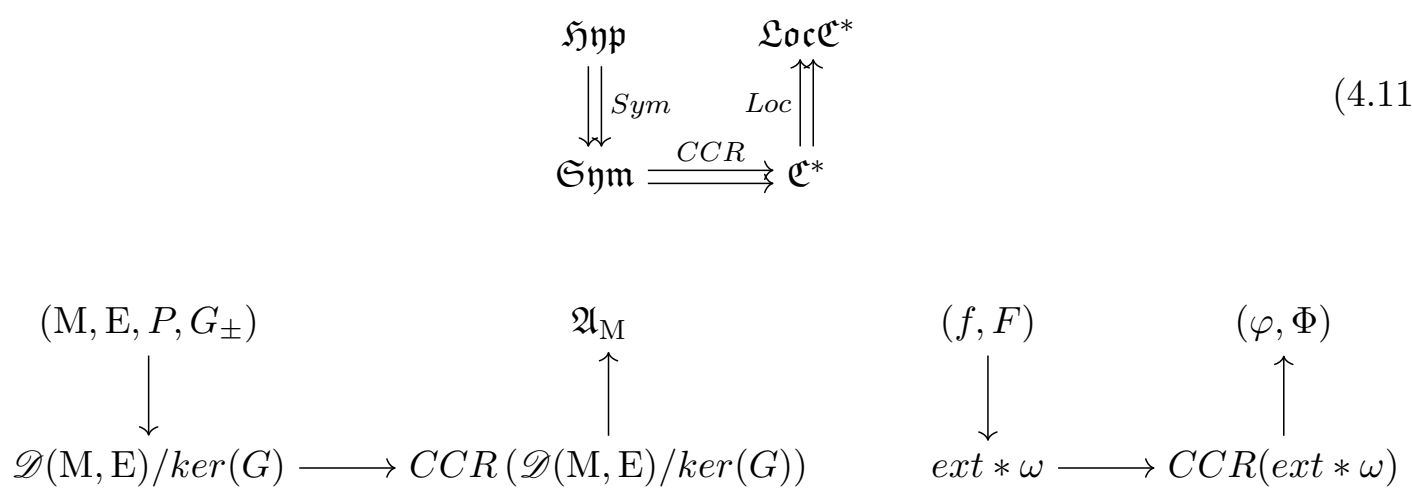

In this final part of the chapter, we would like to present an example of a theory satisfying the formalism presented and the Haag-Kastler axioms, hence recollecting some part of the material presented.

Let us first consider again the function spaces $C^{\infty}(\mathrm{M}, \mathbb{C})$ and $\mathscr{D}(\mathrm{M}, \mathbb{C})$, like in chapter 2 - i.e., in the example to come, the regarded bundle will be $\mathbb{C} \longrightarrow$ M. By taking one element of each space, say $f \in C^{\infty}(\mathrm{M})$ and $u \in \mathscr{D}(\mathrm{M})$, we may consider each of these functions separately as a distribution via the pairing $\langle u, f\rangle=\int_{\mathrm{M}} u f d V$. Consider now the Klein-Gordon equation 


$$
\left(\square+m^{2}\right) f=0 .
$$

We now know there is a pair of Green's functions $G_{ \pm}: \mathscr{D}(\mathrm{M}) \longrightarrow C^{\infty}(\mathrm{M})$ such that $G_{ \pm}\left(\square+m^{2}\right)=\left(\square+m^{2}\right) G_{ \pm}=$id and supp $G_{ \pm} f \subset J^{ \pm}(\operatorname{supp} f)$. Since the KleinGordon operator $\left(\square+m^{2}\right)$ is self-adjoint, we may continuously extend Green's functions to distributions as

$$
\begin{gathered}
f \in C^{\infty}(\mathrm{M}) \longmapsto G_{ \pm}(f): \mathscr{D}(\mathrm{M}) \longrightarrow \mathbb{C} \\
G_{ \pm}(f)(u):=\left\langle G_{\mp} f, u\right\rangle .
\end{gathered}
$$

Denoting this operator extension by $G_{ \pm}^{\prime}$, we then have $G_{ \pm}^{\prime}=G_{\mp}$, and so $G=G_{+}-$ $G_{-} \Rightarrow G^{\prime}=-G$. One should notice that this is nothing other than what was presented in chapter 3, section "Green's operator". Once again we emphasize the origin of the change future-past $\pm \longmapsto \mp$ in this extension: we always have $\left\langle G_{+} f, u\right\rangle=\left\langle G_{+} f,(\square+\right.$ $\left.\left.m^{2}\right) G_{+} u\right\rangle$; however, under these conditions we cannot ensure the self-adjointness of the differential operator $\square+m^{2}$, since the integration domain is in general non-compact and we cannot guarantee that $G_{ \pm} u$ decays fast enough. However, for $\left\langle G_{+} f,\left(\square+m^{2}\right) G_{-} u\right\rangle$, the compactness of the set $J^{+}(\operatorname{supp} f) \cap J^{-}(\operatorname{supp} u)$ follows from the hypothesis of a globally hyperbolic space.

Consider now a Cauchy surface $S \subset \mathrm{M}$ and the operators $\nabla_{\mathfrak{n}}: C^{\infty}(\mathrm{M}) \longrightarrow C^{\infty}(S)$, the forward normal derivative, and $\rho_{0}: C^{\infty}(\mathrm{M}) \longrightarrow C^{\infty}(S)$, the restriction operator. Let $u \in C^{\infty}(\mathrm{M})$ and $u_{0}:=\rho_{0} u, u_{1}:=\nabla_{\mathfrak{n}} u$. Define the adjoints $\nabla^{*}$ and $\rho_{0}^{*}$ from $\mathscr{D}^{*}(\mathrm{M})$ to $C^{\infty}(S)^{*}$. According to the extension $G_{ \pm}^{\prime}: \mathscr{D}^{*}(\mathrm{M}) \longrightarrow\left(C^{\infty}(\mathrm{M})\right)^{*}$, when then have $G \rho_{0}^{*}, G \nabla^{*}: \mathscr{D}^{*}(S) \longrightarrow C^{\infty}(\mathrm{M})^{*}$. As presented in [18], those operators reduce to continuous operators $\mathscr{D}(S) \longrightarrow C^{\infty}(\mathrm{M})$ such that

$$
u:=G \rho_{0}^{*} u_{1}-G \nabla_{\mathfrak{n}}^{*} u_{0}
$$

is the solution to the Cauchy problem with Cauchy data $u_{0}, u_{1}$.

We now turn to the quantum problem. We introduce the CCR representation over a Cauchy surface $\mathrm{S}$ as follows. Consider a complex Hilbert space $\mathcal{H}$ and a pair of maps

$$
\theta, \pi: \mathscr{D}(S) \longrightarrow \mathscr{L}(D)
$$

defining linear operators on a dense subset $D \subset \mathcal{H}$. Weakening slightly the terminology, we shall name a map with this domain-codomain structure an operator-valued distribution. Impose now the following condition on the maps,

$$
\left[\theta(f), \pi\left(f^{\prime}\right)\right]=i\left\langle f, f^{\prime}\right\rangle .
$$

Example: (the neutral, bosonic scalar Fock space) let $\mathcal{H}_{0}:=\mathbb{C}, \mathcal{H}_{1}=L^{2}(S)$ - the completion of the space of functions $\mathscr{D}(S) \longrightarrow \mathbb{C}$ with respect to the inner product $\left\langle f, f^{\prime}\right\rangle$, 
and define the Hilbert space $\mathcal{H}:=\bigoplus_{n=0}^{\infty} \operatorname{Sym} \bigotimes_{n} \mathcal{H}_{1}=\bigoplus_{n=0}^{\infty} \mathcal{H}_{n}, \mathcal{H}_{n}=$ Sym $\bigotimes_{n} \mathcal{H}_{1}$. If $a$ and $a^{\dagger}$ are the usual creation and annihilation operators defined, as in [26], by $a, a^{\dagger}: \mathscr{D}(S) \longrightarrow \mathcal{L}(D)$

$$
\begin{aligned}
a(f) \psi_{0} & :=0 \\
a^{\dagger}(f) \psi_{0} & :=f \quad \forall \psi_{0} \in \mathbb{C}, \\
a(f) \operatorname{Sym}\left(\psi_{1} \otimes \cdots \otimes \psi_{n}\right) & :=n^{1 / 2}\left\langle f, \psi_{1}\right\rangle \operatorname{Sym}\left(\psi_{2} \otimes \cdots \otimes \psi_{n}\right) \\
a^{\dagger}(f) \operatorname{Sym}\left(\psi_{1} \otimes \cdots \otimes \psi_{n}\right) & :=(n+1)^{1 / 2} \operatorname{Sym}\left(f \otimes \psi_{1} \otimes \cdots \otimes \psi_{n}\right)
\end{aligned}
$$

for all $f \in \mathscr{D}(S)$, it is possible to prove that these operators obey the commutation relation - see [26] or [10]

$$
\left[a(f), a^{\dagger}\left(f^{\prime}\right)\right]=-i\left\langle f, f^{\prime}\right\rangle, \quad f, f^{\prime} \in \mathscr{D}(S) .
$$

Consider now the operator-valued distributions $\theta, \pi$ as

$$
\begin{aligned}
\theta(f) & :=\frac{1}{\sqrt{2}}\left(a(f)+a^{\dagger}(f)\right) \\
\pi(f) & :=\frac{i}{\sqrt{2}}\left(a^{\dagger}(f)-a(f)\right) .
\end{aligned}
$$

Then, by means of (4.18), we then have $\theta$ and $\pi$ satisfying the required commutation relation for a CCR representations of the Cauchy surface $S$ over the Hilbert space $\mathcal{H}$.

Once a CCR representation is at hand, the next step is to define the field operator as the operator-valued distribution

$$
f \in \mathscr{D}(\mathrm{M}) \longmapsto \phi(f):=\theta\left(\nabla_{\mathfrak{n}} G f\right)-\pi\left(\rho_{0} G f\right) .
$$

Theorem 16. The field operator $\phi$, defined above to mimic the solution (4.15) of the Cauchy problem, solves the Klein-Gordon equation.

Proof. We want to show that $\left(\square+m^{2}\right) \phi=0$. Let $f \in \mathscr{D}(\mathrm{M})$ and so

$$
\phi(f)=\theta \underbrace{(\nabla G f)}_{\in \mathscr{D}(S)}-\pi \underbrace{\left(\rho_{0} G f\right)}_{\in \mathscr{D}(S)} .
$$

Then,

$$
\phi\left(\left(\square+m^{2}\right) f\right)=\theta(\nabla \underbrace{G\left(\square+m^{2}\right)}_{=0} f)-\pi(\rho_{0} \underbrace{G\left(\square+m^{2}\right)}_{=0} f) .
$$


Besides this, we may also show that the field operator satisfies the commutation relation

$$
\left[\phi(f), \phi\left(f^{\prime}\right)\right]=-i\left\langle\nabla G f, \rho G f^{\prime}\right\rangle+i\left\langle\rho_{0} G f, \nabla G f^{\prime}\right\rangle=-i\left\langle f, G f^{\prime}\right\rangle .
$$

The last expression is proved in [18], corollary 1.3, as an immediate consequence of equation (4.15).

We next introduce the net of algebras. By introducing the Weyl form of the CCR representation, we ensure the boundness of the operators involved; according to the Baker-Campbell-Hausdorff relation for the exponential of operators (see [7]),

$$
e^{A} e^{B}=e^{A+B+\frac{1}{2}[A, B]+\frac{1}{12}[A,[A, B]]+\frac{1}{12}[B,[B, A]]+\cdots},
$$

we have, considering (4.17),

$$
\begin{aligned}
W\left(f, f^{\prime}\right) & :=\exp \left\{i\left[\theta(f)-\pi\left(f^{\prime}\right)\right]\right\} \\
W\left(f, f^{\prime}\right) W\left(g, g^{\prime}\right) & =W\left(f+g, f^{\prime}+g^{\prime}\right) \exp \left\{\frac{-i}{2}\left[\left\langle f, g^{\prime}\right\rangle-\left\langle g, f^{\prime}\right\rangle\right]\right\} .
\end{aligned}
$$

Consider now $W$ as map $\mathscr{D}(S) \oplus \mathscr{D}(S) \equiv \mathscr{D}(S)^{2} \longrightarrow \mathcal{L}(D)$, and define $\omega: \mathscr{D}(S)^{2} \times$ $\mathscr{D}(S)^{2} \longrightarrow \mathbb{R}, \omega\left((f, g),\left(f^{\prime}, g^{\prime}\right)\right):=\left[\left\langle f, g^{\prime}\right\rangle-\left\langle g, f^{\prime}\right\rangle\right]$. It then follows immediately that $\omega$ defines a symplectic form, and so the pair $(W, \omega)$ is a symplectic vector space.

With all these conditions, we also have, for $t \in \mathbb{R}$,

$$
\exp \{i \phi(f) t\}=W\left(t \nabla G f, t \rho_{0} G f\right) .
$$

This allows us to define a net of $C^{*}$-algebras as follows: for open $O \subset \mathrm{M}$ causally compatible, relatively compact and globally hyperbolic, consider $f \in \mathscr{D}(\mathrm{M})$ with supp $f \subset O$ and

$$
\begin{aligned}
\mathfrak{A}(O) & :=C^{*} \text {-algebra generated by } \exp \{i \phi(f) t\} \\
\mathfrak{A} & :=\overline{\bigcup_{O} \mathfrak{A}(O)},
\end{aligned}
$$

the completion with respect to the norm topology, [27]. We briefly comment that it is possible to obtain the CCR representation from the Weyl system by considering $t \in$ $\mathbb{R} \longmapsto W\left(t f, t f^{\prime}\right)$ so that $\left.\lim _{t \rightarrow \tau} W\left(t f, t f^{\prime}\right)=W\left(\tau f, \tau f^{\prime}\right)\right)$, and by means of Stone's theorem we may define the operators $\theta$ and $\pi$ as

$$
\begin{aligned}
\exp \{i \theta(f) t\} & :=W(t f, 0) \\
\exp \{i \pi(f) t\} & :=W(0, t f) .
\end{aligned}
$$

Besides, following this, line the field may then be defined from equation (4.23). 
Theorem 17. The net of algebras $\mathfrak{A}(O)$ is independent of the choice of the Cauchy surface $S$. Once the Cauchy surface is chosen, the net is also independent of the symplectic space defining the $C C R$ representation $(\mathcal{H}, W)$.

Proof. Consider two representations $(\mathcal{H}, W)$ and $(\tilde{\mathcal{H}}, \tilde{W})$ for a given Cauchy surface $S$; we must prove there is an isomorphism between the algebras $h: \mathfrak{A} \longrightarrow \tilde{\mathfrak{A}}$ such that $h(\mathfrak{A}(O))=\tilde{\mathfrak{A}}(O)$, but this follows from theorem 14. Since the algebras are generated by $W$ and $\tilde{W}$, this means that $h: \mathfrak{A} \longrightarrow \tilde{\mathfrak{A}}$ is such that $h(W)=\tilde{W} \Rightarrow h(\exp \{i \phi t\})=$ $\exp \{i \tilde{\phi} t\}$, and thus $h(\mathfrak{A}(O))=\tilde{\mathfrak{A}}(O)$.

Consider now two Cauchy surfaces in $\mathrm{M}$, say $S$ and $\tilde{S}$, and some representation $(\mathcal{H}, W)$ over $\mathscr{D}(S)$. Take $\tilde{\mathcal{H}}=\mathcal{H}$ and construct $\tilde{W}$ from the restriction of the field $\phi$ to $\tilde{S}$,

$$
\tilde{W}\left(f, f^{\prime}\right):=W\left(\nabla G \tilde{\rho}_{0}^{*} f-\nabla G \tilde{\nabla}^{*} f^{\prime}, \rho_{0} G \tilde{\rho}_{0}^{*} f-\rho_{0} G \tilde{\nabla}^{*} f^{\prime}\right) .
$$

It follows then that $\exp \{i \tilde{\phi}(f) t\}=\exp \{i \phi(f) t\}$ - see the details in [18], theorem 3 .

As a last comment, with respect to fields, we should understand them as operatorvalued distributions, a family of maps whose exponential $\mathscr{D}\left(\mathrm{M}, \mathrm{E}^{*}\right) \longrightarrow \mathfrak{A}(\mathrm{M})$ or $\phi$ : $\mathscr{D}\left(O, \mathrm{E}^{*}\right) \longrightarrow \mathfrak{A}(O)$, as in (4.23), respects the diagram

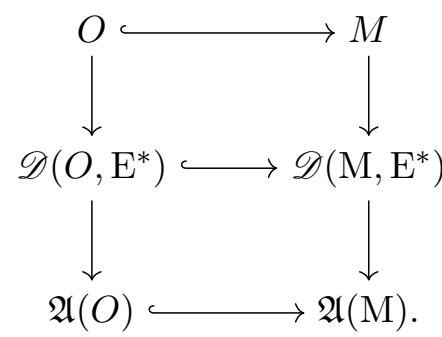

A family of operators respecting the commutativity of a diagram like this is called a natural transformation. We finally have a relation between sections in the vector bundle and fields.

As for the Haag-Kastler axioms, we may not prove the algebra defined in (4.24) satisfies them, simply because the construction of the presented example mimics the general formalism developed in this chapter, which in turn was proved to obey those axioms. However, we refer to [18] for an explicit proof that the free scalar field is in agreement with Haag-Kastler.

We thus constructed an association between globally hyperbolic manifolds and the algebra of possible observables related to this manifold, an association we called quantization. The development presented, however, was quite abstract, as some fundamental and motivational discussions could not be presented in this text. For instance, the motivation on the behalf of the use of $C^{*}$-algebras, and alternative algebraic structures as well were not discussed. Rather, some references were indicated previously. Natural next steps could be the study of Dirac fields, thus explicitly including spin in the theory, which in turn would involve the study of gauge theories, or an attempt to an interacting 
theory, although the presence of interaction significantly increases the complexity of the problem, and few interacting models were precisely presented until now. Another possible content to follow up this work would be an analysis of physical states, which could also contain analysis of the Hadamard condition and of the KMS condition.

Since the precise formulation of quantum field theories by Gårding and Wightman, as presented in [28], our comprehension of quantum physics, specifically of quantum field theory, evolved significantly, not only from a technical point of view, but also in more conceptual terms. In this context, the formalism of Haag and Kastler provided us with a new way to understand or to look at Nature, i.e. through the nets of algebras; these, in turn, evolve into an interesting inverse problem: if our perception of space is due to observations we are always performing, how could we obtain space from the algebra? This interesting inverse problem also goes beyond the scope of this work, but it would also be a natural follow-up.

All these possible ramifications become significantly more complex in the context of general curved space-time: as we have seen, the absence of symmetry transformations hinders or precludes extensions of well-defined objects on Minkowski space, as vacuum states, for example. In this text a basis for the approach of quantum theories on curved background was presented, and a simple example discussed, but this field goes much further, as we still lack a precise description for many aspects of local quantum physics. Under these conditions, this attempt to a conclusion for this work is vague but honest: we are left with a complex and incomplete, but fundamental and a bit general description of relativistic quantum theories. Furthermore, we are left with many questions, yet to be answered (or even asked), and, at most, only the basics to explore them. This is, of course, partially because of the limitations of this work, and of the author, but also reflects the much it is yet to be done and studied in a framework that attempts to a rigorous local quantum theory. 


\section{Index}

*, 40, 96

Algebra, 96

Automorphism, 97

Morphism, 97

Subalgebra, 97

$:=, 21$

$B V(F), 49$

$C^{*}$

Algebra, 96

Condition, 96

Quasi-local algebra, 106

$F_{ \pm}^{\Omega^{\prime}}(x), 82$

$I(x), 28$

$I_{+}(x), 28$

$I_{-}(x), 28$

$R_{ \pm}^{\Omega}(\alpha, x), 68$

$W F(T), 50$

$\mathscr{D}(\mathrm{M}, \mathrm{E}), 52$

$\mathscr{D}^{*}(\mathrm{M}, \mathrm{E}, V), 52$

Topology, 53

$F_{ \pm}^{\Omega^{\prime}}, 81$

KK, 21

N, 21

$\mathbb{N}^{*}, 21$

$\mathbb{R}_{+}^{0}, 21$

$\mathbb{R}_{+}, 21$

$\mathscr{R}_{ \pm}^{\sigma}(x), 77$

$\mathscr{S}, 34$

$\mathscr{S}^{*}, 35$

$\cdot, 21$

$\equiv, 22$

$\mathbb{1}, 96$

$\mathcal{M}^{n}, 21$

$\mathfrak{C}^{*}, 97$
$\mathfrak{H y \mathfrak { y } ,} 101$

$\mathfrak{L o c e}^{*}, 107$

$\mathfrak{S y m}, 103,104$

$\mathscr{D}(\mathrm{M}, \mathrm{E}), 26$

$\mathscr{F}_{p}(U), 24$

$\mathscr{L}(\mathrm{M}), 24$

$\mu_{x}, 68$

$\|f\|_{\alpha, \beta}, 34$

$\bar{z}, 21$

sing supp $T, 38$

supp $T, 37$

$\tilde{f}, 41$

$\tilde{f}_{y}, 42$

$f_{y}, 42$

Acausal Set, 29

Achronal Set, 29

Algebra, 96

Banach, 96

Identity, 96

Representation, 98

Unital, 96

Almeida, Ricardo Costa de, 44

Array, 94

Atlas, 23

Base Space, 25

Category, 95

Cauchy

Development, 30

Global Problem, 89

Local Problem, 87

Problem, 85

Surface, 30 
Causal

Curve, 28

Set, 29

Vector, 28

Causal Future

of a point, 29

of a set, 29

Causal Past

of a point, 29

of a set, 29

Causality Condition, 30

Strong, 30

Causally Compatible Set, 29

CCR

Algebra, 100

Representation, 100

$\mathrm{CCR}(V), 100$

Chart, 23

Chronological Future

of a point, 28

of a set, 29

Chronological Past

of a point, 29

of a set, 29

Connection, 31

on vector bundles, 26

Convergence

of test-sections, 52

Convex, 29

Convolution, 40

Cotangent Space, 25

Covariant Derivative, 27

d'Alembert Operator, 31, 32, 62

Generalized, 31

Dandelion, 25

Diffeomorphism, 23

Differential, 24

Differential Operator, 30

Formal Adjoint, 53, 63

Principal Symbol, 31

Differential Structure, 23

Dimension, 23

Distributions, 33

Asymptotically regular, 49

Boundary value of, 49
Derivative of, 38

Dirac delta, 52

Directed regular point, 50

Heaviside, 37

Product of, 40, 44, 46

Regular, 33, 36, 52

Space of, 35

Tempered, 35

Domain, 94

ext, 103

Field, 112, 114

Formal Adjoint, 53

Fourier Transform

Adjoint, 40

Inverse, 40

of a distribution, 40

of a function, 39

Functor, 95

From $\mathfrak{H} \mathfrak{y p}$ to $\mathfrak{L o c e}^{*}, 108$

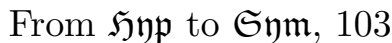

Fundamental Solution, 61, 62

Advanced, 81

for the d'Alembertian, 64

Retarded, 81

True, 75

Future Compact, 29

Geodesically Convex, 29

Geodesics, 29

Globally Hyperbolic Manifold, 30

Green's operator, 91

Hörmander's Theorem, 51

Hadamard Coefficients, 71, 72

Index of a form, 28

Inextensible Curve, 30

Involution, 96

Kanzi

Micheline, 25

Klein-Gordon Equation, 110

Lightlike

Curve, 28

Vector, 28 
Localization, 44

Lorentzian Manifold, 28

Manifold

Riemannian, 28

Smooth, 23

Timeoriented, 28

Topological, 23

Measurement, 93

Metacategory, 94

Metagraph, 94

Metric

Lorentzian, 28

Riemannian, 28

Signature, 21

Minkowski Space

Metric siganture, 21

Morphism, 94

Multi-index, 34

Natural

Transformation, 114

Norm

k-norm, 51

Normally Hyperbolic Operator, 31, 32

Normed Algebra, 96

Nulllike

Vector, 28

Object, 94

Observable, 93

Orientation, 27

Parallel Vector Field, 27

Parseval's Identity, 56

Partially ordered set with orthogonality relation, 106

Past Compact, 29

Physical System, 93

Plancherel's Identity, 56

Primitive algebra, 109

Projection

of a vector bundle, 25

Pseudo-inner Product, 28

Quantization, 101
Rank, 25

Riemmanian exponential map, 29

Riesz Distribution, 64

Advanced, 64

locally defined, 68

Retarded, 64

Schwartz Space, 34

Section (of a vector bundle), 26

support of, 26

Seminorm, 34

Singular Support, 38

Singular support, 53

Spacelike

Compact, 92

Curve, 28

Vector, 28

Spacetime, 28

Star-shaped, 67

State, 93

Strohmaier, Alexander, 41

Strong Causality Condition, 30

Support

Of distributions, 37,53

Singular, 38

Symplectic Vector Space, 98

Category, 103

Symplectomorphisms, 103

Tangent Space

at a point, 24

Tensor, 22

k-tensor, 23

Tensor Product

of maps, 22

Test Functions, 35

Test-sections, 52

Time separation function, 91

Timelike

Curve, 28

Vector, 28

Total Space, 25

Transport Equation, 71

Trivialization

local trivialization, 25

Trivializing Open Set, 25

118 
Vector Bundle, 24

Cotangent, 25

Dual, 25

Product bundle, 25

Wave Equation, 62

Wave Front Set, 50

Weyl system, 98 


\section{Bibliography}

[1] DIRAC, P.A.M. The Quantum theory of the emission and absorption of radiation. Proc. Roy. Soc. London, 114:243-265, 1927.

[2] BRUNETTI, Romeo; FREDENHAGEN, Klaus; VERCH, Rainer. The generally covariant locality principle - A new paradigm for local quantum physics. Commun.Math.Phys., 237:31-68, 2003.

[3] HALZEN, F.; MARTIN, Alan D. Quarks and Leptons : an introductory course in modern particle physics. Wiley, New York, 1984.

[4] SREDNICKI, Mark. Quantum field theory. Cambridge University Press, Cambridge, 2007.

[5] LEE, John M. Riemannian Manifolds: an introduction to curvature. Graduate Texts in Mathematics. Springer, 1950.

[6] HOFFMAN, Kenneth; KUNZE, Ray. Linear Algebra. Prentice Hall, New Jersey, 2nd edition, 1971.

[7] BARATA, João C. A. Curso de Física Matemática. Lecture notes available at $h t t p: / /$ denebola.if.usp.br/ jbarata/Notas_de_aula/notas_de_aula.html.

[8] TU, Loring W. An Introduction to Manifolds. Springer, 2nd edition, 2010.

[9] O’NEILL, Barrett. Semi-Riemannian Geometry. Academic Press, 1983.

[10] BÄR, Christian; GINOUX, Nicolas; PFÄFFLE, Frank. Wave Equations on Lorentzian Manifolds and Quantization. European Mathematical Society Publishing House, Germany, 2007.

[11] CARMO, Manfredo Perdigão. Geometria Riemanniana. IMPA, Rio de Janeiro, 1988.

[12] HAWKING, S. W.; ELLIS, G.F.R. The large scale structure of space-time. Cambridge University Press, Cambridge England New York, 1973.

[13] REED, Michael; SIMON, Barry. Methods of Modern Mathematical Physics II: Fourier Analysis, Self-Adjointness. Academic Press, New York, 1972. 
[14] REED, Michael; SIMON, Barry. Methods of Modern Mathematical Physics I: Functional Analysis. Academic Press, New York, 1980.

[15] BÄR, Christian; FREDENHAGEN, Klaus, editor. Quantum Field Theory on Curved Spacetimes: Concepts and Mathematical Foundations. Number 786 in Lecture Notes in Physics. Springer, Berlin Heidelberg, 2009.

[16] N. BROUDER, C.; VIET DANG and F. HÉLEIN. A smooth introduction to the wavefront set. Journal of Physics A Mathematical General, 47:443001, November 2014.

[17] HÖRMANDER, Lars. The Analysis of Linear Partial Differential Operators I. Springer, Berlin New York, 2003.

[18] J. DIMOCK. Algebras of local observables on a manifold. Commun. Math. Phys., (77):219-228, 1980.

[19] DAPPIAGI, Claudio; HACK, Thomas-Paul; PINAMONTI, Nicola. The Extended algebra of observables for Dirac fields and the trace anomaly of their stress-energy tensor. Rev. Math. Phys., 21:1241-1312, 2009.

[20] MANDL, Frank; SHAW, Graham. Quantum Field Theory. Wiley, Hoboken, N.J, 2010.

[21] PESKIN, Michael; SCHROEDER, Daniel V. An Introduction to Quantum Field Theory. Addison-Wesley, Reading, Mass, 1995.

[22] PEDRA, Walter A. de S. Álgebras $C^{*}$ e fundamentos matemáticos da mecânica quântica e mecânica estatística. Lecture notes currently not available at $h t t p$ : //www.fma.if.usp.br/ wpedra/.

[23] ARAKI, Huzihiro. Mathematical theory of quantum fields. Oxford University Press, New York, 2009.

[24] Mac LANE, Saunders. Categories for the working mathematician. Springer-Verlag, New York, 1971.

[25] KADISON, Richard V.; RINGROSE, John R. Fundamentals of the theory of operator algebras, volume 1. American Mathematical Society, Providence, R.I, 1997.

[26] BRATTELI, Ola; ROBINSON, Derek W. Operator Algebras and Quantum Statistical Mechanics 2. Springer-Verlag, New York, 1987.

[27] HAAG, Rudolf. Local quantum physics : fields, particles, algebras. Springer, Berlin New York, 1996.

[28] STREATER, R. F.; WIGHTMAn, A. S. PCT, Spin and Statistics, and All That. The Mathematical Physics Monograph Series. The Benjamin/Cummings Publishing Company, 3rd edition, 1980.

[29] MUNKRES, James R. Topology. Dorling Kinderley (India) Pvt., 2008. 
[30] BOTELHO, Geraldo; PELLEGRINO, Daniel; TEIXEIRA, Eduardo. Fundamentos de Análise Funcional. SBM, 2012.

[31] CHERN, S.S.; CHEN, W.H.; LAM, K.S. Lectures on Differential Geometry. World Scientific, Singapore River Edge, N.J, 1999. 